Universidade de São Paulo

Faculdade de Medicina de Ribeirão Preto

Departamento de Farmacologia

Ativação supraespinal da via das quinureninas contribui para a manutenção da dor neuropática

Dênis Augusto Santana Reis

Ribeirão Preto

2015 
Universidade de São Paulo

Faculdade de Medicina de Ribeirão Preto

Departamento de Farmacologia

\section{Ativação supraespinal da via das quinureninas contribui para a manutenção da dor neuropática}

\section{Dênis Augusto Santana Reis}

Dissertação apresentada ao programa de Pósgraduação do Departamento de Farmacologia da Faculdade de Medicina de Ribeirão Preto da Universidade de São Paulo para a obtenção do título de Mestre em Ciências.

Área de Concentração: Farmacologia

Orientador: Prof. Dr. Thiago Mattar Cunha

\section{Ribeirão Preto}


Autorizo a reprodução e divulgação total ou parcial deste trabalho, por quaisquer meios convencionais ou eletrônicos, para fins de estudo e pesquisa, desde que citada a fonte.

\section{Ficha Catalográfica}

Santana, Dênis Augusto Reis

Ativação supraespinal da via das quinureninas contribui para a manutenção da dor neuropática. Ribeirão Preto, 2015.

157 p. : il. ; $30 \mathrm{~cm}$

Dissertação de Mestrado apresentada à Faculdade de Medicina de Ribeirão Preto/USP. Área de concentração: Farmacologia.

Orientador: Thiago Mattar Cunha

1.IDO. 2. IFN- $\gamma$. 3. Serotonina (5-HT). 4. Neuropatia. Hipernocicepção nociceptiva mecânica. 5. KMO 


\section{FOLHA DE APROVAÇÃO}

Dênis Augusto Santana Reis

\section{Ativação supraespinal da via das quinureninas contribui para a manutenção da dor neuropática}

Dissertação apresentada à Faculdade de Medicina de Ribeirão Preto da Universidade de São Paulo para a obtenção do título de Mestre em Ciências.

Área de Concentração: Farmacologia

Aprovado em: 03 de fevereiro de 2015

\section{Banca Examinadora:}

Prof. Dr. Thiago Mattar Cunha

Instituição: FMRP - USP Assinatura:

Profa. Dra. Joice Maria da Cunha

Instituição: UFPR - Curitiba Assinatura:

Prof. Dr. Hélio Zangrossi Junior

Instituição: FMRP- USP Assinatura: 
Trabalho realizado no Laboratório de Dor e Inflamação do Departamento de Farmacologia da Faculdade de Medicina de Ribeirão Preto - Universidade de São Paulo com auxílio da Fundação de Apoio e a Pesquisa do Estado de São Paulo (FAPESP). Processo (2013/07968-0) 
DEDICATÓRIA 
“Aos meus pais, Ivani Aparecida e Osmar lima, ao meu irmão Renan Gustavo por serem a base de tudo, o motivo para acordar e fazer o melhor. Desculpem a minha ausência nesses dois anos. Obrigado pelo apoio e por acreditarem sempre em mim. Amo vocês." 
AGRADECIMENTOS 
Agradeço,

À Deus,

Aos meus pais, que nunca mediram esforços para me ajudar. Que são para mim exemplos de pessoas honestas, dignas e elo amor incondicional. Ao meu irmão Renan por todos os momentos bons que passamos nos últimos anos;

A minha grande família, em Londrina, em especial meus avós que sempre me estimularam a estudar e veem a educação como algo dignificante;

Ao Prof. Dr. Thiago Mattar Cunha, por ter acreditado em meu trabalho e me dado à oportunidade de aprender muito durante este tempo;

Ao Prof. Dr. Fernando de Queiroz Cunha, pela disponibilização de seu laboratório;

Ao Prof. Dr. Sergio Henrique Ferreira, pela disponibilização do seu laboratório e pelo grande conhecimento emanado diariamente;

Ao Guilherme Rabelo, que me que sempre me ajudou do começo ao fim do mestrado. Até mesmo quando fui dizer a ele que não queria mais a carreira acadêmica, queria mais coisas para a minha vida, que essa vida não valia o sacrifício ele me apoiou;

À Miriam e a Flavia pela amizade, conversas descontraídas e apoio;

Ao Caio por ser um bom amigo durante essa etapa;

Ao Maurício pelas conversas descontraídas, pelas sérias sobre política e pela amizade;

Ao Jhimmy pelas conversas científicas, discussão de resultados e pela amizade;

À todo pessoal do LID, que de uma forma ou de outra me ajudaram: Rafael Ferreira, Alexandre Lopes, Ferzinha, Larissa Garcia, Jhimmy Talbot, Rangel, Douglas, Priscilla, Anne, Andressa 
Zaparolli, Andressa Freitas, Alexandre Kanashiro, Paula Barbin, Raphael Peres, Paulo de Melo, Jaqueline Raymond, Bruno Mulato e Gabriel Bassi.

À Kátia mesmo brigando comigo quando eu pegava as suas folhas de sulfite sempre me ajudou em tudo, pelas conversas e apoio incondicional;

Ao Serginho no começo não dava muita bola para mim, mas depois virou um grande amigo. Com certeza a convivência naquele laboratório foi melhor por causa das suas brincadeiras e amizade;

Ao Marquinhos por deixar os dias tão divertidos, as suas brincadeiras, músicas e imitações mudavam a cara do laboratório. Além disso, pela amizade e apoio

À Ieda por toda a ajuda ao longo do projeto, bem como dos puxões de orelha quando necessário; À querida Diva Amábile, que sempre lembrou muito a minha mãe, pelas brincadeiras, mesmo em meio das dificuldades consegue expressar alegria;

À Giuliana Bertozi pela amizade, conselhos e por se importar comigo;

À Eleni, pelas conversas sobre viagens, ótimos cortes histológicos e todo auxílio;

Aos docentes e funcionários do Departamento de Farmacologia da FMRP, pela convivência e oportunidade dada a mim de bons aprendizados.

Aos funcionários da secretaria do Departamento de Farmacologia da FMRP-USP: Sônia Maria por todo auxílio, por sanar as minhas dúvidas e pelo apoio; ao José Waldik Ramon pelas ajudas durante as prestações de contas, pelas conversas e brincadeiras;

Aos bioteristas, Júlio, Dener, Orlando e Eliana pelos cuidados com os animais do biotério.

Ao pessoal da Casa Amarela, obrigado pelo convívio, na maior parte das vezes e tirando um ou outro morador esse tempo foi de grande aprendizado;

À FAPESP, pelo auxílio financeiro para a realização deste trabalho 
"Não tenha medo"

Roberto Shinyashiki 
SUMÁRIO 


\section{SUMÁRIO}

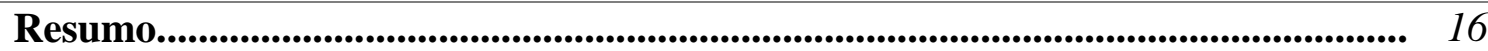

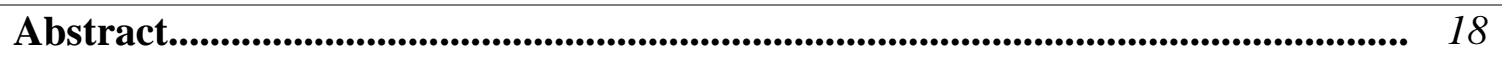

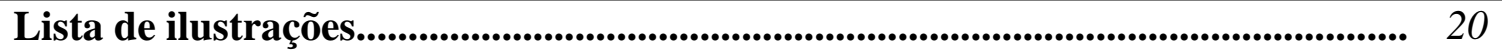

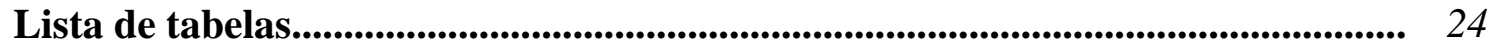

Lista de abreviaturas.................................................................................................. 26

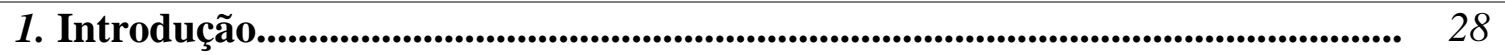

1.1.Transmissão e modulação da nocicepção: via ascendente, descendente 29 facilitatória e inibitória da dor.

1.2.Dor neuropática.............................................................................................. 34

1.3.Via das quinureninas: Indoleamina 2,3-dioxigenase1 (IDO1) e quinurenina 3- 40 monoxigenase $(K M O)$.

1.4.A ativação da via das quinureninas está relacionada com o desenvolvimento da 44 comorbidade depressão associada lesão de nervos periféricos.

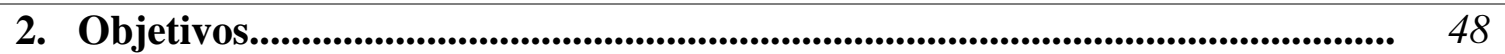

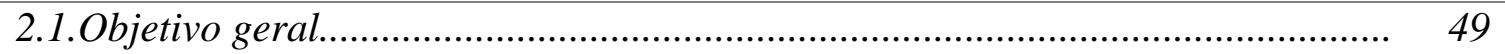

2.2. Objetivos específicos ...................................................................................... 49

3. Materiais e métodos......................................................................................... 51

3.1.Vias de administração de drogas, estereotaxia e microinjeção de drogas no 52 espaço intracerebroventiruclar.

3.2. Drogas e diluentes................................................................................... 54

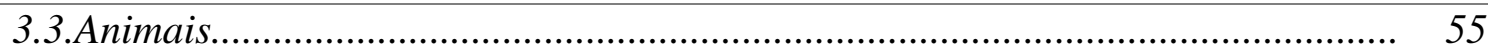

3.4.Testes de avaliação da nocicepção mecânica................................................... 56

3.4.1. Teste de filamentos de von Frey............................................................... 56

3.5.Indução da neuropatia pelo modelo de SNI - spared nerve injury....................... 58

3.6.Avaliação da função motora dos animais por Rota Rod...................................... 59 
3.7.Teste do nado forçado ................................................................................. 60

3.8.Procedimento para coleta da substância cinzenta periaquedutal e no bulbo 61 ventromedial rostral.

3.9.Preparação das amostras da substância cinzenta periaquedutal e do bulbo 62 ventromedial rostral para a técnica de Western blotting.....

3.9.1. Extração de Proteínas............................................................................. 62

3.9.2. Eletroforese e Western blotting.................................................................. 62

3.10. Imunofluorescência para localização de vesículas de 5-HT no RVM de 64 camundongos submetidos a lesão de nervos periféricos

3.11. Análises estatísticas.................................................................................. 66

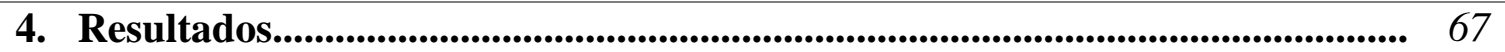

4.1.Cinética de expressão da enzima IDO1 no RVM, na PAG e no hipocampo após 68 a lesão de nervos periféricos

4.2.Avaliação do efeito antinociceptivo do Norharmane sobre a hipersensibilidade 75 mecânica induzida pela lesão de nervos periféricos.

4.3.Cinética de expressão da enzima KMO no RVM e na PAG após a lesão de nervos 81 periféricos......

4.4.Efeito de inibidores da KMO sobre a hipersensibilidade mecânica induzida pela 84 lesão de nervos periféricos......

4.5.Avaliação dos efeitos nociceptivos da microinjeção de quinurenina, ácido 3- 91 hidroxiantranílico e ácido quinolínico no espaço intracerebroventricular de camundongos.

4.6.A hipernocicepção induzida por QUIN depende da ativação da via descendente 98 facilitatória da dor e de ativação glial.

4.7.Avaliação dos níveis de 5-HT no RVM de camundongos submetidos a lesão de 100 nervos periféricos 
4.8.Participação de células T CD4+ e da citocina IFN- $\gamma$ na gênese da dor 102 neuropática......

4.9.A expressão das enzimas IDO1 e KMO no RVM e na PAG após indução de 105 neuropatia pelo modelo de SNI depende da citocina IFN- $\gamma$.

4.10. Avaliação do efeito da microinjeção de IFN- $\gamma$ no espaço 110 intracerebroventricular sob o limiar mecânico de camundongos naives.

4.11. O desenvolvimento da hipersensibilidade mecânica após lesão de nervos 112 periféricos está associada a um comportamento depressivo.

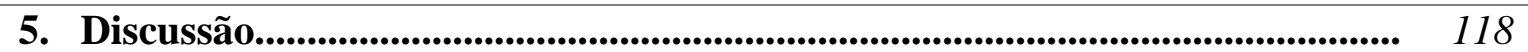

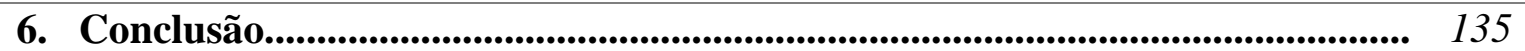

7. Referências bibliográficas..................................................................................... 138

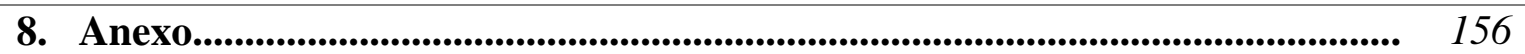


RESUMO 
SANTANA, D.A.R. Ativação supraespinal da via das quinureninas contribui para a manutenção da dor neuropática. Dissertação de Mestrado - Departamento de Farmacologia da Faculdade de Medicina de Ribeirão Preto - Universidade de São Paulo, Ribeirão Preto, SP.

Introdução: Um fator que pode contribuir para o desenvolvimento da dor neuropática é a modulação negativa da via descendente da dor pelo aumento da degradação do triptofano pela ativação da enzima indoleamina 2,3-dioxigenase 1 (IDO1) ou a ativação da via descendente facilitatória da dor por um agonista glutamatérgicos produzido pela enzima quinurenina 3 monoxigenase (KMO). Objetivo: Foi avaliar a participação das enzimas IDO1 e a KMO presente na substância cinzenta periaquedutal (PAG) e no bulbo rostral ventromedial (RVM) no desenvolvimento da dor neuropática em camundongos induzida pelo modelo SNI. Metodologia: A indução da neuropatia experimental foi realizada de acordo com (Bourquin et al., 2006). A expressão da IDO1 e KMO foi realizada pela técnica de Western blotting. A administração de drogas foi realizada por via oral, intraperitoneal, intratecal e intracerebroventricular (i.c.v.). Resultados: Foi observado o aumento da expressão da enzima IDO1 no RVM (7 dias) e PAG (3, 7, 14 e 21 dias) após SNI. A microinjeção de Norharmane no espaço i.c.v. reduziu a hipersensibilidade mecânica no 7,14 e 21 dias após SNI. Corroborando com esses achados, animais deficientes para a enzima IDO1 submetidos a SNI não desenvolvem a hipersensibilidade mecânica. Além disso, a expressão da enzima KMO aumenta significativamente no 7 e 14 dias no RVM e 7 dias na PAG após SNI. Por conseguinte, a administração oral de JM6, pró-droga de liberação lenta do Ro61-8048, ou Ro61-8048 (inibidor da KMO) no espaço i.c.v. reduziu significativamente a hipersensibilidade mecânica nos dias 7,14 ou 21 após SNI. Sabendo que a expressão da enzima IDO1 é modulada pela citocina IFN- $\gamma$, verificamos que os animais deficientes para a citocina IFN$\gamma$ apresentam hipersensibilidade mecânica reduzida. Ainda, os animais IFN- $\gamma$ KO possuem expressão reduzida da IDO1 no RVM 7 dias e na PAG 14 dias após a SNI. Em adição, a microinjeção de doses crescentes de IFN- $\gamma$ no espaço i.c.v. induz uma hipernocicepção mecânica em camundongos naives. Constatamos também que animais $\mathrm{CD} 4+\mathrm{KO}$, mas não os animais $\mathrm{CD} 8+\mathrm{KO}$ apresentam reduzida expressão da enzima IDO1 no RVM e na PAG e consequentemente menor hipersensibilidade mecânica após SNI. A microinjeção dos metabolitos da via das quinureninas, no espaço i.c.v. de camundongos causou hipersensibilidade mecânica, sendo o QUIN o mais potente. Sugerimos que a ativação da via das quinureninas seja dependente da ativação do receptor NMDA, visto que o pré-tratamento local com o MK801 (antagonista seletivos dos receptores NMDA) reverte os efeitos nociceptivos induzidos pelos metabólitos. Além disso, o efeito nociceptivo induzido por QUIN depende ativação da via descendente facilitatória. Constatamos que os animais neuropáticos exibem um comportamento do tipo depressivo e esse comportamento não é observado em animais IFN- $\gamma \mathrm{KO}$ e CD4KO. Por último, avaliamos a participação da via das quinureninas no desenvolvimento do comportamento depressivo associado à SNI e constatamos que esse comportamento depende da ativação das enzimas IDO1 e KMO. Conclusão: Os resultados sugerem que as enzimas IDO1 e KMO, localizadas em regiões supraespinais desempenham um importante papel no desenvolvimento da dor neuropática, assim como da comorbidade depressão. Além disso, a expressão da IDO1 é dependente da sinalização via citocina IFN- $\gamma$ e células CD4+. O mecanismo responsável pelo desenvolvimento da hipersensibilidade neuropática deve-se tanto a redução dos níveis de triptofano/5-HT, diminuição da eficiência da via descendente inibitória, quanto ao aumento dos níveis de QUIN, que ativa a via descendente facilitatória da dor. 
ABSTRACT 
SANTANA, D.A.R. Supraspinal kynurenine pathway contributes to the maintenance of neuropathic pain. Department of Pharmacology, Ribeirao Preto Medical School-University of Sao Paulo. Brazil

Introduction: One factor that may contribute to the development of neuropathic pain is the negative modulation of the descending pain pathway by increased degradation of the activation of tryptophan by enzyme indoleamine 2,3-dioxygenase1 (IDO1) or activation of the descending facilitatory pain pathway for a glutamate agonist produced by the enzyme kynurenine 3 monooxygenase (KMO). Aim: We evaluate the role of IDO1 and $\mathrm{KMO}$ in the periaqueductal gray (PAG) and the rostral ventromedial medulla (RVM) in the development of neuropathic pain in mice induced by SNI model. Methods: Induction of experimental neuropathy was performed according to (Bourquin et al. 2006). The expression of IDO1 and KMO was carried out by Western blotting technique. The drug administration was performed orally, intraperitoneally and intracerebroventricularly (i.c.v) Results. We observed increased IDO1 expression in the RVM (7 days) and PAG (3, 7, 14 and 21 days) after SNI. The microinjection Norharmane in i.c.v. space reduced mechanical hypersensitivity in the 7,14 and 21 days after SNI. Corroborating these findings, mice deficient for the enzyme IDO1 undergoing SNI did not develop mechanical hypersensitivity. Furthermore, the KMO expression was significantly increased in the 7 and 14 days in the RVM and 7 days in PAG after SNI. Therefore, oral administration of JM6, prodrug slow release from Ro61-8048 or Ro61-8048 (KMO inhibitors) within i.c.v. significantly reduced the mechanical hypersensitivity at day 7, 14 or 21 after SNI. Knowing that the expression of IDO1 enzyme is modulated by IFN- $\gamma$ cytokine, it was found that animals deficient for IFN- $\gamma$ cytokine have reduced mechanical hypersensitivity. Moreover, IFN- $\gamma$ ko animals have reduced expression of IDO1 RVM 7 days and 14 days after SNI in the PAG. In addition, microinjection of increasing doses of IFN- $\gamma$ in i.c.v. induced mechanical hyperalgesia. We also found that CD4 + KO animals, but not CD8 + KO animals showed reduced expression of the enzyme IDO1 RVM and PAG and consequently lower mechanical hypersensitivity after SNI. The microinjection of the main metabolites of kynurenine pathway into the i.c.v. spaces induced mechanical hypersensitivity, QUIN being the most potent. We suggest that the activation of the kynurenine pathway was dependent of NMDA receptor activation, whereas the spot pretreatment with MK801 (selective NMDA receptor antagonist) reverses the effects induced by noxious metabolites. After that, the microinjection into i.c.v. spaces of MK801 reduced mechanical hypersensitivity after SNI. Furthermore, nociceptive effect induced by QUIN depends activation of the descending facilitatory. We found that the neuropathic animals exhibit depressive-like behavior and this behavior is not observed in IFN- $\gamma \mathrm{KO}$ and CD4KO mice. Finally, we evaluate the participation of kynurenine pathway in the development of depressive-like behavior associated with SNI and found that this behavior depends on the activation of IDO1 and KMO Conclusion: These results suggest that IDO1 and KMO enzyme, located in supraspinal regions play a role in the development of neuropathic pain as well as comorbidity depression. Furthermore, the expression of IDO1 are dependent on signaling via cytokine IFN- $\gamma$ and CD4+ cells. The mechanism responsible for the development of neuropathic hypersensitivity is due to both reduced levels of tryptophan/5-HT decrease the descending inhibitory pain pathway efficiency, as the increased levels of QUIN, which activates the descending facilitatory pain pathway. 
LISTA DE ILUSTRAÇÕES 


\section{LISTA DE ILUSTRAÇÕES}

Figura 1. Representação esquemática da via das quinureninas, adaptado de Mándi e Vécsei.

Figura 2. Esquema representativo mostrando as ramificações do nervo isquiático..........60

Figura 3. SNI induz hipersensibilidade mecânica em camundongos selvagens...............70

Figura 4 . Neuropatia induz aumento na expressão da enzima IDO1 no

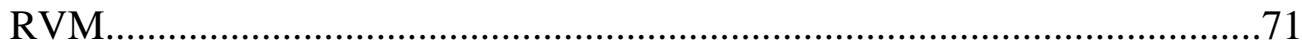

Figura 5. Neuropatia induz aumento na expressão da enzima IDO1 na

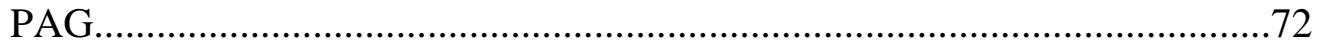

Figura 6. Neuropatia não altera os níveis da enzima IDO1 no hipocampo .....................73

Figura 7. A perfusão intracardíaca altera os níveis de IDO1 na PAG dos animais com neuropatia.

Figura 8. A perfusão intracardíaca altera parcialmente os níveis de IDO1 na RVM dos animais com neuropatia.

Figura 9. Efeito da microinjeção de Norharmane no espaço intracerebroventricular de camundongos 7 dias após a lesão de nervos

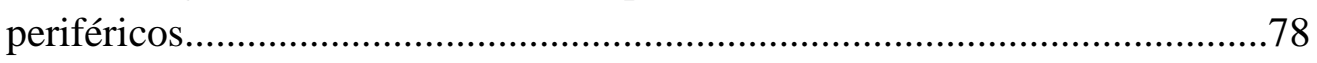

Figura 10. Efeito da administração de Norharmane no espaço intracerebroventricular de camundongos 14 dias após a lesão de nervos periféricos....

Figura 11. Efeito da administração de Norharmane, inibidor da enzima IDO, no espaço intracerebroventricular de camundongos 21 dias após a lesão de nervos periféricos.

Figura 12. Animais geneticamente deficientes para a enzima IDO1 não desenvolvem a hipersensibilidade mecânica induzida por SNI.

Figura 13. Neuropatia induz aumento na expressão da enzima KMO no RVM...............83

Figura 14. Neuropatia induz aumento na expressão da enzima KMO na PAG. .............84

Figura 15. O tratamento por via oral com o JM6 reduz a hipersensibilidade mecânica em animais com neuropatia ( $\left.7^{\circ} \mathrm{dia}\right)$.

Figura 16. O tratamento por via oral com o JM6 reduz a hipersensibilidade mecânica em animais com neuropatia $\left(14^{\circ} \mathrm{dia}\right)$

Figura 17. O tratamento por via oral com o JM6 reduz a hipersensibilidade mecânica em animais com neuropatia $\left(21^{\circ} \mathrm{dia}\right)$

Figura 18. O JM6 interfere parcialmente com a capacidade locomotora dos animais avaliada pelo teste de Rota Rod.

Figura 19. Efeito da microinjeção do Ro61-8048 no espaço intracerebroventricular de camundongos com neuropatia( $\left.7^{\circ} \mathrm{dia}\right)$ 
Figura 20. Efeito da microinjeção de Ro61-8048 no espaço intracerebroventricular de camundongos com neuropatia $\left(14^{\circ} \mathrm{dia}\right)$

Figura 21. Efeito da microinjeção de quinurenina no espaço intracerebroventricular sob o limiar mecânico de camundongos naives. .94

Figura 22. Efeito da microinjeção de ácido 3-hidroxiantranílico (3-HAA) no espaço intracerebroventricular sob o limiar mecânico de camundongos naives ........95

Figura 23. Efeito da microinjeção de ácido quinolínico (QUIN) no espaço intracerebroventricular sob o limiar mecânico de camundongos naives. .......96

Figura 24. Comparação do efeito da microinjeção de doses equimolares (80 nmol) de quinurenina, ácido 3-hidroxiantranílico ou ácido quinolínico no espaço intracerebroventricular sob o limiar mecânico de camundongos naives ........97

Figura 25. Efeito da microinjeção de MK-801 no espaço intracerebroventricular de camundongos com neuropatia $\left(14^{\circ}\right.$ dia $\left.\mathrm{SNI}\right)$. .98

Figura 26. Efeito nociceptivo da microinjeção de ácido quinolínico (QUIN) no espaço intracerebroventricular depende parcialmente da ativação da via facilitatória descente da dor 100

Figura 27. A fluoxetina potencializa o efeito antinociceptivo do 1-metil-triptofano após a lesão de nervos periféricos $\left(21^{\circ}\right.$ dias SNI. 101

Figura 28. Avaliação dos níveis de 5-HT no RVM de animais submetidos a lesão de nervos periféricos

Figura 29. Avaliação da hipersensibilidade nociceptiva mecânica induzida pelo modelo de SNI em animais CD4+-/-, CD8+-/-, B-/-(BKO) e WT 104

Figura 30. Avaliação da hipersensibilidade nociceptiva mecânica induzida pelo modelo de SNI em animais IFN- $\gamma$-/- e selvagens.

Figura 31. A expressão da enzima IDO1 no RVM após a lesão de nervos periféricos $\left(7^{\circ}\right.$ dia SNI) é dependente da citocina IFN- $\gamma$.

Figura 32. A expressão da enzima IDO1 na PAG após a lesão de nervos periféricos $\left(14^{\circ}\right.$ dia SNI) é dependente da citocina IFN- $\gamma$.

Figura 33. A expressão da enzima KMO no RVM após a lesão de nervos periféricos $\left(7^{\circ}\right.$ dia SNI) é dependente da citocina IFN- $\gamma$

Figura 34. A expressão da enzima KMO na PAG após a lesão de nervos periféricos $\left(7^{\circ}\right.$ dia SNI) independe da citocina IFN- $\gamma$

Figura 35. A microinjeção de IFN- $\gamma$ no espaço intracerebroventricular causa hipersensibilidade nociceptiva mecânica de camundongos naives.

Figura 36. SNI (7 dias) induz um comportamento do tipo "depressivo" em camundongos WT, mas não em IFN- $\gamma$ KO e CD4 KO.

Figura 37. SNI (14 dias) induz um comportamento do tipo "depressivo" em camundongos WT, mas não em IFN- $\gamma$ KO e CD4 KO. 116

Figura 38. SNI (21 dias) induz um comportamento do tipo "depressivo" em camundongos WT, mas não em IFN- $\gamma$ KO e CD4 KO..... 
Figura 39. O comportamento depressivo induzido pela lesão de nervos periféricos depende das enzimas IDO1 e KMO. .............................................................118 


\section{LISTA DE TABELAS}




\section{LISTA DE TABELAS}

Tabela 1: Drogas utilizadas 54

Tabela 2: Transformação da pressão em grama dos filamentos de von frey para a escala

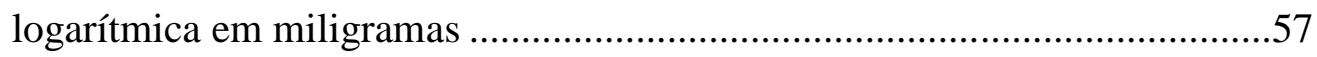

Tabela 3: Anticorpos utilizados no western blotting.....................................................64

Tabela 3: Anticorpos utilizados na imunofluorescência para localização das vesículas de 5-HT no RVM de camundongos .65 
LISTA DE ABREVIATURAS 


\section{LISTA DE ABREVIATURAS}

DRG: gânglio da raiz dorsal

SNI: spared nerve injury

SNC: sistema nervoso central

SNP: sistema nervoso periférico

PAG: substância cinzenta periaquedutal

RVM: bulbo rostral ventromedial

IDO1: indoleamina 2,3-dioxigenase 1

KMO: quinureninas 3-monoxigenase

QUIN: ácido quinolínico

KYNA: Ácido quinurênico

IFN- $\gamma$ : interferon gama

IMI: imipramina

Nor: Norharmane

Ro: Ro61-8048

1-MT: 1 metil triptofano

i.c.v.: espaço intracerebroventricular

NMDA: N-metil D-Aspartato

KO: knockout

DR: Núcleo dorsal da rafe 
INTRODUÇÃO 


\section{INTRODUÇÃO}

\subsection{Transmissão e modulação da nocicepção: via ascendente, descendente facilitatória e inibitória da dor}

Durante o processo evolutivo, os animais desenvolveram diversos mecanismos fisiológicos que permitiram a sobrevivência, dentre os mecanismos mais importantes destaca-se a dor. A dor leva o indivíduo a ter consciência de que sua integridade física está sendo ameaçada, permitindo que o mesmo possa evitar possíveis lesões e auto proteger-se. De acordo com a Associação Internacional para o Estudo da Dor (IASP) a dor pode ser definida como uma "experiência desagradável que envolve aspectos sensoriais, emocionais e cognitivos associada a uma lesão real ou potencial”.

Apesar da importância da dor para a preservação da integridade física do indivíduo, é frequente a ocorrência de analgesia durante situações de perigo ou estresse intenso. Em condições patológicas, a dor pode se tornar persistente, resultando em um estado de má adaptação, que ocorre por uma combinação de alterações nos eventos básicos da nocicepção, associadas a disfunções de origem física, emocional, psicológica e social. Portanto, trata-se de uma síndrome que compromete de maneira transitória ou permanente a qualidade de vida, assim como a capacidade de trabalho de seus portadores (Chong et al., 2003).

A experiência ou percepção da dor é um processo complexo que envolve diversas áreas no sistema nervoso central e periférico, iniciando-se com a percepção do estímulo doloroso pelo SNP a até a transmissão e interpretação no SNC. Após a ocorrência de um estímulo doloroso, nociceptores periféricos são ativados, fibras 
mielinizadas (fibras-A $\delta$ ) e não mielinizadas (fibras C) transduzem o estímulo nociceptivo no SNP. O axônio origina-se do corpo celular presente no GRD ou no gânglio trigeminal e adentra o SNC (Woolf, 2007). Os potenciais de ação iniciam-se na periferia e propagamse ao longo dos axônios dos neurônios aferentes primários. Esses potenciais de ação induzem a liberação de neurotransmissores excitatórios como glutamato, substância P e neuromoduladores (BDNF) no corno dorsal da medula espinal (Argoff, 2011).

As fibras aferentes primárias inervam lâminas superficiais (I e II) e profundas, V e VI, do corno dorsal da medula espinal. As projeções oriundas das lâminas I e V projetam-se via trato espinotalâmico para o tálamo e via espinobulbar para estruturas subcorticais: hipotálamo, amigdala, substância cinzenta periaquedutal e bulbo ventromedial rostral. A informação nociceptiva transmitida através da lâmina IV, V e VI ascendem para o cérebro sendo relevantes para a percepção da dor (Millan, 2002).

A medula espinal, antes considerada uma simples estação intermediária para os impulsos sensoriais, atualmente é considerada uma estrutura complexa contendo uma grande variedade neuronal e arranjos sinápticos, bem como considerável número de neurotransmissores e neuropeptídios. Essa estrutura permite não somente a recepção e a transmissão dos impulsos sensoriais, bem como um elevado grau de modulação central, envolvendo integração, seleção e dispersão apropriada dos impulsos sensoriais (Bonica, 1990). Além da participação primordial da medula espinal no controle da dor, as sinapses moduladoras não estão restritas à medula, mas também a outras estruturas supraespinais.

Estudos realizados entre os anos de 1970 e 1980 mostraram que influências inibitórias oriundas da PAG e RVM modulariam a excitabilidade da medula espinal, principalmente do corno dorsal, posteriormente ficou claro que essas projeções agiam facilitando ou inibindo a transmissão nociceptiva e atualmente está claro que existe uma via descendente inibitória e outra facilitatória da dor. Esses estudos demonstraram que a 
estimulação elétrica de várias regiões supraespinais suprimiam a percepção da dor (Reynolds, 1969).

A PAG é uma estrutura mesencefálica localizada parcialmente ao redor do aqueduto cerebral e integra informações sensórias ascendentes com influências descendentes oriundas de outras regiões cerebrais (hipotálamo, amigdala e hipocampo). A PAG apresenta um papel dual em relação à modulação da dor, participando da via descendente inibitória e facilitatória da dor.

Foi relatado que a estimulação elétrica da PAG inibe a transmissão da nocicepção e os reflexos nociceptivos (Mayer et al., 1976; Aimone et al., 1986). Nesse sentido, foi demonstrado que a microinjeção de glutamato ou de morfina na PAG ou no RVM induz antinociccepção (Gebhart, 1982; Aimone et al., 1987).

A PAG possui um papel dual em relação a modulação da dor:

A participação dessa região cerebral na modulação negativa da transmissão da nocicepção foi demonstrado por Morgan e colaboradores (1991). Nesse trabalho, a estimulação elétrica da PAG reduziu a hipersensibilidade mecânica induzida por um estímulo inflamatório na pata de ratos (Morgan et al., 1991).

Por outro lado, a participação da PAG na facilitação da transmissão da nocicepção foi demonstrado por $\mathrm{Hu}$ e colaboradores (2009). Nesse trabalho os pesquisadores criaram um camundongo transgênico que superexpressa a subunidade NR2B na PAG. O resultado da superexpressa dessa subunidade foi o aumento da condutância do canal que resultou no aumento da hipersensibilidade mecânica induzida pela injeção de CFA na pata dos animais, bem como exacerbação da resposta do tempo de licking na segunda fase do teste da formalina, sugerindo que o aumento da 
neurotransmissão glutamatérgica via ativação NMDA na PAG facilite a transmissão da nocicepção(Hu et al., 2009)

Anteriormente considerava toda a estrutura ao redor do aqueduto cerebral como sendo a PAG, posteriormente ficou claro que principalmente que na porção rostral existe uma estrutura denominada núcleo dorsal da rafe (DR). O DR é uma região mesencefálica que contém um rica neurotransmissão serotonérgica que projetam-se para diversas regiões do cérebro (Dahlstrom et al., 1964). Esses neurônios contendo 5-HT estão envolvidos em várias funções fisiológicas, incluindo aprendizado, memória, modulação da dor e do comportamento (Michelsen et al., 2008).

Projeções ascendentes diretamentente modulam transmissão da nocicepção no tálamo. Resultados neurofisiológicos e farmacológicos sugerem que neurônios serotonérgicos do DR tem um efeito inibitório sobre a transmissão da dor (Wang et al., 1994). Além disso, tem sido demonstrado que a estimulação elétrica dessa estrutura causa analgesia (Oliveras et al., 1974).

A PAG não envia projeções diretamente para a medula espinal, mas sim para o RVM que é a via de saída do sistema descendente de modulação da dor (Brooks et al., 2005;)

O RVM é uma é uma região bulbar composta pelos núcleo magno da rafe/formação reticular e foi demonstrado que a sua estimulação elétrica pode tanto inibir quanto facilitar a nocicepção. O RVM possui três tipos de neurônios intrínsecos os “oncells", os "off-cells" e os "neutral-cells"; os "off-cells" associados com a inibição e a atividade dos "on-cells" com a facilitação da transmissão dos impulsos nociceptivos que adentram a medula espinal, porém não sabe-se exatamente qual a participação dos neurônios do tipo “neutral-cells” na modulação da nocicepção (Fields et al., 1991). 
Atualmente, sabe-se que o limiar nociceptivo é menor quando a população de “on-cells" estão ativas e as "off-cells" silenciadas, desse modo os "off-cells" estão normalmente ativos e tem a sua atividade reduzida consideravelmente após o aparecimento de algum estimulo nocivo que por sua vez leva a ativação dos neurônios do tipo "on-cells", e de modo reflexo à atividade das "off-cells" retorna e ocorre a inibição da nocicepção. No entanto, foi observado que em modelos experimentais de dor neuropática ocorreria o aumento da atividade dos neurônios "on-cells" e "off-cells" em resposta a lesão periférica de nervos, mas por algum problema na dinâmica entre ativação e inibição, a modulação da dor não é bem sucedida e a dor cronifica-se (Porreca et al., 2002).

Assim como a PAG, o RVM também apresenta um papel dual em relação a modulação da dor:

A participação do RVM na via descendente inibitória da dor foi demonstrado por Venegas e colaboradores (1984). Nesse trabalho foi relatado que a estimulação elétrica do RVM inibe o comportamento de retirada de calda no teste do tail flick. Com o intuito de aprofundar o entendimento do mecanismo pelo qual isso acontecia, foi observado que a estimulação elétrica ativa preferencialmente as "off-cells" e o aumento da atividade desse tipo celular inibe a transmissão da nocicepção (Vanegas et al., 1984)

Por outo lado, o papel do RVM na facilitação foi demonstrado por Pertovara e colaboradores (1996). Nesse trabalho, foi demonstrado que a microinjeção de lidocaína no RVM ou na PAG reduzia a hipersensibilidade mecânica induzida pela lesão de nervos periféricos. O efeito analgésico da lidocaína sugere que essas estruturas estariam ativas, facilitando a transmissão da nocicepção, ao passo que a administração de lidocaína um 
bloqueador que canais de sódio, reduz a atividade neuronal local, ao reduzir a transmissão de potenciais de ação (Pertovaara et al., 1996)

Os principais neurotransmissores envolvidos com a modulação endógena da dor são: a serotonina, a noradrenalina, endocanabinóides e opióides.

Assim, normalmente a PAG e o RVM modulam de modo negativo a transmissão da nocicepção. Quando o organismo é exposto a algum agente prónociceptivo o eixo PAG/RVM/medula espinal é desinibido a nocicepção é transmitida, processada e uma resposta adequada é dada a ela. Posteriormente, a essa facilitação o eixo PAG/RVM/medula espinal novamente inibe o sistema e o quadro de hipernocicepção mecânica cessa. Entretanto, alterações no padrão desinibição, facilitação e inibição do eixo PAG/RVM/medula espinal tem sido implicado num tipo de dor, a dor neuropática.

\subsection{Dor neuropática}

Um tipo de dor crônica destaca-se por sua grande relevância clínica é a dor neuropática, sendo que a sua prevalência no Reino Unido, nos Estados Unidos e no Canada, varia de $1 \%$ a 17,9 \% da população (Carter et al., 2001; Toth et al., 2009). A dor neuropática resulta de lesões que acometem o sistema nervoso periférico e central que envolvem múltiplas mudanças patofisiológicas causadas pelo traumatismo mecânico, doenças metabólicas, produtos químicos neurotóxicos, infecção ou ainda por invasão de tumores (Woolf et al., 1999; Dworkin et al., 2003; Seifert et al., 2009).

Apesar dos mecanismos responsáveis pelo desenvolvimento da dor neuropática não estarem totalmente elucidados, sabe-se que ela resulta da interação entre 
os neurônios, células do sistema imune e gliais em diferentes níveis que englobam o gânglio da raiz dorsal (GRD), a medula espinal e em estruturas supraespinais associadas com as vias da dor (Moalem et al., 2006; Scholz et al., 2007).

A injúria de nervos periféricos altera a atividade normal das fibras nociceptivas aferentes primárias, aumentando o número de potenciais ectópicos, diminuindo o limiar de ativação que por sua vez podem promover dor espontânea, bem como, dor dependente de estímulo, caracterizada como alodinia (dor induzida por estímulo que normalmente não provoca dor) e/ou hiperalgesia (resposta aumentada a um estímulo normalmente doloroso) (Jensen et al., 2001; Amir et al., 2002). Essa atividade anormal está relacionada com o aumento da expressão, distribuição e cinética de canais de sódio voltagem dependente $\left(\mathrm{Na}_{\mathrm{v}}\right)$, liberação de fatores de crescimento no local da lesão, nos nervos adjacentes ou no GRD, sendo principalmente os subtipos de $\mathrm{Na}_{\mathrm{v}} 1.3$, 1.6, 1.8 e 1.9 associados com o desenvolvimento do quadro neuropático (Xie et al.; Vabnick et al., 1996; Hinson et al., 1997; Ro et al., 1999; Michaelis et al., 2000; Baker et al., 2001; Sommer, 2003).

Uma das consequências do aumento da atividade dos neurônios sensitivos periféricos é a sensibilização do corno dorsal da medula espinal através liberação excessiva de neurotransmissores excitatórios, aumento da expressão de $\mathrm{Na}_{\mathrm{v}} 1.3$ e da ativação de diversas vias de sinalização intracelulares (PKC e MAPKs) em neurônios da medula espinal (Ji et al., 2001; Obata et al., 2003). Sabe-se também que a sensibilização espinal apresenta além do componente neuronal, um componente imune com ativação de células da glia e liberação de quimiocinas/citocinas pró-inflamatórias que contribuem para o desenvolvimento e manutenção da hipersensibilidade neuropática (Nicol et al., 1997). 
A dor neuropática não resulta apenas de mecanismos periféricos ou espinais, mas também de mecanismos supraespinais, como a sensibilização de regiões envolvidas na modulação da dor. Desse modo, foi observado que após a lesão de nervos ocorre o aumento da expressão de genes envolvidos com o ciclo celular, apoptose, transdução de sinal e neuroproteção em regiões supraespinais (Tang et al., 2009), bem como a ativação de células da glia na bulbo ventromedial rostral (RVM) e na substância cinzenta periaquedutal (PAG), sendo que ambas as estruturas compõem a via descendente da dor. (Takeda et al., 2009; Mor et al., 2010).

Outras alterações relevantes no processo de sensibilização central são alterações na síntese de neurotransmissores excitatórios ou até mesmo a fosforilação das subunidades dos receptores glutamatérgicos do tipo NMDA. Os NMDA são receptores ionotrópicos compostos por diferentes subunidades, NR1, NR2 e NR3. A subunidade NR1 é um componente essencial do receptor, a fosforilação do mesmo modula a atividade do canal, facilitando a transmissão dos impulsos nociceptivos em modelos de dor inflamatória e neuropática (Cerne et al., 1992; Masu et al., 1993; Zou et al., 2000; Gao et al., 2005). No modelo de constrição crônica do nervo ciático (CCI) foi observado o aumento dos níveis de TNF- $\alpha$ no hipocampo, de TNF- $\alpha$ e IL-1 $\beta$ no RVM seguido pela fosforilação da subunidade NR1 do receptor NMDA. Resultados similares foram observados após a microinjeção de TNF- $\alpha$ e IL-1 $1 \beta$ no RVM, os quais causaram o aumento da fosforilação da subunidade NR1 e hiperalgesia, que foi revertida por um antagonista do receptor NMDA (Ignatowski et al., 1999; Wei et al., 2008). Dessa forma, alguma disfunção nessas estruturas afetaria a via descendente da dor, contribuiria para a sensibilização central e desenvolvimento da dor neuropática. 
A estimulação elétrica da coluna ventral da PAG causa analgesia em ratos, submetidos a um modelo experimental de dor neuropática, por meio da inibição do corno dorsal pela via descendente inibitória (Lee et al., 2000). Outros estudos demonstraram que a PAG estaria envolvida na via descendente facilitatória da dor podendo contribuir para o desenvolvimento da dor neuropática (Lovick, 2008; Jaggi et al., 2011). Estudos recentes tem demonstrado diminuição dos níveis de NGF (nerve growth factor) e aumento da expressão de GFAP (glial fibrillary acidic protein) que é indicativo de atividade astrocítica na PAG e como essas alterações podem alterar o funcionamento da circuitaria neuronal local, sugere-se que poderiam estar envolvidas no desenvolvimento da dor neuropática (Mor et al., 2010; Norman et al., 2010; Vivoli et al., 2010).

Desse modo, foi demonstrado que a ativação neuronal e/ou atividade do RVM contribui para hipersensividade mecânica neuropática, haja visto que a microinjeção de lidocaína no RVM após a ligadura do nervo espinal reduziu a alodinia causada pela lesão de nervos (Pertovaara et al., 1996). Isso sugere que o aumento da atividade da via descendente facilitatória da dor composta basicamente pelo eixo PAG/RVM/MEDULA ESPINAL contribui para o desenvolvimento da dor neuropática.

A 5-HT exerce diversos efeitos modulatórios na transmissão nociceptiva no corno dorsal (Millan, 2002). Nesse sentido, foi demonstrado que a redução dos níveis de 5-HT atenuam a analgesia induzida pela morfina (Messing et al., 1977). A ativação de receptores 5-HT1a pós-sinápticos diminuem a excitabilidade dos neurônios da via espinotalâmico e dos 5-HT1b/d localizados em interneurônios excitatórios inibem a liberação de neurotransmissores em neurônios aferentes primários.

A ativação da via serotonérgica descendente possui efeitos facilitários via 5HT2 e 5-HT3 (Gebhart, 2004; Suzuki et al., 2004). Os receptores 5-HT3 diferem de todas 
as classes dos receptores de 5-HT por que são compostos por multisubunidades que formam receptores acoplados a canais iônicos e quando ativados levam a despolarização celular. Tanto ativação dos 5-HT3 pré-sinápticos quando dos pós-sinápticos tem efeitos pró-nociceptivos caracterizado pelo aumento da liberação de neurotransmissores por neurônios nociceptivos e aumento da excitabilidade de neurônios da via espinotalâmica, respectivamente (Kwon et al., 2013).

Assim, a via serotonérgica descendente apresenta um papel duplo: efeitos inibitórios (descendente inibitória) e facilitatórios (descendente facilitatória) dependendo dos estados nociceptivos (Millan, 2002; Vanegas et al., 2004; Kuner, 2010). Se por um lado, tem sido descrito que a exposição aguda ou crônica a estímulos dolorosos causa a ativação de neurônios serotonérgicos no RVM, seguido pelo aumento da renovação de 5HT na medula espinal (Taguchi et al., 1992; Mason, 1999). De outro, a estimulação do RVM ou da PAG causa a liberação de serotonina na medula espinal (Cui et al., 1999). Em um modelo experimental de dor neuropática, a 5-HT, via 5-HT1a espinal contribui para a analgesia induzida pela estimulação elétrica de neurônios no córtex (Viisanen et al., 2010). Além disso, diminuição da liberação de 5-HT na medula espinal, caracterizada pela diminuição da eficácia da via descendente inibitória da dor (Goettl et al., 2002; Liu et al., 2010) Nesse sentido, lesões na via descendente serotonérgica reduzem ou previnem o desenvolvimento da hiperalgesia associada a lesão de nervos periféricos (Porreca et al., 2002; Ossipov et al., 2010).

Logo, tanto a ineficiência da via descendente inibitória quanto a atividade exacerbada da via descendente facilitatória poderia contribuir para o desenvolvimento da dor neuropática facilitando a transmissão da informação nociceptiva na medula espinal (Calejesan et al., 2000; Lima et al., 2002). Devido a complexidade e desconhecimento 
dos mecanismos envolvidos na gênese e manutenção da dor neuropática, ela normalmente não é revertida com os tratamentos convencionais para o alivio da dor, anti-inflamatórios e analgésicos opióides (Woolf et al., 1999; Woolf et al., 2004). Uma alternativa terapêutica para o tratamento dessa patologia é o uso de medicamentos que modificam os sistemas de monoaminas, como os antidepressivos tricíclicos (Sindrup et al., 2005; Su et al., 2009; Farghaly et al., 2012a).

Os antidepressivos tricíclicos foram introduzidos para o tratamento da neuropatia diabética há muito tempo, baseado em observações empíricas, desde então diversos estudos randomizados e controlados mostraram a sua eficácia no alivio da dor (Davis et al., 1977; Sindrup et al., 2005). O mecanismo de ação mais provável desses fármacos em relação à dor neuropática é inibir a recaptação das monoaminas na fenda sináptica, restaurando dessa forma a via inibitória descendente da dor, assim, bloqueando a transmissão dos estímulos nociceptivos. Além disso, sabe-se que a eficácia dos antidepressivos tricíclicos varia de acordo com tipo de recaptação de monoaminas que é inibida (Farghaly et al., 2012b).

Portanto, além dos indícios de que a lesão periférica de nervos poderia perturbar o balanço entre a via descendente facilitatória e inibitória da dor, e contribuir para a gênese e/ou manutenção desta patologia, também tem sido sugerido que a dor crônica resultaria em partes de uma redução dos níveis endógenos de 5-HT tanto em regiões espinhais quanto supraespinais e fármacos que aumentassem os níveis de 5-HT na fenda sináptica poderiam atenuar a dor (Ren et al., 2002). 


\subsection{Via das quinureninas: Indoleamina 2,3-dioxigenase1 (IDO1) e quinurenina 3- monoxigenase (KMO)}

Sabe-se desde os anos 1970 que existem duas enzimas diferentes envolvidas no metabolismo do triptofano, o precursor da 5-HT, através de uma série de reações denominadas via das quinureninas. Essas duas enzimas são a triptofano 2,3-dioxigenase e indoleamina 2,3-dioxigenase (IDO1), recentemente foi descrito uma nova enzima envolvida com o metabolismo do triptofano e devido a sua homologia gênica foi intitulada IDO2. Embora as três enzimas catalisem a mesma reação, existe um distinto padrão de expressão e características bioquímicas, o que sugere um papel biológico diferente para cada uma (Munn et al., 2013).

Em resposta a estímulos inflamatórios, a IDO1 é induzida em uma ampla gama de células, e tem sido implicada na modulação da resposta imune à infecções e tumores (Munn et al., 2013). Embora seja fisiologicamente expressa em vários tecidos (intestino, pulmão, cérebro, epidídimo e timo, por exemplo), a transcrição aumentada de IDO1 é limitada a tipos específicos de células, tais como células dendríticas, macrófagos, células gliais, neurônios, fibroblastos, eosinófilos e células epiteliais, porém, em homeostasia sua expressão é muito baixa. Entretanto, em doenças como a esquizofrenia, a inflamação e a depressão sua expressão é aumentada consideravelmente (Dantzer et al., 2008). As citocinas pró-inflamatórias como o IFN- $\gamma$, TNF- $\alpha$, IL-1 e IL-6 induzem aumento da expressão e atividade da IDO1 (Heyes et al., 1990; Chon et al., 1996; Pemberton et al., 1997; Babcock et al., 2000).

A IDO2 é expressa em várias linhagens de células relacionadas ao câncer, sugerindo que essa enzima desempenhe um papel no surgimento de tumores, apesar de 
sua expressão ser constitutiva em alguns tecidos, como fígado, rins, tecidos reprodutivos femininos, entre outros (Metz et al., 2007; Platten et al., 2012).

Alguns tecidos expressam ambas as isoformas de IDO (IDO1 e IDO2) em outros, a expressão é restrita para apenas uma delas, sugerindo não haver redundância funcional entre essas enzimas (Ball et al., 2007). Além disso, a expressão dessas enzimas em resposta a estímulos é diferente. A IDO1, por exemplo, é induzida sistemicamente em células endoteliais durante infecções, como na malária e leishmaniose, de modo dependente de IFN- $\gamma$, enquanto mantém inalterada a expressão de RNAm para IDO2 (Hansen et al., 2004; Ball et al., 2009).

As enzimas IDO1 e IDO2 são codificadas em genes adjacentes uns aos outros no cromossomo 8. Quanto à sequência de aminoácidos, possuem 43\% de similaridade, não possuindo relações estruturais com a TDO (Ball et al., 2009). São caracterizadas por uma estrutura monomérica, com peso molecular entre 42 e $45 \mathrm{kDa}$. A análise da estrutura cristalina da enzima IDO1 proveniente de humanos, revelou um grande domínio Cterminal, no qual se localiza o grupamento heme, responsável pela atividade catalítica da enzima, e um pequeno domínio não catalítico N-terminal, sem função aparente (Sugimoto et al., 2006).

A metabolização do triptofano produz vários metabolitos ativos, incluindo o 3-hidroxiantranílico, o ácido quinolínico e o ácido quinurênico (figura 1). O 3hidroxiquinurênico (3-HK) é formado a partir da quinurenina pela enzima Quinurenina 3-monooxigenase (KMO) e está envolvido na geração de espécies reativas de oxigênio como o peróxido de hidrogênio/radical hidroxila.

A KMO é uma enzima que catalisa a 3-hidroxilação da quinurenina na presença de NADPH e oxigênio molecular, localiza-se altamente expressa na membrana externa das mitocôndrias e em tecidos como o fígado, rins e fagócitos (macrófagos e 
monócitos). No SNC é expressa predominantemente em micróglias e tem a sua expressão modulada por diversas citocinas (Leklem, 1971; Alberati-Giani et al., 1996; Giorgini et al., 2008).

Sabe-se que ocorre o aumento da expressão da KMO em condições inflamatórias e o bloqueio dessa enzima poderia ser grande valia pois impediria a geração de 3-HK e de ácido quinolínico, haja vista que o 3-HK é precursor do ácido quinolínico (Heyes et al., 1993; Okuda et al., 1996). O ácido quinolínico é um agonista dos receptores glutamatérgicos do tipo NMDA (N-methyl-D-aspartate), sendo este um dos produtos finais da via das quinureninas (Stone et al., 1981). Dessa forma, o ácido quinolínico com seu efeito excitotóxico ao ativar persistentemente os receptores NMDA, elevando os níveis intracelulares de cálcio, causando disfunção neuronal/morte celular e participando da sensibilização de regiões supraespinais e o 3-hidroxiquinurênico gerando espécies reativas de oxigênio, bem como sendo convertido em ácido quinolínico podem juntos causar uma série de danos/alterações celulares que contribuem para o desenvolvimento da dor neuropática (Eastman et al., 1989; Kim et al., 2004).

Por outro lado, o ácido quinurênico é um antagonista dos receptores glutamatérgicos do tipo NMDA, AMPA e cainato e colinérgicos ( $\alpha 7 \mathrm{nAChR})$, e teria desse modo um efeito protetor sob a excitotoxidade causada pela ativação dos receptores NMDA pelo ácido quinolínico, além disso foi descrito recentemente que o ácido quinurênico é um agonista do receptor GPR35, sendo que a sua ativação está implicada na diminuição da produção de citocinas pró-inflamatórias (Swartz et al., 1990; Wang et al., 2006; Stone, 2007; DiNatale et al., 2010; Schwarcz et al., 2012) . Até o presente momento, tem sido relatado que as células produtoras dos metabólitos da IDO1 no SNC são os neurônios, as micróglias e os astrócitos (Guillemin et al., 2005). 
O protótipo de inibidor da enzima KMO é o Ro 61-8048 (Rover et al., 1997). Entretanto, o Ro 61-8048 é metabolicamente instável, dessa forma foi desenvolvido em 2011 uma droga de liberação lenta de Ro 61-8048, o JM6, que mostrou-se eficaz no tratamento de doenças neurodegenerativas crônicas (Zwilling et al., 2011).

Se por uma lado a ativação da enzima IDO1 causa a diminuição da eficiência da via descendente inibitória via diminuição dos níveis de triptofano/5-HT, a ativação da KMO teria um efeito aditivo ao ativar a via descendente facilitatória via QUIN, dessa forma esses dois efeitos somados propiciariam o desenvolvimento da hipersensibilidade após a lesão de nervos periféricos.

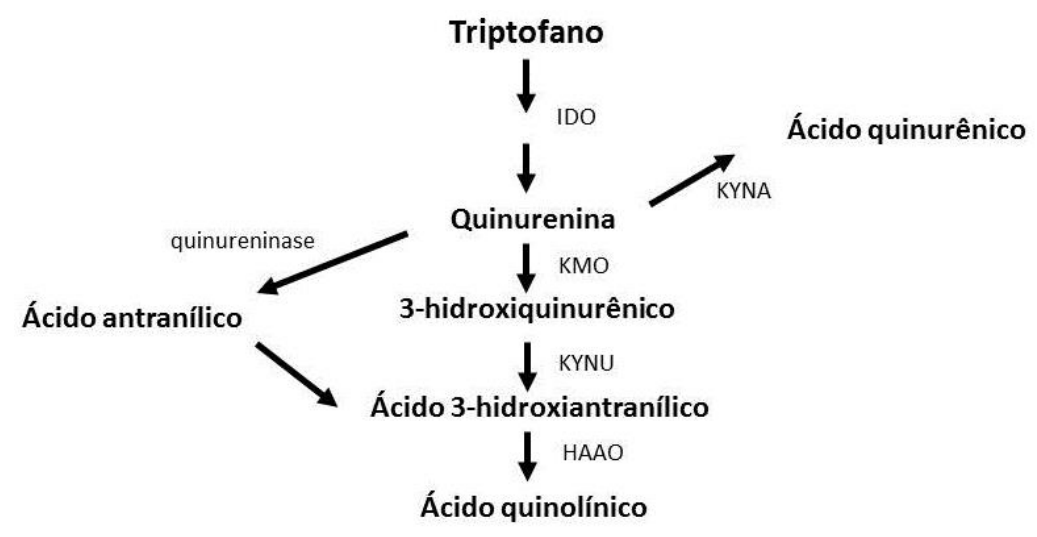

Figura 1. Representação esquemática da via das quinureninas, adaptado de Mándi e Vécsei (Mandi et al., 2012). As reações dessa via são catalisadas pelas enzimas quinurenina 3-Monooxigenase (KMO), quinureninase (KYNU), oxidase do ácido 3hidroxiantranico (HAAO), quinurenina 3-Monooxigenase (KMO) e quinurenina aminotransferase (KYNA). 


\subsection{A ativação da via das quinureninas está relacionada com o desenvolvimento da comorbidade depressão associada lesão de nervos periféricos}

Embora a maior parte dos estudos envolvendo dor neuropática foque o nível medular, tem aumentado o interesse em investigar a participação de estruturas supraespinais no desenvolvimento da dor crônica, incluindo a dor neuropática (Urban et al., 1999; Vanegas et al., 2004).

A dor neuropática aumenta a transmissão sináptica em regiões específicas do sistema nociceptivo, sabe-se que aumento da expressão gênica de citocinas próinflamatórias no tronco encefálico está envolvida nesse aumento de atividade, por exemplo (Apkarian et al., 2006). A neuropatia causa alterações em estruturas supraespinais, facilitando a transmissão do sinal nociceptivo através da ativação da via desdente facilitatória da dor, caracterizado pelo eixo PAG/RVM/MEDULA ESPINAL (Willis, 1985; Gebhart, 2004) .

Quadros de dores crônicas estão associados ao aumento do risco de desenvolver desordens do humor, mais do que $50 \%$ dos indivíduos que sofrem de dor crônica possuem algum sintoma de depressão (Dworkin et al., 1991). O possível link entre dor crônica e depressão são os seguintes:

- Neuroinflamação

Um dos melhores modelos para avaliar a relação da inflamação crônica com o desenvolvimento de depressão é o tratamento de pacientes com câncer ou hepatite C utilizando a citocina IFN- $\alpha$. 
A terapia com IFN- $\alpha$ causa depressão profunda numa parte dos pacientes, outra parte apresentam apenas alguns sintomas de depressão e outros desenvolvem mania ao término do tratamento. Além disso, outras citocinas tem sido relacionadas com a neuroinflamação e desenvolvimento da depressão como a IL-6, TNF- $\alpha$, IL-1 $1 \beta$ que causam diversas alterações gliais e neuronais contribuindo para o desenvolvimento dessa doença (Miller et al., 2005; Berthold-Losleben et al., 2008; Norman et al., 2010; Raison et al., 2013).

- Ativação da via das quinureninas

Além dos efeitos descritos acima, as citocinas podem modular a disponibilidade de neurotransmissores no SNC. A ativação da via das quinureninas, mais especificamente das enzimas IDO1 e KMO, desviam o eixo triptofano/5-HT para triptofano/quinureninas/QUIN. A relevância clínica disso foi comprovado ao associar níveis elevados de QUIN/quinureninas no líquido cerebrospinal de indivíduos em tratamento com IFN- $\alpha$ (Miller et al., 2009).

O QUIN ao ativar a neurotransmissão glutamatérgica seria de extrema relevância para o desenvolvimento da depressão, pois ativa tanto receptores NMDA sinápticos e extra sinápticos, a ativação dos últimos levam a diminuição da expressão de BDNF (brain-derived neurotrophic factor), um potente indutor de neurogênese. Dessa forma, a ativação da via das quinureninas reduz os níveis de triptofano, consequentemente de 5-HT, produzindo quinureninas e QUIN, que por sua vez ativa a circuitaria glutamatérgica, reduzindo os níveis de BDNF, a neurogênese e contribuiria dessa forma para o desenvolvimento do comportamento depressivo (Ganong et al., 1986; Heyes et al., 1992; Koo et al., 2008). 
Kim e colaboradores (2012) demonstraram que a ativação da via das quinureninas está relacionada com o desenvolvimento da dor crônica inflamatório e com o desenvolvimento da comorbidade depressão. Foi constatado que indivíduos com dores crônicas nas costas e depressão apresentavam níveis elevados da citocina IL-6 e da enzima IDO1, bem como a atividade enzimática da mesma, sendo esses achados consistentes com os encontrados com animais de experimentação (Kim et al., 2012).

Levando em consideração a teoria monoaminérgica e glutamatérgica da depressão a ativação da via das quinureninas seria o ponto chave para o desenvolvimento da comorbidade depressão associada a lesão de nervos pois ela reduz os níveis de triptofano, cosequentemente de 5-HT e por outro lado aumenta os níveis de QUIN, um potente agonista glutamatérgico.

A teoria da deficiência da 5-HT na depresão originou-se de observações clínicas nos anos 1950s. Na época pacientes com tuberculose eram tratados com Iproniazida, inesperadamente os indivíduos que apresentavam depressão associada a tuberculose tinham uma significativa melhora clínica, posteriormente foi descrito que esse fármaco inibia as enzimas MAO-A/B (monoamino oxidase) e aumentava os níveis de 5-HT no cérebro (Lopez-Munoz et al., 2009). Outros estudos mostraram que a depleção aguda de triptofano induz o aparecimento dos sintomas de depressão, depressão leve, que é revertido com antidepressivos que aumentam os níveis de 5-HT (Leyton et al., 1997; Delgado, 2006).

Além da teoria serotonérgica da depressão, no final da década de 1990 foi criada a hipótese glutamatérgica da depressão. Em 1959, Crane e colaboradores demonstraram que altas doses de D-cicloserina tem efeito antidepressivo, esse farmaco é um agonista parcial dos receptores NMDA, em altas doses age como um antagonista. 
Esse foi o primeiro relato acerca da importância da neurotransmissão glutamatérgica na fisiopatologia da depressão. Posteriormente, uma série de trabalhos demonstraram que alterações nos níveis de glutamato no sangue e no líquido cerebroespinal de pacientes com depressão (Kim et al., 1982; Altamura et al., 1993).

Além disso, os níveis de glutamato correlacionam-se com a severidade dos sintomas da depressão (Mitani et al., 2006). Dessa forma, o aumento da atividade glutamatérgica via ativação NMDA está associada com o desenvolvimento da depressão, a redução da atividade glutamatérgica, isto é, o antagonismo NMDA teria um efeito antidepressivo. Os antagonistas NMDA: MK-801, Quetamina, Amantadina, entre outros, apresentam efeitos antidepressivos em diversos modelos animais (Trullas et al., 1990; Maj et al., 1992; Yilmaz et al., 2002).

Diante das evidências descritas acima, formulamos a hipótese de que após a lesão de nervos periféricos ocorre o aumento da expressão/atividade das enzimas IDO1 e KMO em estruturas supraespinais (PAG e RVM) sabidamente envolvidas na fisiopatologia da dor neuropática, contribuindo para o desenvolvimento da dor neuropática por modulação negativa da via serotoninérgica descendente inibitória e ativação da via descendente facilitatória da dor via QUIN. Além disso, a redução dos níveis de 5-HT e o aumento dos de QUIN favoreceria o desenvolvimento da comorbidade depressão associada a lesão de nervos periféricos. 
OBJETIVOS 


\section{OBJETIVOS}

\subsection{Objetivo geral}

O objetivo do presente trabalho foi investigar a participação da ativação da enzima IDO1 e KMO em estruturas supraespinais (PAG e RVM) no desenvolvimento da dor neuropática. Além disso, avaliar os mecanismos envolvidos na indução dessas enzimas, focando no papel da citocina pró-inflamatória IFN- $\gamma$, bem como a relação da ativação das enzimas IDO1/KMO e da citocina IFN- $\gamma$ com o desenvolvimento do comportamento depressivo associado a lesão de nervos periféricos.

\subsection{Objetivos específicos}

2.2.1. Avaliar a expressão da enzima IDO1 na PAG, no RVM e no hipocampo após a lesão de nervos periféricos;

2.2.2. Avaliar a expressão da enzima KMO na PAG e no RVM após a lesão de nervos periféricos;

2.2.3. Avaliar o efeito da deleção genética ou da inibição farmacológica supraespinal da enzima IDO1 sob a hipersensibilidade mecânica induzida pela lesão de nervos periféricos;

2.2.4. Avaliar o efeito da inibição farmacológica sistêmica e supraespinal da enzima KMO sob a hipersensibilidade mecânica induzida pela lesão de nervos periféricos: evidência indireta da participação do ácido quinolínico; 
2.2.5. Avaliar os efeitos nociceptivos da microinjeção de quinurenina, ácido 3hidroxiantranílico e ácido quinolínico no espaço intracerebroventricular de camundongos naives;

2.2.6. Investigar o mecanismo nociceptivo do QUIN: ativação da via descendente facilitatória;

2.2.7. Avaliar os níveis de 5-HT no RVM de animais selvagens e geneticamente deficientes para a enzima IDO1 submetidos à SNI.

2.2.8. Investigar a participação de células T CD4+ e da citocina IFN- $\gamma$ na gênese da dor neuropática, bem como na expressão da enzima IDO1 e KMO na PAG e no RVM;

2.2.9. Investigar o desenvolvimento da comorbidade depressão, focando a participação das células T CD4+, da citocina IFN- $\gamma$, da enzima IDO1 e KMO e dor neuropática em camundongos submetidos a lesão de nervos periféricos; 
MATERIAL E MÉTODOS 


\section{MATERIAIS E MÉTODOS}

Os procedimentos experimentais foram realizados de acordo com as normas estabelecidas pelo Comitê de Ética em experimentação animal da Faculdade de Medicina de Ribeirão Preto da Universidade de São Paulo. Além disso, os experimentos foram realizados de acordo com as diretrizes para uso de animais experimentais em estudos de dor da IASP (Zimmermann, 2001). O requerimento para o uso de animais de experimentação foi protocolado sob $\mathrm{n}^{\circ}$ 45/2013, na Comissão de Ética em Experimentação animal da Faculdade de Medicina de Ribeirão Preto da Universidade de São Paulo (anexo 1).

\subsection{Vias de administração de drogas, estereotaxia e microinjeção de drogas no espaço intracerebroventricular}

As drogas foram administradas pela via intratecal (i.t.), intraperitoneal (i.p), oral (v.o) e no espaço intracerebroventricular (i.c.v.) de camundongos.

A técnica utilizada para injeção intratecal foi descrita por Papir-Kricheli et al. (1987) modificada, na qual cada animal foi anestesiado com isoflurano e posteriormente realizado tricotomia da região lombar (Papir-Kricheli et al., 1987). Com a coluna vertebral arqueada, uma agulha hipodérmica $\mathrm{n}^{\circ} 26$ foi inserida no espaço subaracnóide medular, perfurando a região medial entre as vértebras L4 e L5 $( \pm 1)$ num ângulo de $45^{\circ}$. Sendo o volume injetado de $5 \mu \mathrm{L}$. Os animais recuperaram a consciência imediatamente após a injeção e nenhum comprometimento motor foi observado. 
Para injetar drogas no espaço intracerebroventricular (ventrículo lateral) dos camundongos foi necessário implantar uma cânula-guia no crânio dos animais, como descrito a seguir. Os animais foram anestesiados com tribromoetanol $(250 \mathrm{mg} / \mathrm{kg}$ i.p., Aldrich Chemical Co. Inc., Milwaukee, USA). Após a tricotomia, o camundongo teve o crânio fixado a um estereotáxico (Stoelting, Wood Dale, Illinois, USA), em seguida, foi realizada a assepsia local e administração de lidocaína juntamente com fenilefrina, anestésico local e vasoconstritor, respectivamente. Posteriormente, a calota craniana foi exposta através de uma incisão na pele, afastando-se totalmente o periósteo, seguida da limpeza da calota com água oxigenada a 10\%. Em seguida, o crânio foi perfurado com uma broca de uso odontológico, seguindo-se as coordenadas estabelecidas pelo Atlas de Coordenadas Estereotáxicas de Cérebro de Camundongo (FRANKLIN et al., 2007) (0.4 $\mathrm{mm}$ posteriormente a bregma, lateral de $1.0 \mathrm{~mm}$ e vertical de $-1.2 \mathrm{~mm}$ ). Através deste orifício, foi introduzido uma cânula de aço inoxidável ( $8 \mathrm{~mm}$ de comprimento), constituída por um segmento de agulha hipodérmica de $0,6 \mathrm{~mm}$ de diâmetro externo. A cânula foi fixada ao crânio por um parafuso previamente implantado na calota craniana e por uma prótese de resina acrílica autopolimerizável (Simplex, DFL Ind. Com., Brasil). Um mandril de 0,2 mm de diâmetro externo foi introduzido na cânula, para evitar a obstrução da mesma durante o período de recuperação.

Como medida profilática, ao final da cirurgia, os animais receberam uma injeção intramuscular de 0,2 ml de pentabiótico veterinário (Pentabiotico®, FontouraWyeth, SP, Brazil, 80.000 UI, intramuscular) e de analgésico não esteroidal, flunixin meglumine (Banamine®, Schering Plough, Brazil, 2,5 mg/kg, subcutâneo). Após o implante da cânula guia o animal ficou sob repouso por 7 dias no Biotério do Departamento de Farmacologia da Faculdade de Medicina de Ribeirão Preto da Universidade de São Paulo. 


\subsection{Drogas e diluentes}

As drogas, diluentes e suas respectivas origens, utilizadas no presente trabalho se encontram listadas na Tabela 1.

\section{Tabela 1: Drogas utilizadas}

\begin{tabular}{|c|c|c|c|}
\hline Drogas / Origem & Atividade & Dose & $\begin{array}{c}\text { Veículo para } \\
\text { diluição }\end{array}$ \\
\hline $\begin{array}{l}\text { Norharmane } \\
\text { (Sigma, USA) }\end{array}$ & $\begin{array}{c}\text { Inibidor não } \\
\text { competitivo da } \\
\text { enzima } \\
\text { indoleamine } \\
\text { 2,3-dioxigenase }\end{array}$ & $\begin{array}{l}300 ; 900 \\
\mathrm{nmol} / \mu \mathrm{L}\end{array}$ & Salina \\
\hline $\begin{array}{c}\text { MK801 } \\
\text { (Tocris, USA) }\end{array}$ & $\begin{array}{l}\text { Antagonista dos } \\
\text { receptores } \\
\text { NMDA }\end{array}$ & $10 \mathrm{nmol} / \mu \mathrm{L}$ & Salina \\
\hline $\begin{array}{c}\text { Ácido } \\
\text { quinolínico }(2,3- \\
\text { Pyridinedicarbo } \\
\text { xylic acid) } \\
\text { (Sigma, USA)** }\end{array}$ & $\begin{array}{l}\text { Metabólito da } \\
\text { via das } \\
\text { quinureninas e } \\
\text { potente agonista } \\
\text { NMDA }\end{array}$ & $\begin{array}{l}0,8 ; 8 ; 80 \\
\mathrm{nmol} / \mu \mathrm{L}\end{array}$ & Salina \\
\hline $\begin{array}{c}\text { Interferon }-\gamma \\
(\text { IFN- } \gamma) / \\
\text { Petrotech, USA }\end{array}$ & $\begin{array}{c}\text { Citocina } \\
\text { próinflamatória }\end{array}$ & $\begin{array}{c}0,2 ; 0,02 \\
0,002 \\
\mu \mathrm{g} / \mu \mathrm{L}\end{array}$ & Salina \\
\hline $\begin{array}{c}\text { L-Kynurenine } \\
\text { (Sigma, USA) }\end{array}$ & $\begin{array}{c}\text { Produto da } \\
\text { degradação do } \\
\text { triptofano }\end{array}$ & $\begin{array}{l}0,8 ; 8 ; 80 \\
\mathrm{nmol} / \mu \mathrm{L}\end{array}$ & Salina \\
\hline $\begin{array}{c}\text { Ácido 3- } \\
\text { hidroxiantranílic } \\
\text { o } \\
(\text { Sigma, USA)** }\end{array}$ & $\begin{array}{l}\text { Metabólito da } \\
\text { via das } \\
\text { quinureninas e } \\
\text { precursor do }\end{array}$ & $\begin{array}{l}0,8 ; 8 ; 80 \\
\mathrm{nmol} / \mu \mathrm{L}\end{array}$ & Salina \\
\hline
\end{tabular}




\begin{tabular}{|c|c|c|c|}
\hline & $\begin{array}{c}\text { ácido } \\
\text { quinolínico }\end{array}$ & & \\
\hline $\begin{array}{c}\text { Ro 61-8048 } \\
\text { (Sigma, USA) }\end{array}$ & $\begin{array}{c}\text { Inibidor } \\
\text { competitivo da } \\
\text { enzima } \\
\text { quinurenina 3- } \\
\text { monoxigenase }\end{array}$ & $\begin{array}{c}3 ; 30 ; 300 \\
\mathrm{nmol} / \mu \mathrm{L}\end{array}$ & $\begin{array}{c}\text { Salina+DMSO } \\
(0,5 \%)\end{array}$ \\
\hline $\begin{array}{l}\text { 1-metil- } \\
\text { triptofano }\end{array}$ & $\begin{array}{c}\text { Inibidor } \\
\text { competitivo da } \\
\text { enzima } \\
\text { indolemanina } \\
\text { 2,3-dioxigenase }\end{array}$ & $\begin{array}{c}3 \\
\text { mg/animal }\end{array}$ & Salina \\
\hline $\begin{array}{c}\text { Imipramina } \\
\text { (Sigma) }\end{array}$ & $\begin{array}{c}\text { Antidepressivo } \\
\text { tricíclico }\end{array}$ & $10 \mathrm{mg} / \mathrm{kg}$ & Salina \\
\hline LY 278,584 & $\begin{array}{l}\text { Antagonista } \\
\text { seletivo dos } \\
\text { receptores 5- } \\
\text { HT3a }\end{array}$ & $\begin{array}{l}20 \mathrm{nmol} / \\
\text { animal i.t. }\end{array}$ & Salina \\
\hline JM6 & $\begin{array}{l}\text { Pró-droga de } \\
\text { liberação lenta } \\
\text { de Ro61-8048 }\end{array}$ & $\begin{array}{c}100 \mathrm{e} \\
300 \mathrm{mg} / \mathrm{kg}\end{array}$ & salina \\
\hline
\end{tabular}

** as drogas ácido quinolínico e Ácido 3-hidroxiantranílico por serem ácidos de força moderada, após a diluição tinham o pH ajustado para o pH fisiológico.

\subsection{Animais}

Foram utilizados camundongos machos C57BL/6 (WT) provenientes do Biotério Central da Universidade de São Paulo, Campus de Ribeirão Preto (USP-RP). Os camundongos nocautes para células $\mathrm{T} \mathrm{CD}^{+}$, células $\mathrm{T} \mathrm{CD} 8^{+}$, células $\mathrm{B}, \mathrm{IFN}-\gamma$ e IDO1 
foram criados no Centro de Criacao de camundongos especiais da FMRP-USP. Todos os animais foram mantidos, por pelo menos 2 dias antes dos experimentos, no Biotério do Departamento de Farmacologia da Faculdade de Medicina de Ribeirão Preto, com comida e água ad libitum, em salas com temperatura e ciclo claro/escuro controlados. Os animais foram colocados no local de experimentação com pelo menos 1 hora de antecedência para ambientação. Todos os testes comportamentais foram realizados entre 8 e 17 horas. Cada experimento utilizou entre 5 a 8 animais por grupo.

\subsection{Testes de avaliação da nocicepção mecânica}

A nocicepção mecânica foi mensurada em diferentes tempos após a lesão de nervos periféricos nos animais (modelo SNI), comumente os experimentos foram realizados até 21/28 dias após a indução da hipersensibilidade mecânica. Também foi avaliado a nocicepção mecânica após injeção(ões) da(s) droga(s) de ácido quinolínico, IFN- $\gamma$, ácido 3-hidroxiantranilico e quinurenina nos animais, seguidas ou não de tratamento (MK801, por exemplo), bem como a avaliação a hipersensibilidade induzida por CFA utilizando-se a técnica de von Frey

\subsubsection{Teste de filamentos de von Frey}

A avaliação da hipersensibilidade nociceptiva mecânica em camundongos foi realizada como previamente descrito (Bourquin et al., 2006) . Os animais foram colocados em caixas de acrílico, cujo assoalho é constituído por uma rede de malha de 
arame não maleável, 15-30 minutos antes do experimento, para habituação ao ambiente. Uma série de filamentos de von Frey (0,008 a 1,4 g) (North Coast Medical, Inc. Morgan Hill, CA) foi aplicada na pata posterior direita, como pode ser observado na figura $2 b$. $\mathrm{O}$ estímulo foi interrompido após a observação da resposta nociceptiva, caracterizada por flexão seguida de retirada da pata, "flinch". Cada um dos filamentos de von Frey foi aplicado 10 vezes por aproximadamente 3 segundos. O filamento de menor força capaz de induzir resposta foi determinado como sendo o limiar mecânico $(\mathrm{g})$. A pressão exercida por cada filamento em gramas foi convertida em miligramas e normalizadas para a escala logarítmica (tabela 2) para que fosse possível a realização de testes estatísticos paramétricos, como o ANOVA de duas vias. Os testes foram realizados antes (basal condição livre de droga, veículo ou de processo cirúrgico) e após administração de drogas, veículo e realização de processo cirúrgico para indução de neuropatia.

Tabela 2. Transformação da pressão em grama dos filamentos de von frey para a escala logarítmica em miligramas

\begin{tabular}{lll}
\hline $\mathbf{g}$ & $\mathbf{m g}$ & $\mathbf{l o g}$ \\
\hline $\mathbf{0 , 0 0 8}$ & 8 & 0,90309 \\
$\mathbf{0 , 0 2}$ & 20 & 1,30103 \\
$\mathbf{0 , 0 4}$ & 40 & 1,60206 \\
$\mathbf{0 , 0 7}$ & 70 & 1,845098 \\
$\mathbf{0 , 1 6}$ & 160 & 2,20412 \\
$\mathbf{0 , 4}$ & 400 & 2,60206 \\
$\mathbf{0 , 6}$ & 600 & 2,778151 \\
\hline
\end{tabular}




\begin{tabular}{lll}
\hline $\mathbf{1}$ & 1000 & 3 \\
$\mathbf{1 , 4}$ & 1400 & 3,146128 \\
\hline
\end{tabular}

\subsection{Indução da neuropatia pelo modelo de SNI - spared nerve injury}

Sob anestesia de isoflurano (2\%) foi realizada uma incisão cirúrgica na pele da superfície lateral da coxa de camundongos e seguida de uma secção diretamente através do músculo femoral para expor o nervo isquiático e suas três divisões: os nervos peroneal, tibial e sural. O procedimento de SNI compreende em axotomia e uma ligadura dos nervos peroneal e tibial, deixando o nervo sural intacto (Figura 3). O músculo e a pele foram fechados com sutura cirúrgica. O grupo controle teve os nervos expostos, mas não foi realizada a axotomia destes nervos (Bourquin et al., 2006). 
a

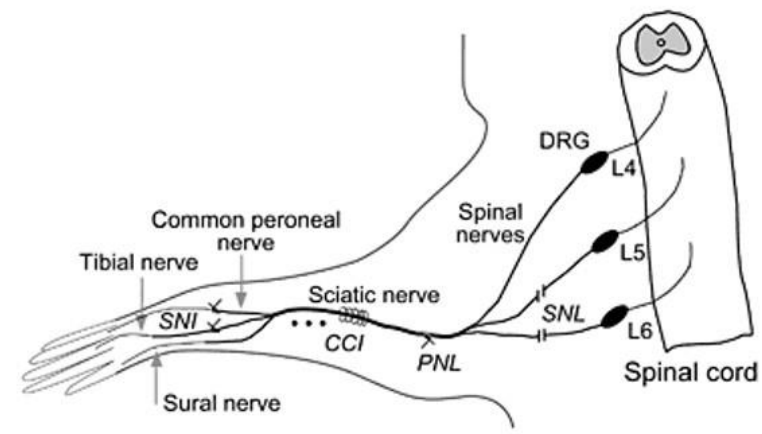

b

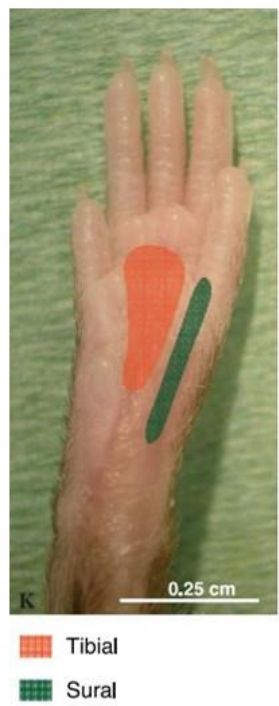

Figura 2. Esquema representativo mostrando as ramificações do nervo isquiático. Na cirugia de SNI os nervos tibial e comum peroneal são amarrados e axotomizados, deixando o nervo sural intacto. b: Dermátomo da inervação do nervo isquiático na pata de camundongos. Após a amarradura seguia pela axotomia do comum peroneal e tibial apenas a inervação do sural continua intacta, como mostrado em verde

\subsection{Avaliação da função motora dos animais por Rota Rod}

Para avaliar um possível déficit na atividade motora dos camundongos, após o tratamento com o inibidor da KMO (JM6), utilizou-se o teste de Rota rod (Dunham et al., 1957). Este equipamento consiste em um cilindro rotatório com raio de espaço de aproximadamente 2,7 centímetros e altura de 40 centímetros. $\mathrm{O}$ aparelho possui 4 baias, com espaço de 3 centímetros para cada camundongo, de modo que quatro animais são avaliados por vez. O camundongo deve caminhar continuamente sobre o cilindro em rotação, para avaliar o tempo que consegue ficar seguro ao aparato. Os animais foram inicialmente mantidos sobre os cilindros por 5 minutos, para habituação. Cinco minutos 
após o período de ambientação, os camundongos foram novamente colocados sobre o Rota rod e a velocidade de rotação foi mantida em $35 \mathrm{rpm}$ por um período 120 segundos. A latência para queda dos animais foi medida automaticamente através de um sensor mecânico localizado no chão do aparato.

\subsection{Teste do nado forçado}

O teste do nado forçado é amplamente usada para detecção de drogas com efeitos antidepressivos. Nesse trabalho fui utilizado uma variação do teste do nado forçado intitulado teste de swimining no qual os animais não foram submetidos a um préteste. No dia do teste, sendo sempre posteriormente a indução ou não da neuropatia, s animais eram inicialmente colocados em cilindros de vidro $(30 \mathrm{~cm}$ de diâmetro x 40 de altura $\mathrm{cm} / 25 \mathrm{~cm}$ de água a $24^{\circ} \mathrm{C}$ ). O teste tinha a duração de $5 \mathrm{~min}$, durante esse tempo é registrado o tempo total de imobilidade. A água era trocada a cada teste para evitar a influência de substância de alarme (Porsolt et al., 1977; Cryan et al., 2002). Como controle positivo de ação antidepressiva foi usado a imipramina $(10 \mathrm{mg} / \mathrm{kg})$.

Foi consederada como sendo imobilidade o tempo que o animal mantinha parte da cabeça fora da água, bem como membros dianteiros e traseiros imóveis, dessa forma o animal mantinha-se "boiando na água" 


\subsection{Procedimento para coleta da substância cinzenta periaquedutal e no bulbo ventromedial rostral}

A coleta da PAG e do RVM foram realizados nos seguintes tempos previamente determinados:

- Indução da dor neuropática, modelo SNI: Sham, 3, 7, 14 e 21 dias após a cirurgia;

- Injeção de ácido quinolínico: Veículo, 1, 5 e 24 horas após a primeira injeção;

- Animais IFN- $\gamma$ KO 7 e 14 dias após SNI;

- Avaliar se a IDO presente no RVM e KMO estão localizadas em células residentes ou circulantes 7 dias após SNI.

Os animais foram primeiramente anestesiados com isoflurano (2\%) seguida de eutanásia, os cérebros foram removidos do crânio e colocados sob papel filtro numa placa de Petri no gelo, sendo o cérebro constantemente umidificado com solução salina resfriada. O RVM foi coletado após o corte lamina coronal de aproximadamente $1 \mathrm{~mm}$ entre o encéfalo e o cerebelo, sendo o RVM coletado com uma agulha de "punch". Posteriormente o mesencéfalo foi dissecado e a PAG removida. Ambos os procedimentos de remoção foram realizados de acordo com Atlas de Coordenadas Estereotáxicas de Cérebro de Camundongo (FRANKLIN et al., 2007).

Os RVM e PAG foram removidos e estocados a $-70^{\circ} \mathrm{C}$, em $100 \mu \mathrm{L}$ (PAG) e $50 \mu \mathrm{L}(\mathrm{RVM})$ de tampão RIPA® ( (Sigma-Aldrich) juntamente com um coquetel de inibidores de proteases (Tris- $\mathrm{HCl} 50$ mM, pH 7.4; Na-deoxicolato 1\%; $\mathrm{NaCl} 150 \mathrm{mM}$; 
EDTA $1 \mathrm{mM}$; Triton X-100 1\%; SDS 0,1\%; PMSF $1 \mathrm{mM}$; Aprotinina, leupeptina e pepstatin $1 \mathrm{mg} / \mathrm{mL}$ ) para realização da técnica de western blotting.

\subsection{Preparação das amostras da substância cinzenta periaquedutal e do bulbo ventromedial rostral para a técnica de Western blotting}

\subsubsection{Extração de Proteínas}

Após coletar os RVM e PAG em tampão RIPA Buffer® (sigma Aldrich) com inibidores de proteases e fosfatases em $50 \mu \mathrm{L}$ e $100 \mu \mathrm{L}$, respectivamente, as amostras foram processadas com o uso do homogeneizador Dremel 10.8 V Lithium-íon/com ponteira de acrílico. O homogenato foi centrifugado a $10000 \mathrm{rpm}(10 \mathrm{~min})$ a $4^{\circ} \mathrm{C}$. Uma alíquota do sobrenadante foi separada para dosagem de proteínas pelo método colorimétrico Coomassie (Bradford) Protein Assay Kit (Pierce, Rockford, IL USA).

\subsubsection{Eletroforese e Western blotting}

Volumes de amostras do homogenato, correspondente a 10 ou $30 \mu \mathrm{g}$ (valor definido previamente) de proteínas foram incubadas com tampão de amostras na proporção (1:1), a $70^{\circ} \mathrm{C}$ durante $(10 \mathrm{~min})$, condição desnaturante. Em seguida, as amostras foram aplicadas em gel de poliacrilamida de 15-8 \% dependendo da proteína a ser investigada (Tabela 3) na presença de SDS (SDS-PAGE) para separação por eletroforese, utilizando-se o sistema Mini-Protean II Eletrophoresis Cell (Bio-Rad Laboratories, Hercules CA, USA). A corrida foi realizada sob voltagem de $80 \mathrm{~V}$, 
utilizando-se o tampão de corrida Tris- $\mathrm{HCl} 25$ nM, pH 8,3, glicina $192 \mathrm{mM}$ e SDS 0,1\% p/v. As proteínas separadas por SDS-PAGE foram transferidas para membranas de nitrocelulose 0,2 $\mu \mathrm{m}$ (Amersham Pharmacia Biotech, Little Chalfont, UK), utilizando-se o sistema de transferência Trans Blot Turbo (Bio-Rad Laboratories, Hercules CA, USA). Após o fracionamento das proteínas, o gel e a membrana de nitrocelulose foram incubados no tampão de transferência (Tris-HCl 25 mM, pH 8,3, glicina 192 mM, 20\% de metanol) por (100 min). A transferência foi realizada sob voltagem constante de $25 \mathrm{~V}$ e 15 A, durante 7 min para IDO e 30 min para as demais proteínas. Após a transferência as membranas foram coradas com Ponceau $0,5 \%$ e ácido tricloroacético 3\%, para certificação de que houve transferência das proteínas. Em seguida, as membranas foram lavadas em água deionizada e o bloqueio dos sítios antigênicos inespecíficos foi realizado pela incubação das membranas, sob agitação continua(tabela).

Após o bloqueio, as membranas foram lavadas três vezes com TBS contendo 0,1\% de Tween 20, por (5 min). Em seguida foram incubadas com os anticorpos primários e posteriormente com os anticorpos secundários, IgG conjugado à peroxidase (1:1.000; HRP; Jackson ImmunoResearch, PA, USA), por uma hora, a temperatura ambiente, tabela 3. Após esta incubação, as membranas foram novamente lavadas três vezes com TBS contendo $0,1 \%$ Tween 20 por 5 min. Para revelar as membranas, estas foram incubadas com uma mistura de reagentes do kit de quimioluminescência (ECL, Amersham Pharmacia Biotech, Little Chalfont, UK) como descrito no manual de instruções e levadas ao aparelho (Gel Doc ${ }^{\mathrm{TM}} \mathrm{XR}+$ System) por aproximadamente $10 \mathrm{~min}$.

Todos os resultados foram quantificados com o software Image Lab e os resultados expressos como níveis relativos de expressão proteica em relação ao grupo controle/ veículo/ naíve (\% do controle). Foi adotado esse tipo de análise dos dados a fim de que pudéssemos plotar diversos géis no mesmo gráfico pois nesse caso cada gel teria 
o seu controle, sendo essa apresentação adotada apenas quando os níveis da proteína $\beta$ actina eram idênticos.

Tabela 3: Anticorpos utilizados no western blotting

\begin{tabular}{|c|c|c|c|c|c|}
\hline $\begin{array}{l}\text { Anticorpo/ } \\
\text { Origem }\end{array}$ & Gel & $\begin{array}{l}\text { Peso } \\
(\mathrm{kDa})\end{array}$ & Bloqueio & $\begin{array}{ll}\text { Diluição } & \text { do } \\
\text { anticorpo } & \\
\text { primário } & \end{array}$ & $\begin{array}{l}\text { Anticorpo } \\
\text { secundário }\end{array}$ \\
\hline $\begin{array}{lr}\text { IDO } & \text { E-7 } \\
\text { (Santa } & \text { Cruz } \\
\text { Biotechnology, } \\
\text { Inc) }\end{array}$ & $12 \%$ & 42 & $\begin{array}{l}\text { Leite } 5 \% \\
\text { overnight }\end{array}$ & 1:500/7hrs & Mouse \\
\hline $\begin{array}{l}\text { KMO/NBP1- } \\
\mathbf{4 4 2 6 3} \\
\text { (Novus } \\
\text { Biologicals) }\end{array}$ & $10 \%$ & 58 & $\begin{array}{l}\text { Leite } 5 \% / \\
2 \mathrm{hrs}\end{array}$ & $\begin{array}{l}\text { 1:2000/ } \\
\text { overnight }\end{array}$ & Rabbit \\
\hline$\beta$-actina & -- & 43 & $\begin{array}{l}\text { BSA 5\% } \\
/ 1 \mathrm{hrs}\end{array}$ & $1: 1000 / 1 \mathrm{hr}$ & Mouse \\
\hline
\end{tabular}

3.10. Imunofluorescência para localização de vesículas de 5-HT no RVM camundongos submetidos a lesão de nervos periféricos

Primeiramente os animais foram anestesiados (isoflurano 2\%) e submetidos a lesão de nervos periféricos. Após 7 dias os animais foram novamente anestesiados (isoflurano $2 \%$ ) e perfundidos com solução salina $0,9 \%$, seguido de paraformaldeido $4 \%$ (PFA) tamponado com tampão fosfato 0,1 M. Em seguida, foi realizada cirurgia para remoção dos cérebros dos camundongos dos seguintes grupos: sham WT, $7^{\circ} \mathrm{d}$ SNI WT $7^{\circ} \mathrm{d}$ SNI IDO1 KO. Os cérebros foram pós-fixados em solução de PFA 4\%, a $4^{\circ} \mathrm{C}$, por aproximadamente 2 horas. Logo após, retirou-se a solução de PFA e adicionou-se solução 
de sacarose a 30\%, por 12 horas. Em seguida, os tecidos foram congelados em isopentano e foram cortados em criostato a $20 \mu \mathrm{m}$.

Antes do ensaio de imunofluorescência, as lâminas foram mantidas em estufa a vácuo por aproximadamente 2 horas, para proporcionar uma melhor adesão dos cortes às lâminas. Em seguida as lâminas foram lavadas 3 vezes com PBS. Assim, estas foram submersas em solução de glicina $0,1 \mathrm{M}$, por $30 \mathrm{~min}$, para a completa retirada de compostos do grupo dos aldeídos. Em seguida, realizou-se o bloqueio de ligações inespecíficas, pela incubação com solução de BSA 2\% e Triton X-100 a 2\%, diluídos em PBS, por 1 hora. Após o bloqueio, foram realizados as marcações para 5-HT.

Tabela 4: Anticorpos utilizados na imunofluorescência para localização das vesículas de 5-HT na PAG e RVMde camundongos

\begin{tabular}{cccc}
\hline Anticorpo & Alvo & Hospedeiro & $\begin{array}{c}\text { Diluição do } \\
\text { anticorpo } \\
\text { primário }\end{array}$ \\
\hline 5-HT (Abcam) & Vesículas contendo 5-HT & Rat & $1: 500$ \\
\hline Alexa 488 & $\begin{array}{c}\text { Anticorpo secundário } \\
\text { conjugados ao agente } \\
\text { (Life Technologies) }\end{array}$ & $\begin{array}{c}\text { Mouse anti- } \\
\text { fluorescente, Alexa Flúor } \\
488\end{array}$ & \\
& Rat & \\
\hline
\end{tabular}

Os cortes foram incubados com o anticorpos primários, nas combinações descritas acima, por 24 horas a temperatura de $4^{\circ} \mathrm{C}$. Em seguida, as lâminas foram lavadas 5 vezes com PBS durante 5 min cada lavagem. Antes de incubar as lâminas com os anticorpos secundários foram centrifugados (10000 rpm por $10 \mathrm{~min}$ ) para evitar a 
formação de grumos. $\mathrm{O}$ anticorpo secundário foi preparado em uma concentração duas vezes mais diluída do que o anticorpo primário (1\% de BSA em PBS) e incubado por 2 horas à temperatura ambiente. Os anticorpos secundários são conjugados à Alexa Fluor e estão listados tabela 4. Em seguida, as lâminas foram lavadas (5 vezes com PBS, 5 min) para retirar o excesso de anticorpo secundário. Finalmente, as lâminas foram montadas em solução de fluormount diluído em PBS (1:2). As imagens foram obtidas através de microscopia confocal (SP5, Leica, Wetzlar, Alemanha).

\subsection{Análises estatísticas}

Os resultados foram expressos como média \pm erro padrão da média (E.P.M.). O número amostral foi representado na legenda de cada figura. A análise dos resultados foi feita pelo teste de análise de variância (ANOVA two way) quando existiu interação entre os tratamentos e o tempo, seguido pelo post-test de Bonferroni. Quando os resultados foram de apenas um ponto (tempo) as análises foram realizadas usando ANOVA one way, seguido pelo post-test de Bonferroni. O nível de significância será de $P<0,05$. Para a realização das análises estatísticas supracitadas foi utilizado programa estatístico computadorizado (GraphPad Prism Software, GraphPad Prism 5 , USA, 2007). 


\section{RESULTADOS}




\section{RESULTADOS}

\subsection{Cinética de expressão da enzima IDO1 no RVM, na PAG e no hipocampo após a lesão de nervos periféricos}

Com o intuito de avaliar se a expressão da enzima IDO1 presente no RVM, na PAG e no hipocampo correlaciona-se com o desenvolvimento da neuropatia, os animais foram submetidos a cirurgia de SNI, seguido pela coleta do RVM, PAG e do hipocampo nos dias pré determinados (3, 7, 14 e 21 dias após a lesão de nervos) e os níveis da enzima IDO1 foram avaliados pela técnica de western blotting.

Os animais submetidos a lesão de nervos periféricos desenvolveram hipersensibilidade nociceptiva mecânica a partir do $3^{\circ}$ dia posterior a lesão, figura 3 . Além disso, a neuropatia induziu o aumento da expressão proteica da enzima IDO1 no RVM, observando o pico de expressão no $7^{\circ}$ dia após a indução da neuropatia pelo modelo SNI, quando comparado com o grupo sham, figura 4. Na PAG foi observado o aumento da expressão da enzima IDO1 no $3^{\circ}, 7^{\circ}, 14^{\circ}$ e $21^{\circ}$ dia após a indução da neuropatia, sendo o pico de expressão presente no $14^{\circ}$ dia após a indução da neuropatia pelo modelo SNI, quando comparado com o grupo sham, figura 5.

Pelo fato dos animais neuropáticos apresentarem um comportamento depressivo associado ao quadro de hipersensibilidade mecânica e o hipocampo fazer parte do substrato neural da depressão (Norman et al., 2010) foi avaliado os níveis da enzima IDO1 no hipocampo. Porém, não foi observado o aumento significativo na expressão da enzima IDO1 nessa estrutura quando comparado com o grupo sham, figura 6. 
Por fim, com o intuito de avaliar se a enzima IDO1 estava localizada em alguma célula residente no RVM/PAG ou em alguma célula circulante/aderida a vasos sanguíneos, essas estruturas cerebrais foram coletadas sendo parte dos animais submetidos a perfusão intracardiaca. Foi observado que a perfusão intracardiaca reduziu significativamente os níveis da enzima IDO1 na PAG sham, figura 7, entretanto reduziu apenas parcialmente no RVM sham, figura 8.

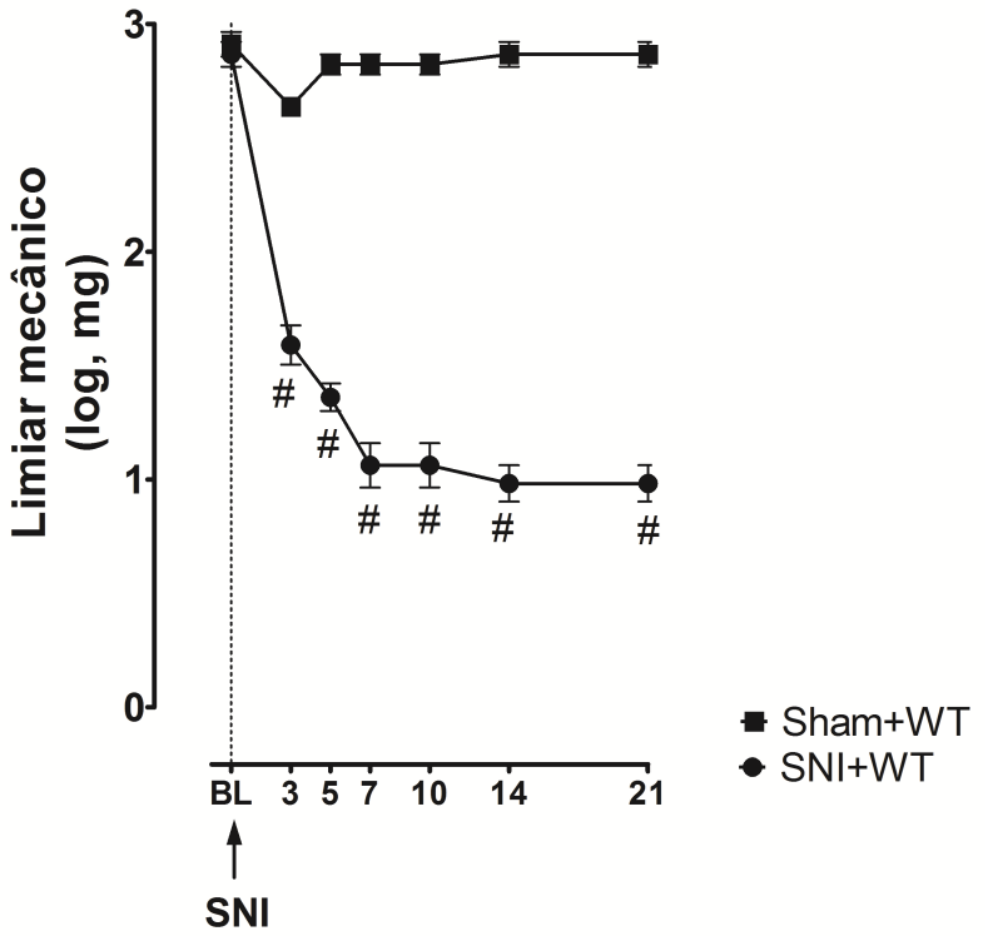

\section{Figura 3. SNI induz hipersensibilidade nociceptiva mecânica em camundongos} selvagens. Camundongos C57BL/6 foram submetidos à cirurgia para indução de neuropatia pelo método de SNI, assim como seu respectivo grupo controle sham. Os resultados foram expressos pela média \pm e.p.m. de 6 animais por grupo. \# indica diferenças estatisticamente significantes do grupo SNI quando comparado com o grupo sham $(\mathrm{p}<0,05)$. 


\section{A Sham $3 \quad 7 \underline{14} 21$ dias}

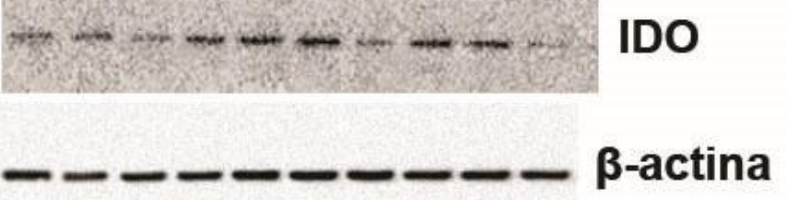

B

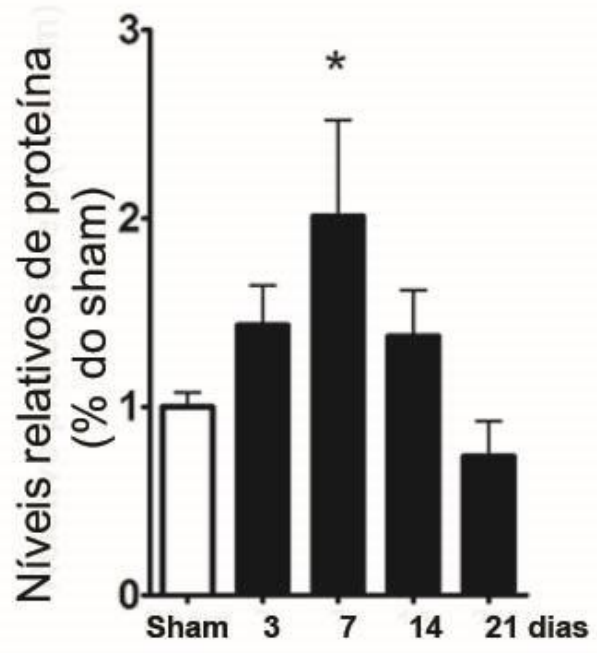

Figura 4. Neuropatia induz aumento na expressão da enzima IDO1 no RVM. Após cirurgia de lesão de nervos periféricos os RVM $(n=3-4)$ foram removidos cirurgicamente no $3^{\circ}, 7^{\circ}, 14^{\circ}$ e $21^{\circ}$ dias e processados para a análise dos níveis proteicos da enzima IDO1 pela técnica de western blotting. A: Representação das bandas da IDO1 e $\beta$-actina na membrana de nitrocelulose. B: Os dados foram representados como densidade relativa, obtidos pelo cálculo da razão das densidades óticas e normalizados pelo grupo sham. * $p<0.05$ comparado com grupo sham. Teste ANOVA seguido pelo teste de Bonferroni para comparar os tratamentos. O nível de significância adotado foi de $p<0.05$. 


\section{A Sham 3 7 14 21 dias}

thruserten: 100

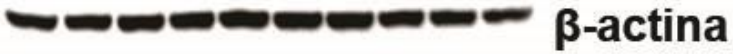

B

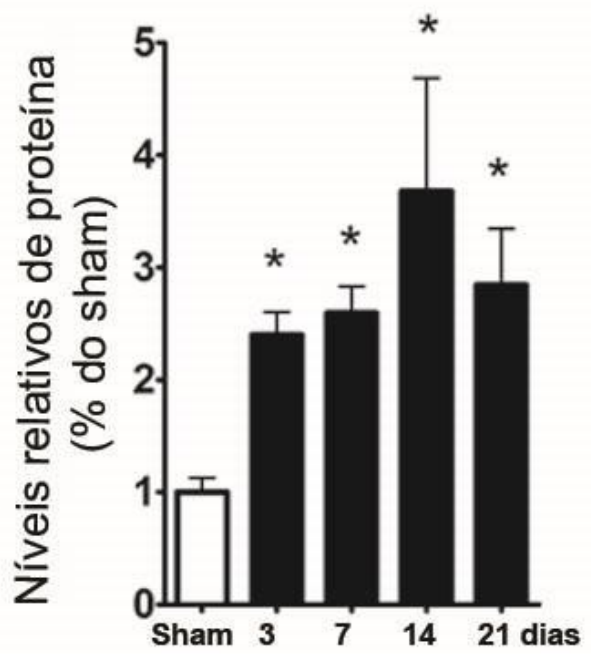

Figura 5. Neuropatia induz aumento na expressão da enzima IDO1 na PAG. Após cirurgia de lesão de nervos periféricos as $\mathrm{PAG}(\mathrm{n}=4)$ foram removidas cirurgicamente nos $3^{\circ}, 7^{\circ}, 14^{\circ}$ e $21^{\circ}$ dias e processados para a análise dos níveis proteicos da enzima IDO 1 pela técnica de western blotting. A: Representação das bandas da IDO1 e $\beta$-actina na membrana de nitrocelulose. B: Os dados foram representados como densidade relativa, obtidos pelo cálculo da razão das densidades óticas e normalizados pelo grupo sham. ${ }^{*} p<0.05$ comparado com grupo sham. Teste ANOVA seguido pelo teste de Bonferroni para comparar os tratamentos. O nível de significância adotado foi de $p<0.05$. 
A Sham 3 7 14 21 dias

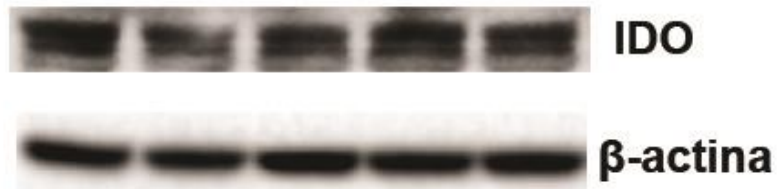

B

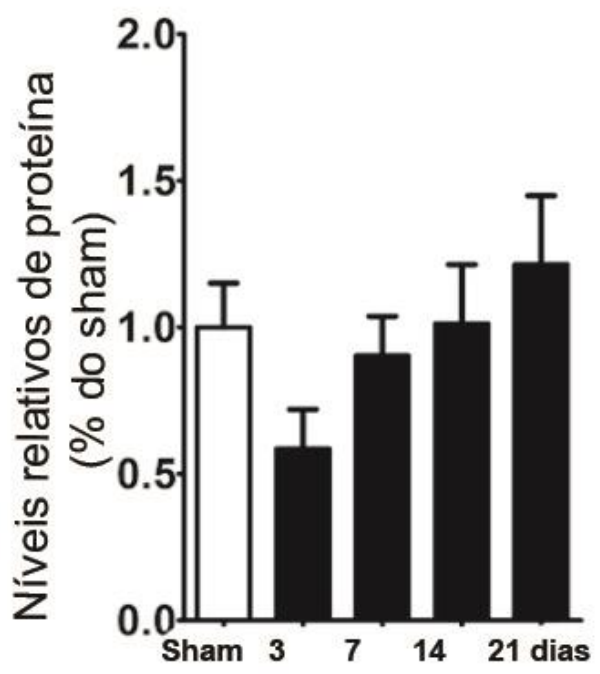

Figura 6. Neuropatia não altera os níveis da enzima IDO1 no hipocampo. Após cirurgia de lesão de nervos periféricos os hipocampos $(n=4)$ foram removidos cirurgicamente nos $3^{\circ}, 7^{\circ}, 14^{\circ}$ e $21^{\circ}$ dias e processados para a análise dos níveis proteicos da enzima IDO1 pela técnica de western blotting. A: Representação das bandas da IDO1 e $\beta$-actina na membrana de nitrocelulose. B: Os dados foram representados como densidade relativa, obtidos pelo cálculo da razão das densidades óticas e normalizados pelo grupo sham. ${ }^{*} p<0.05$ comparado com grupo sham. Teste ANOVA seguido pelo teste de Bonferroni para comparar os tratamentos. O nível de significância adotado foi de $p<0.05$. 


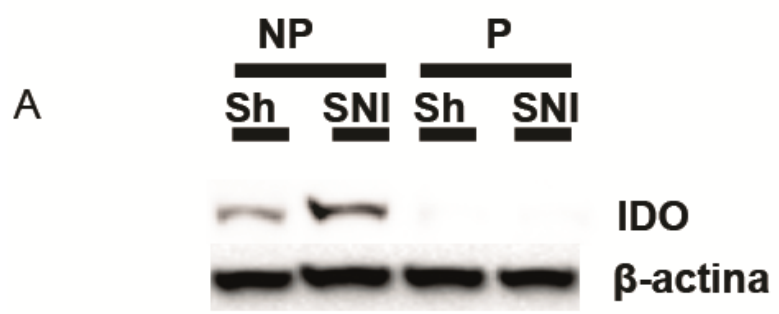

B

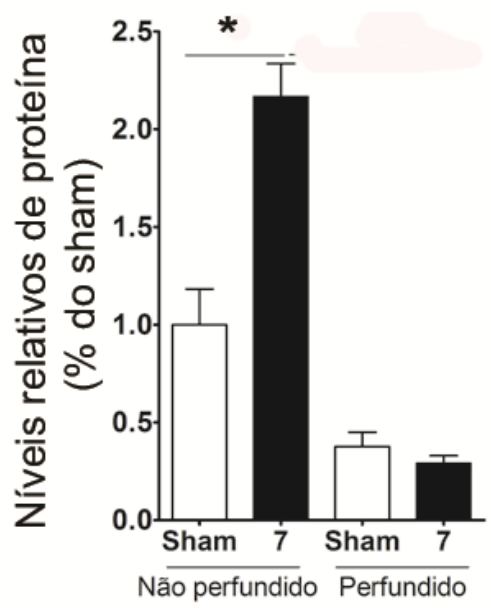

Figura 7. A enzima IDO1 presente na PAG está localizada em células circulantes de animais com neuropatia 7D. 7 dias após cirurgia de lesão de nervos periféricos as PAGs $(\mathrm{n}=3)$ foram removidos cirurgicamente e processados para a análise dos níveis proteicos da enzima IDO1 pela técnica de western blotting. NP refere-se ao grupo que não foi submetido à perfusão intracardiaca previamente a retirada da PAG e P refere-se ao grupo submetido à perfusão intracardiaca. A: Representação das bandas da IDO1 e $\beta$-actina na membrana de nitrocelulose. B: Os dados foram representados como densidade relativa, obtidos pelo cálculo da razão das densidades óticas e normalizados pelo grupo sham. * $p<0.05$ comparado com grupo sham não perfundido. Teste ANOVA seguido pelo teste de Bonferroni para comparar os tratamentos. O nível de significância adotado foi de $p<0.05$. 

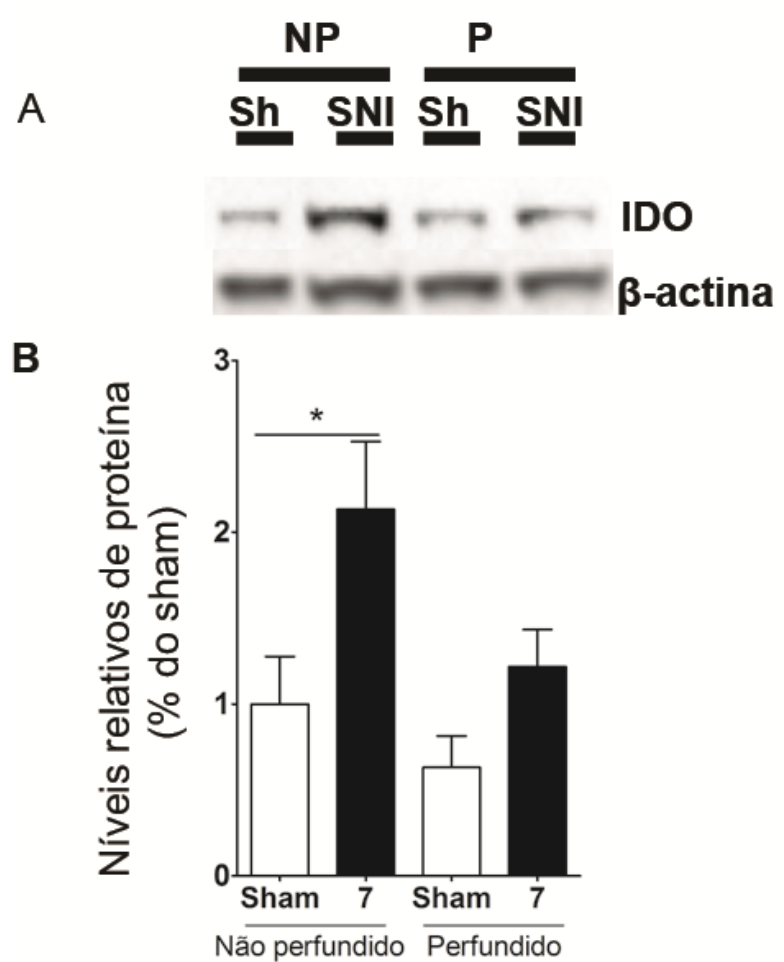

Figura 8. A enzima IDO1 presente no RVM está localizada tanto em células circulantes quanto residentes de animais com neuropatia 7D. 7 dias após cirurgia de lesão de nervos periféricos as RVMs $(n=3)$ foram removidos cirurgicamente e processados para a análise dos níveis proteicos da enzima IDO1 pela técnica de western blotting. NP refere-se ao grupo que não foi submetido à perfusão intracardiaca previamente a retirada da RVM e P refere-se ao grupo submetido à perfusão intracardiaca. A: Representação das bandas da IDO1 e $\beta$-actina na membrana de nitrocelulose. B: Os dados foram representados como densidade relativa, obtidos pelo cálculo da razão das densidades óticas e normalizados pelo grupo sham. $* p<0.05$ comparado com grupo sham não perfundido.. Teste ANOVA seguido pelo teste de Bonferroni para comparar os tratamentos. O nível de significância adotado foi de $p<0.05$. 


\subsection{Avaliação do efeito antinociceptivo do Norharmane sobre a hipersensibilidade mecânica induzida pela lesão de nervos periféricos}

Resultados prévios de Souza et al., 2015 (resultados não publicados) sugerem que o tratamento sistêmico via oral ou intraperitoneal com 1 metil-triptofano/Norharmane (inibidores da enzima IDO1) praticamente abolem a hipersensibilidade mecânica após a lesão de nervos, enquanto a injeção desses inibidores pela via intratecal no espaço subaracnóide reduz parcialmente a alodinia mecânica, indicando a existência de outros sítios de expressão da enzima IDO1, como regiões supraespinais.

Para tanto, foram utilizados 5 grupos experimentais (sham, sham+900 nmol de Nor; SNI+veículo; SNI+300 nmol Nor; SNI+900 nmol de Nor) primeiramente os animais tiveram o limiar basal determinado pela técnica de von frey e posteriormente foram submetidos a cirurgia de indução de dor neuropática (SNI), dois dias após foi implantada uma cânula guia no ventrículo lateral dos animais para a microinjeção de Norharmane ou veículo.

Em $7^{\circ}$ dias após a indução da neuropatia, os animais receberam doses crescentes de Norharmane ( 300 ou $900 \mathrm{nmol}$ ), sendo esse inibidor microinjetado no espaço i.c.v. com o auxílio de uma cânula guia implantada previamente. Foi observado uma redução significativa na hipersensibilidade nociceptiva mecânica induzida por SNI na $1^{\mathrm{a}}, 3^{\mathrm{a}}$ e $5^{\mathrm{a}}$ hora após a microinjeção de 300 e $900 \mathrm{nmol}$ de Norharmane no espaço i.c.v. quando comparado com o grupo neuropático que recebeu apenas a microinjeção de veículo ou $900 \mathrm{nmol}$ de Norharmane, (Figura 9). Em 14 dias após a lesão de nervos o tratamento com Norharmane também reduziu a hipersensibilidade nociceptiva mecânica dos animais. A microinjeção de $300 \mathrm{nmol}$ de Norharmane reduziu a hipersensibilidade 
nociceptiva mecânica na $1^{\mathrm{a}}$ e $3^{\mathrm{a}}$ hora após a administração e a de $900 \mathrm{nmol}$ reduziu na $1^{\mathrm{a}}$, $3^{a}$ e $5^{a}$ hora em relação ao grupo neuropático que recebeu apenas a microinjeção de veículo ou 900 nmol de Norharmane, Figura 10. Por último, o tratamento com 300 nmol de Norharmane no $21^{\circ}$ dias após a lesão de nervos reduziu significativamente a hipersensibilidade nociceptiva mecânica na $1^{\mathrm{a}}$ e $3^{\mathrm{a}}$ hora, enquanto a dose de $900 \mathrm{nmol}$ na $1^{\mathrm{a}}, 3^{\mathrm{a}}$ e $5^{\mathrm{a}}$ hora em relação ao grupo neuropático que recebeu apenas uma microinjeção de veículo ou 900 nmol de Norharmane no espaço i.c.v. Figura 11.

Vale ressaltar que a microinjeção de Norharmane no grupo sham (sham+900 nmol de Nor ) não alterou o limiar mecânico basal dos animais, sugerindo um efeito analgésico especifico dessa droga.

Corroborando os achados descritos acima, após induzir neuropatia em animais geneticamente deficientes para a enzima IDO1 foi constatado que esses animais não desenvolvem hipersensibilidade nociceptiva mecânica quando comparado com animais WT, figura 12 . 


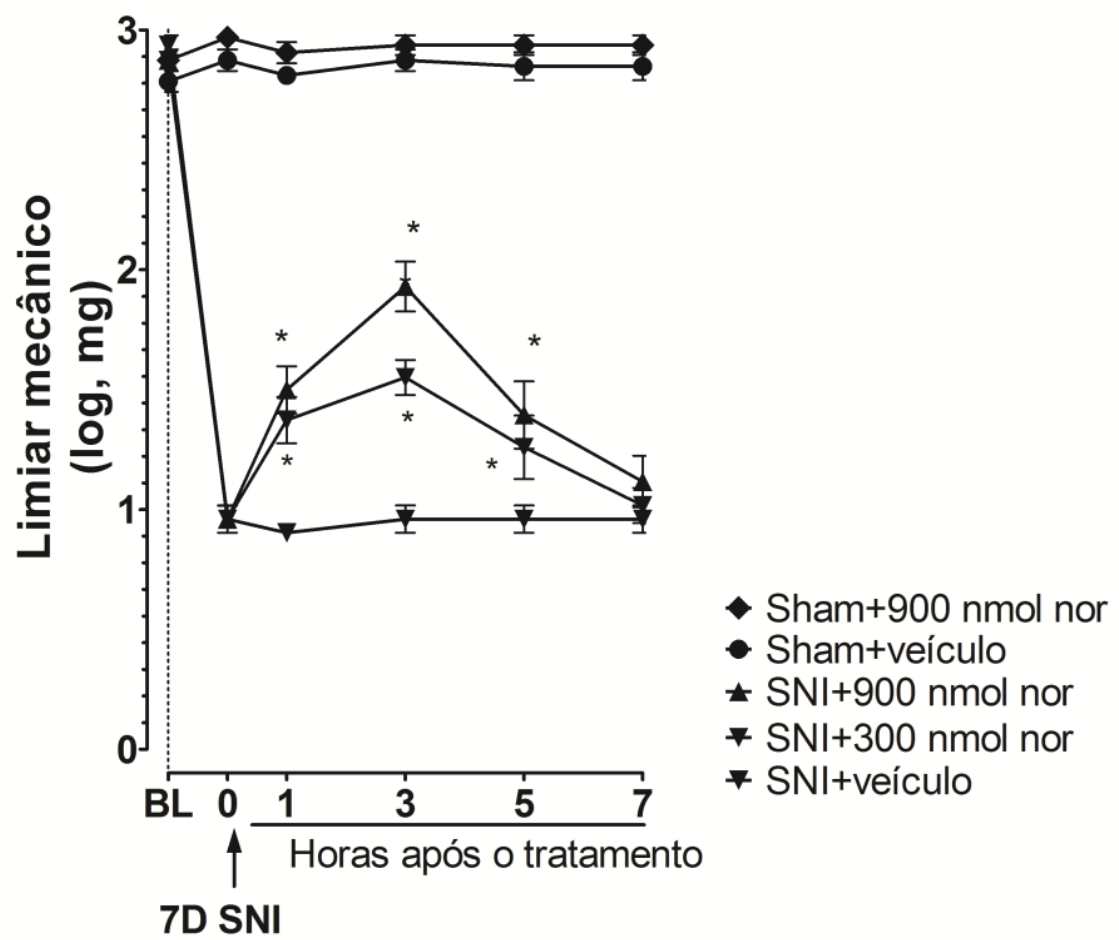

Figura 9. Efeito da microinjeção de Norharmane no espaço intracerebroventricular de camundongos 7 dias após a lesão de nervos periféricos. A intensidade de hipersensibilidade nociceptiva mecânica foi avaliada antes de qualquer procedimento (BL) e após a cirurgia no $7^{\circ}$ dia após a cirurgia de SNI. O Painel mostra a intensidade de hipersensibilidade nociceptiva mecânica avaliada pela técnica de von Frey no $7^{\circ}$ dia após a lesão de nervos, ao longo da $1^{\mathrm{a}}, 3^{\mathrm{a}}, 5^{\mathrm{a}}$ e $7^{\mathrm{a}}$ hora após a microinjeção de Norharmane no espaço i.c.v. dos camundongos $(\mathrm{n}=7)$. * $p<0.05$ comparado com grupo SNI+veículo. Teste ANOVA de duas vias seguido pelo teste de Bonferroni para comparar os tratamentos. O nível de significância adotado foi de $p<0.05$. 


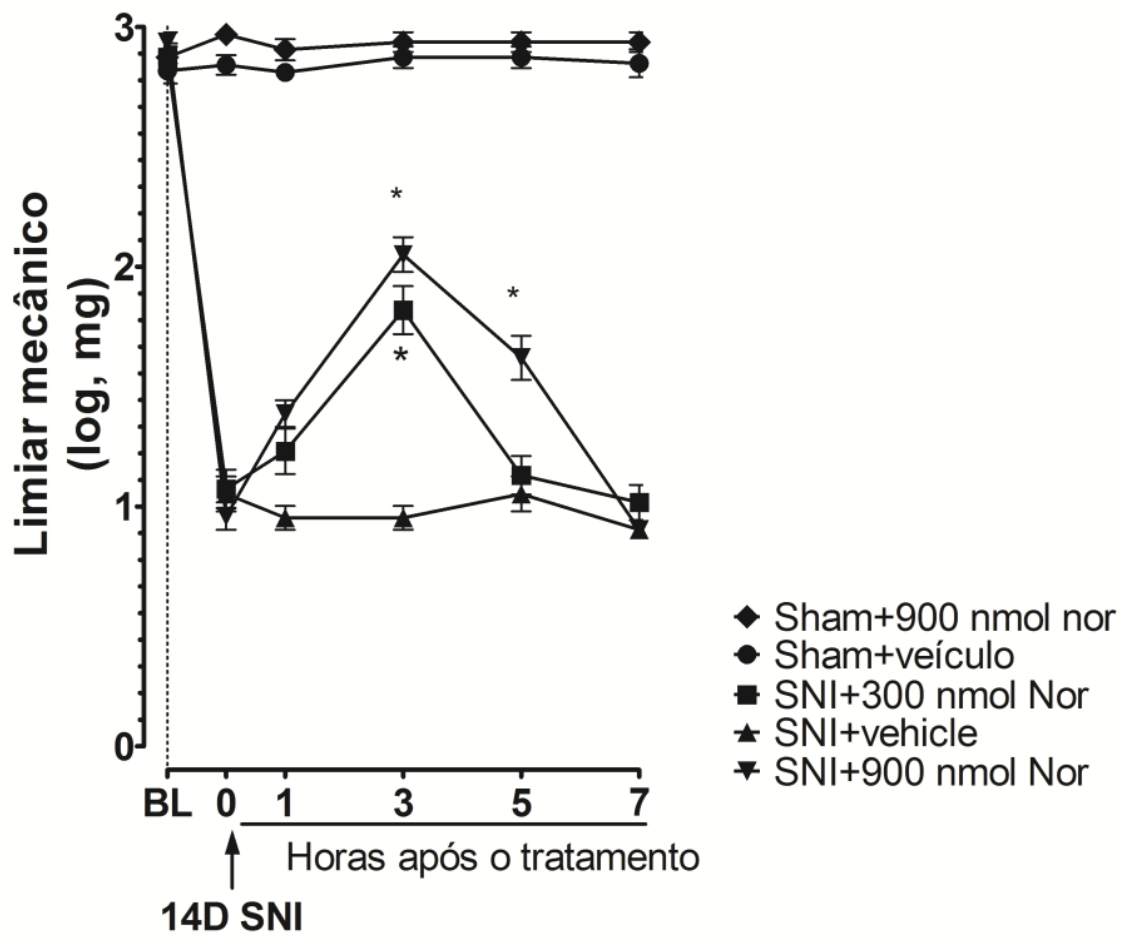

Figura 10. Efeito da administração de Norharmane no espaço intracerebroventricular de camundongos 14 dias após a lesão de nervos periféricos. A intensidade de hipersensibilidade nociceptiva mecânica foi avaliada antes de qualquer procedimento (BL) e após a cirurgia no $14^{\circ}$ dia após a cirurgia de SNI. O Painel mostra a intensidade de hipersensibilidade nociceptiva mecânica avaliada pela técnica de von Frey no $14^{\circ}$ dia após a lesão de nervos, ao longo da $1^{\mathrm{a}}, 3^{\mathrm{a}}, 5^{\mathrm{a}}$ e $7^{\mathrm{a}}$ hora após a microinjeção de Norharmane no espaço i.c.v. dos camundongos $(\mathrm{n}=7){ }^{*} p<0.05$ comparado com grupo SNI+veículo. Teste ANOVA de duas vias seguido pelo teste de Bonferroni para comparar os tratamentos. O nível de significância adotado foi de $p<0.05$. 


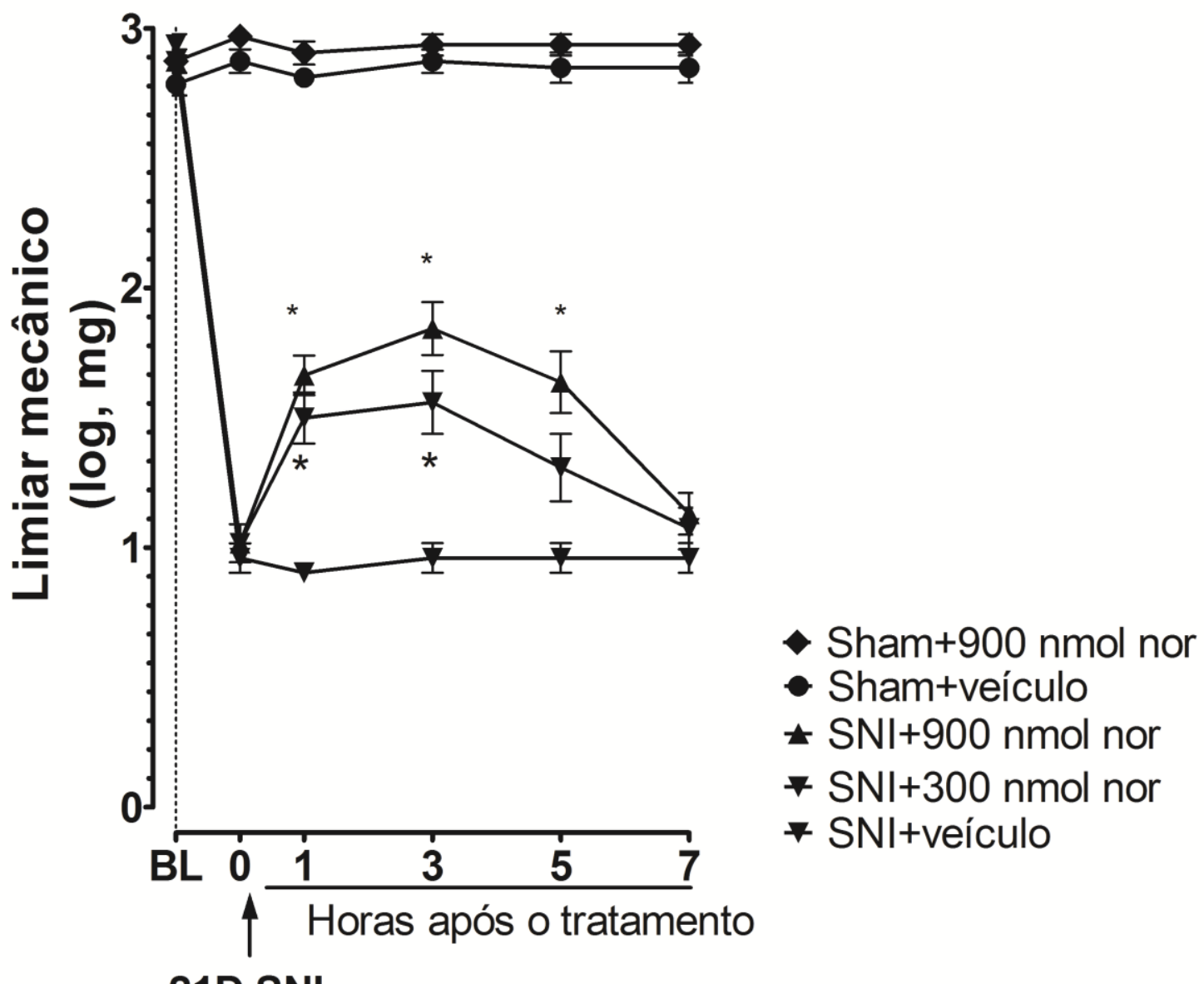
21D SNI

Figura 11. Efeito da administração de Norharmane, inibidor da enzima IDO, no espaço intracerebroventricular de camundongos 21 dias após a lesão de nervos periféricos. A intensidade de hipersensibilidade nociceptiva mecânica foi avaliada antes de qualquer procedimento (BL) e após a cirurgia no $21^{\circ}$ dia após a cirurgia de SNI. O Painel mostra a intensidade de hipersensibilidade nociceptiva mecânica avaliada pela técnica de von Frey no $21^{\circ}$ dia após a lesão de nervos, ao longo da $1^{\mathrm{a}}, 3^{\mathrm{a}}, 5^{\mathrm{a}}$ e $7^{\mathrm{a}}$ hora após a microinjeção de Norharmane no espaço i.c.v. dos camundongos $(\mathrm{n}=7)$. ${ }^{*} p<0.05$ comparado com grupo SNI+veículo. Teste ANOVA de duas vias seguido pelo teste de Bonferroni para comparar os tratamentos. O nível de significância adotado foi de $p<0.05$. 


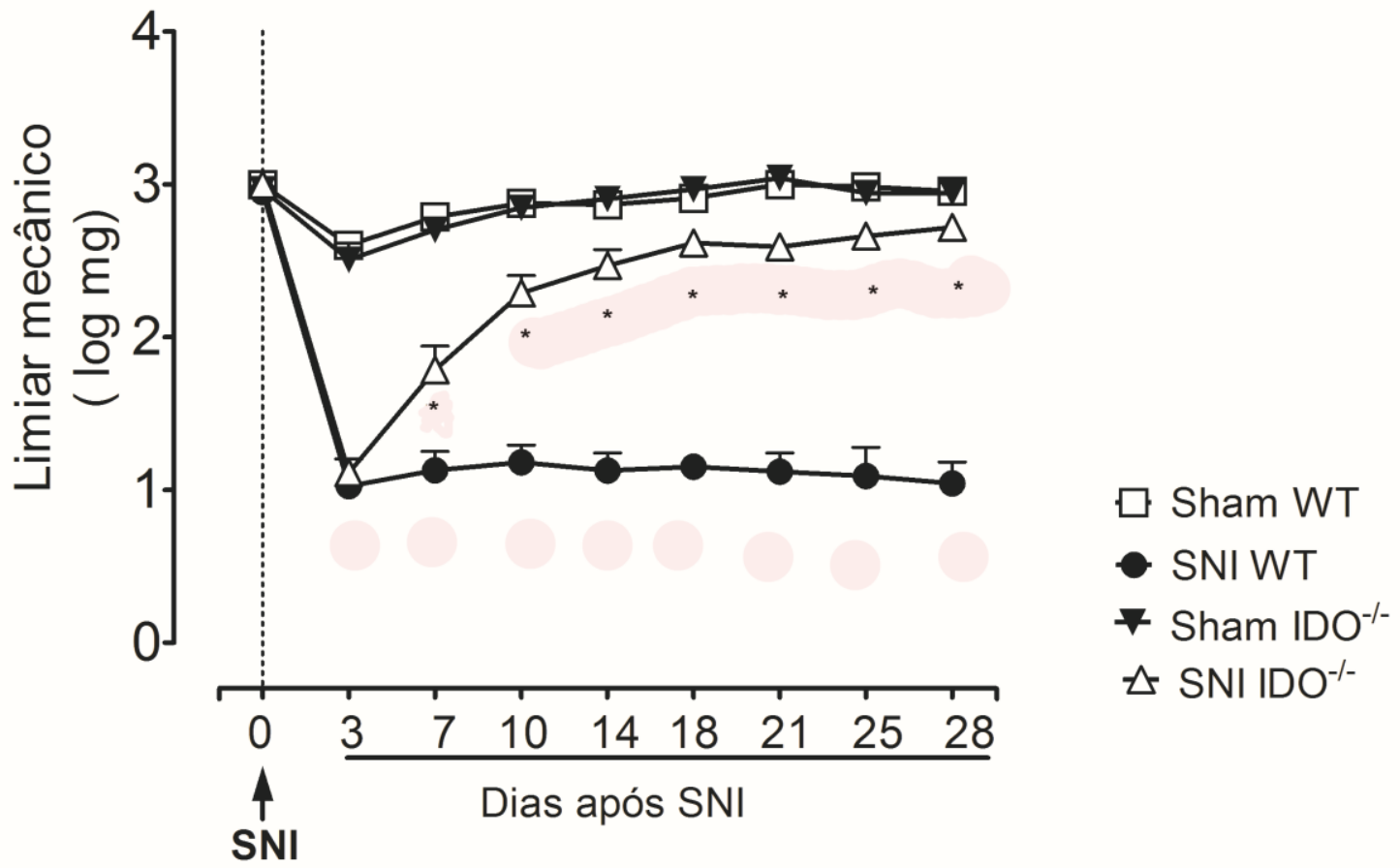

Figura 12. Animais geneticamente deficientes para a enzima IDO1 não desenvolvem a hipersensibilidade nociceptiva mecânica induzida por SNI. A intensidade de hipersensibilidade nociceptiva mecânica foi avaliada antes de qualquer procedimento (dia 0) e até do $28^{\circ}$ dia após a cirurgia de SNI. O Painel mostra a intensidade de hipersensibilidade nociceptiva mecânica avaliada pela técnica de von Frey após a lesão de nervos $(\mathrm{n}=7)$. * $p<0.05$ comparado com grupo SNI WT. Teste ANOVA de duas vias seguido pelo teste de Bonferroni para comparar os tratamentos. O nível de significância adotado foi de $p<0.05$. 


\subsection{Cinética de expressão da enzima KMO no RVM e na PAG após a lesão de nervos periféricos}

Com o intuito de avaliar se a expressão da enzima KMO correlaciona-se com o desenvolvimento da hipersensibilidade mecânica induzida por SNI, animais WT foram submetidos à lesão de nervos periféricos, seguido pela coleta do RVM e PAG nos dias pré determinados $(3,7,14$ e 21 dias após $\mathrm{SNI})$ e os níveis da enzima KMO foram avaliados pela técnica de western blotting.

A neuropatia induziu o aumento da expressão proteica da enzima KMO no RVM no $7^{\circ}$ e $14^{\circ}$ dia, sendo o pico de expressão no $7^{\circ}$ dia após a indução da neuropatia pelo modelo SNI, quando comparado com o grupo sham, figura 13 . Na PAG foi observado o aumento da expressão da enzima KMO apenas no $7^{\circ}$ dia após a indução da neuropatia, quando comparado com o grupo sham, figura 14. Diferentemente do que aconteceu com a IDO1 no RVM e PAG, a perfusão intracardiaca não alterou os níveis da enzima KMO nessas estruturas (resultados não mostrados). Sugerindo que a mesma está localizada em células residentes, possivelmente micróglias. 
A Sham 3 7 14 21 dias
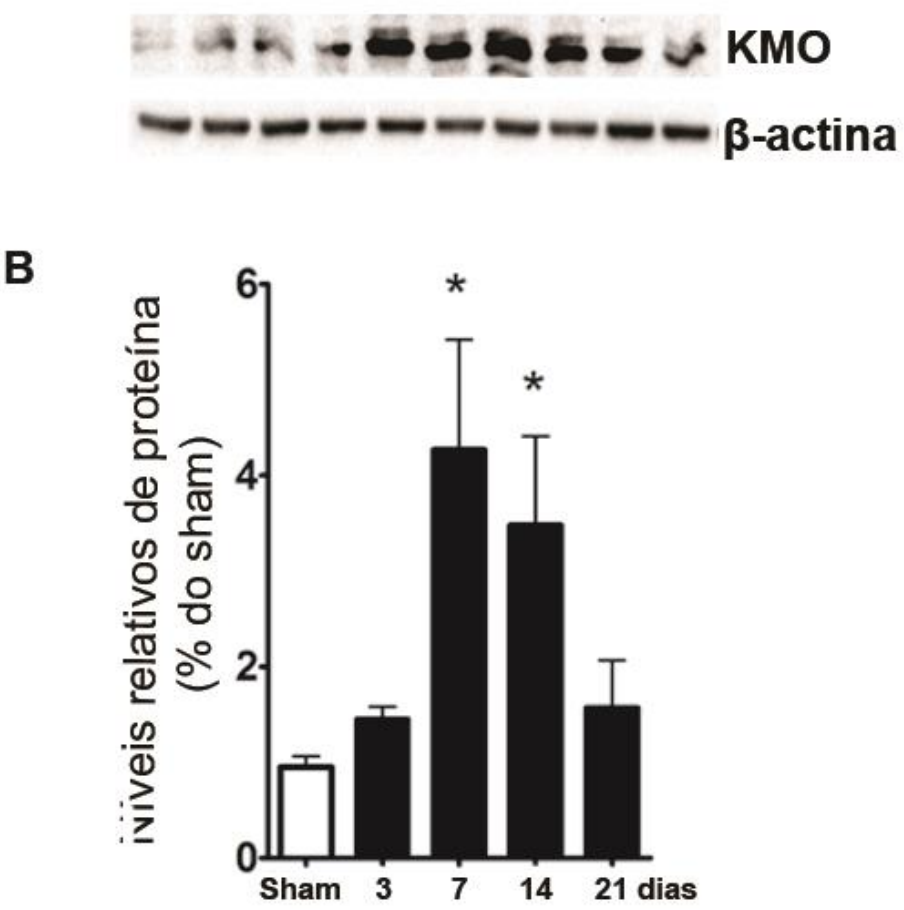

Figura 13. Neuropatia induz aumento na expressão da enzima KMO no RVM. Após cirurgia de lesão de nervos periféricos os RVM ( $n=4-5)$ foram removidos cirurgicamente $\operatorname{nos} 3^{\circ}, 7^{\circ}, 14^{\circ}$ e $21^{\circ}$ dias e processados para a análise dos níveis proteicos da enzima KMO pela técnica de western blotting. A: Representação das bandas da KMO e $\beta$-actina na membrana de nitrocelulose. B: Os dados foram representados como densidade relativa, obtidos pelo cálculo da razão das densidades óticas e normalizados pelo grupo sham. ${ }^{*} p<0.05$ comparado com grupo sham. Teste ANOVA seguido pelo teste de Bonferroni para comparar os tratamentos. O nível de significância adotado foi de $p<0.05$. 
A Sham 3 7 14 21 dias

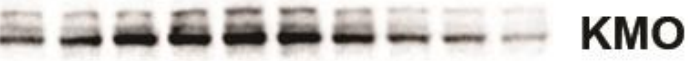

$------\cdots-\beta$-actina

B

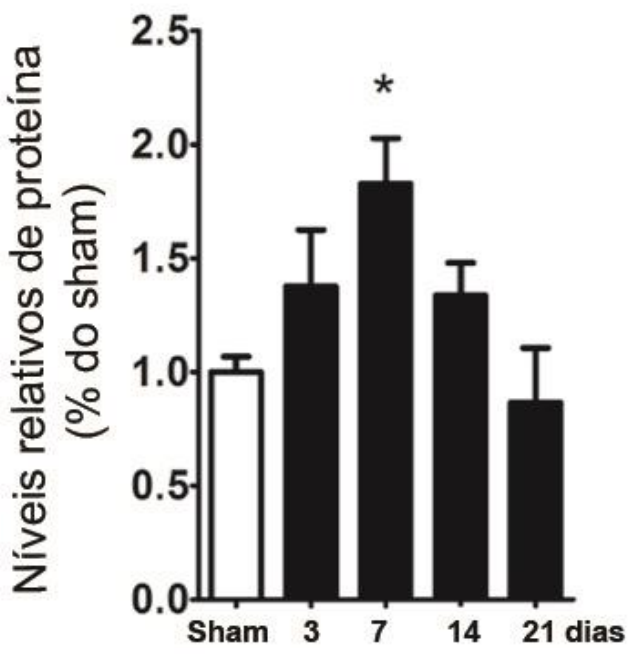

Figura 14. Neuropatia induz aumento na expressão da enzima KMO na PAG. Após cirurgia de lesão de nervos periféricos as $\mathrm{PAG}(\mathrm{n}=4)$ foram removidos cirurgicamente nos $3^{\circ}, 7^{\circ}, 14^{\circ}$ e $21^{\circ}$ dias e processados para a análise dos níveis proteicos da enzima KMO pela técnica de western blotting. A: Representação das bandas da KMO e $\beta$-actina na membrana de nitrocelulose. B: Os dados foram representados como densidade relativa, obtidos pelo cálculo da razão das densidades óticas e normalizados pelo grupo sham. ${ }^{*} p$ $<0.05$ comparado com grupo sham. Teste ANOVA seguido pelo teste de Bonferroni para comparar os tratamentos. O nível de significância adotado foi de $p<0.05$. 


\subsection{Efeito de inibidores da KMO sobre a hipersensibilidade mecânica induzida pela lesão de nervos periféricos}

Com o intuito de avaliar a participação da enzima KMO no desenvolvimento da hipersensibilidade mecânica induzida por SNI, os animais receberam a droga JM6 por via oral ou o Ro 61-8048 no espaço intracerebroventricular após a lesão de nervos periféricos.

Primeiramente os animais foram submetidos a cirurgia de SNI e no $7^{\circ}, 14^{\circ} \mathrm{e}$ $21^{\circ}$ dia após a indução da neuropatia, os animais receberam a administração pela via oral $100 \mathrm{mg} / \mathrm{kg}$ ou $300 \mathrm{mg} / \mathrm{kg}$ ou veículo. A administração por via oral do JM6 reduziu significativamente a hipersensibilidade nociceptiva mecânica dos animais com neuropatia de modo dose-dependente no $7^{\circ}$ (figura 15), $14^{\circ}$ (figura 16) e $21^{\circ}$ (figura 17) dias após a lesão de nervos.

Além disso, não foi observado alteração alguma no limiar mecânico basal do grupo sham que recebeu o tratamento com 300mg/kg de JM6. Ainda, realizamos o teste do Rotarod para verificarmos se o JM6 poderia estar sedando ou causando alguma disfunção motora nos animais. Foi observado que apenas a dose de $300 \mathrm{mg} / \mathrm{kg}$ de JM6 causou algum comprometimento motor nos animais 5 horas após a administração das drogas, figura 18.

Segundamente, os animais receberam doses crescentes de Ro 61-4880; 300 e $900 \mathrm{nmol}$ no $7^{\circ}$ e $14^{\circ}$ dia, sendo esse inibidor microinjetado no espaço i.c.v. com o auxílio de uma cânula guia que havia sido implantada no cérebro dos camundongos uma semana antes do experimento comportamental. No $7^{\circ}$ dia após SNI, a inibição da KMO 
utilizando o Ro 61-4880 reduziu significativamente a hipersensibilidade nociceptiva mecânica dos animais com neuropatia, quando comparado com o grupo neuropático que recebeu apenas a microinjeção de veículo (Figura 19). No $14^{\circ}$ dia, a inibição da KMO com dose de 300 ou 900 nmol reduziu a hipersensibilidade nociceptiva mecânica dos animais com neuropatia na $3^{\text {a }}$ hora após a microinjeção do inibidor quando comparado com o grupo neuropático que recebeu a microinjeção de veículo (SNI+veículo) figura 20.

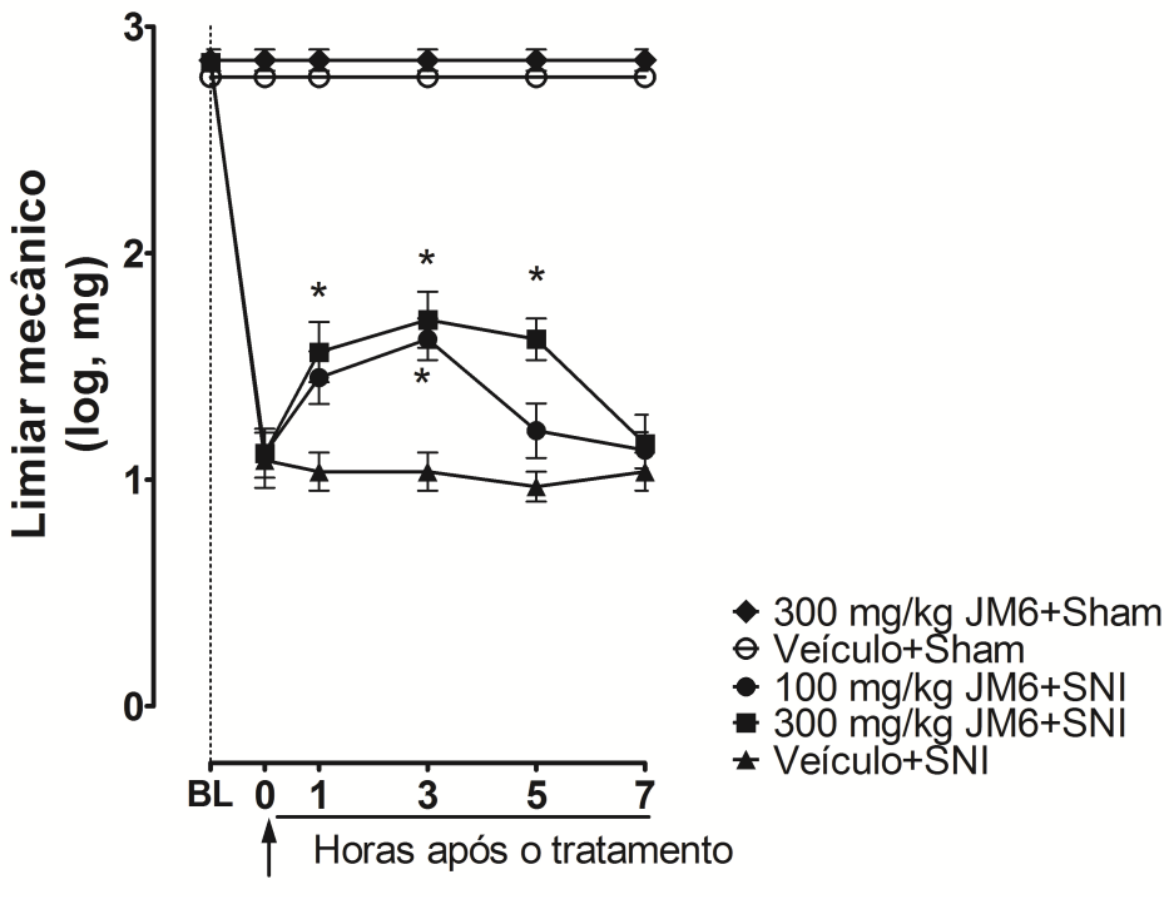

7D SNI

\section{Figura 15. O tratamento por via oral com o JM6 reduz a hipersensibilidade} nociceptiva mecânica em animais com neuropatia ( $7^{\circ}$ dia). A intensidade de hipersensibilidade nociceptiva mecânica foi avaliada antes de qualquer procedimento (BL) e após a cirurgia no $7^{\circ}$ dia (zero hora). O Painel mostra a hipersensibilidade nociceptiva mecânica avaliada pelos filamentos de von Frey no $7^{\circ}$ dia após a lesão de nervos, respectivamente, ao longo da $1^{\mathrm{a}}, 3^{\mathrm{a}}, 5^{\mathrm{a}}$ e $7^{\mathrm{a}}$ hora após a administração de do JM6 por via oral aos camundongos $(\mathrm{n}=6)$. $* p<0.05$ comparado com o grupo SNI+veículo. Teste ANOVA de duas vias seguido pelo teste de Bonferroni para comparar os tratamentos. O nível de significância adotado foi de $p<0.05$. 


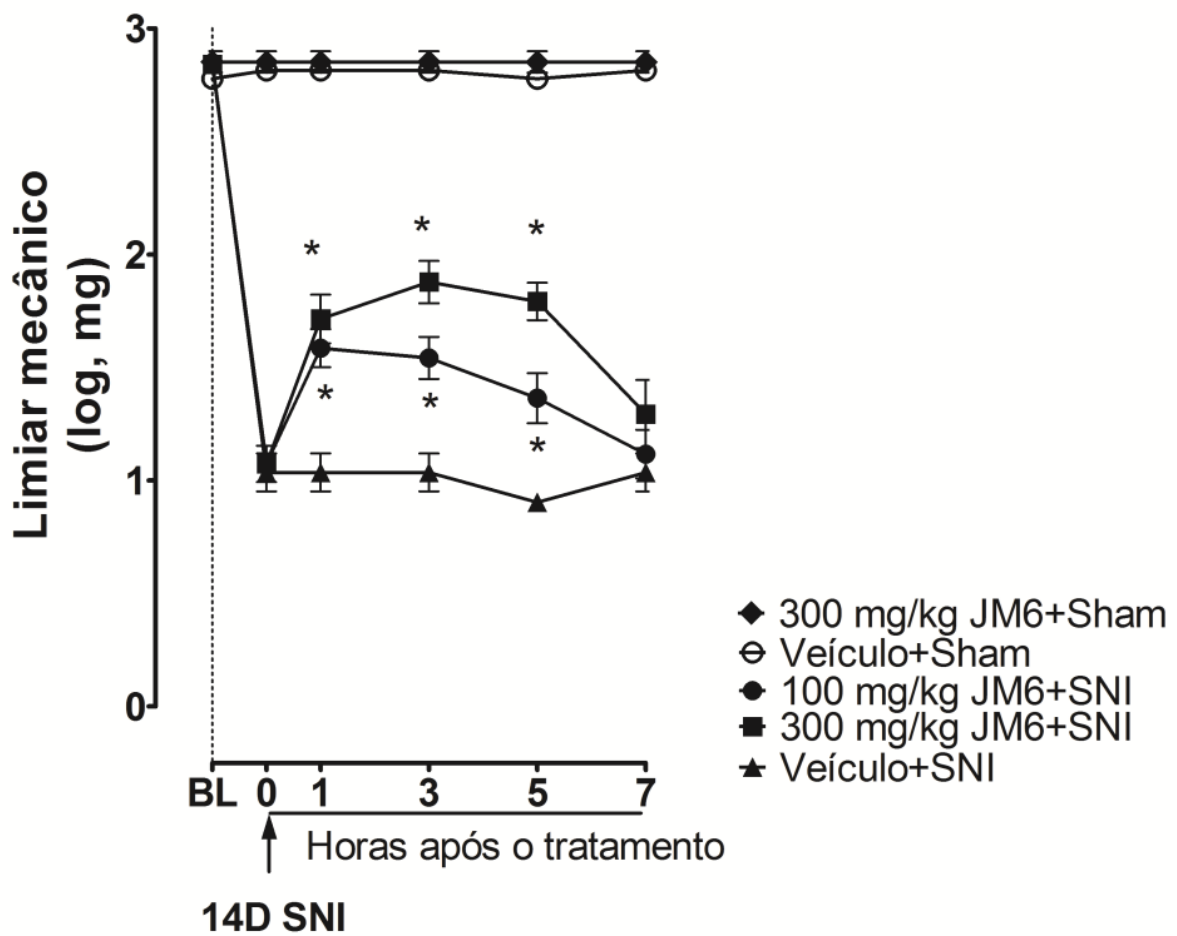

Figura 16. O tratamento por via oral com o JM6 reduz a hipersensibilidade nociceptiva mecânica em animais com neuropatia (14\% dia). A intensidade de hipersensibilidade nociceptiva mecânica o foi avaliada antes de qualquer procedimento (BL) e após a cirurgia no $14^{\circ}$ dia (zero hora). O Painel mostra a intensidade de hipersensibilidade nociceptiva mecânica avaliada pelos filamentos de von Frey no $7^{\circ}$ dia após a lesão de nervos, respectivamente, ao longo da $1^{\mathrm{a}}, 3^{\mathrm{a}}, 5^{\mathrm{a}}$ e $7^{\mathrm{a}}$ hora após a administração de do JM6 por via oral aos camundongos(n=6). * $p<0.05$ comparado com o grupo SNI+veículo. Teste ANOVA de duas vias seguido pelo teste de Bonferroni para comparar os tratamentos. O nível de significância adotado foi de $p<0.05$. 


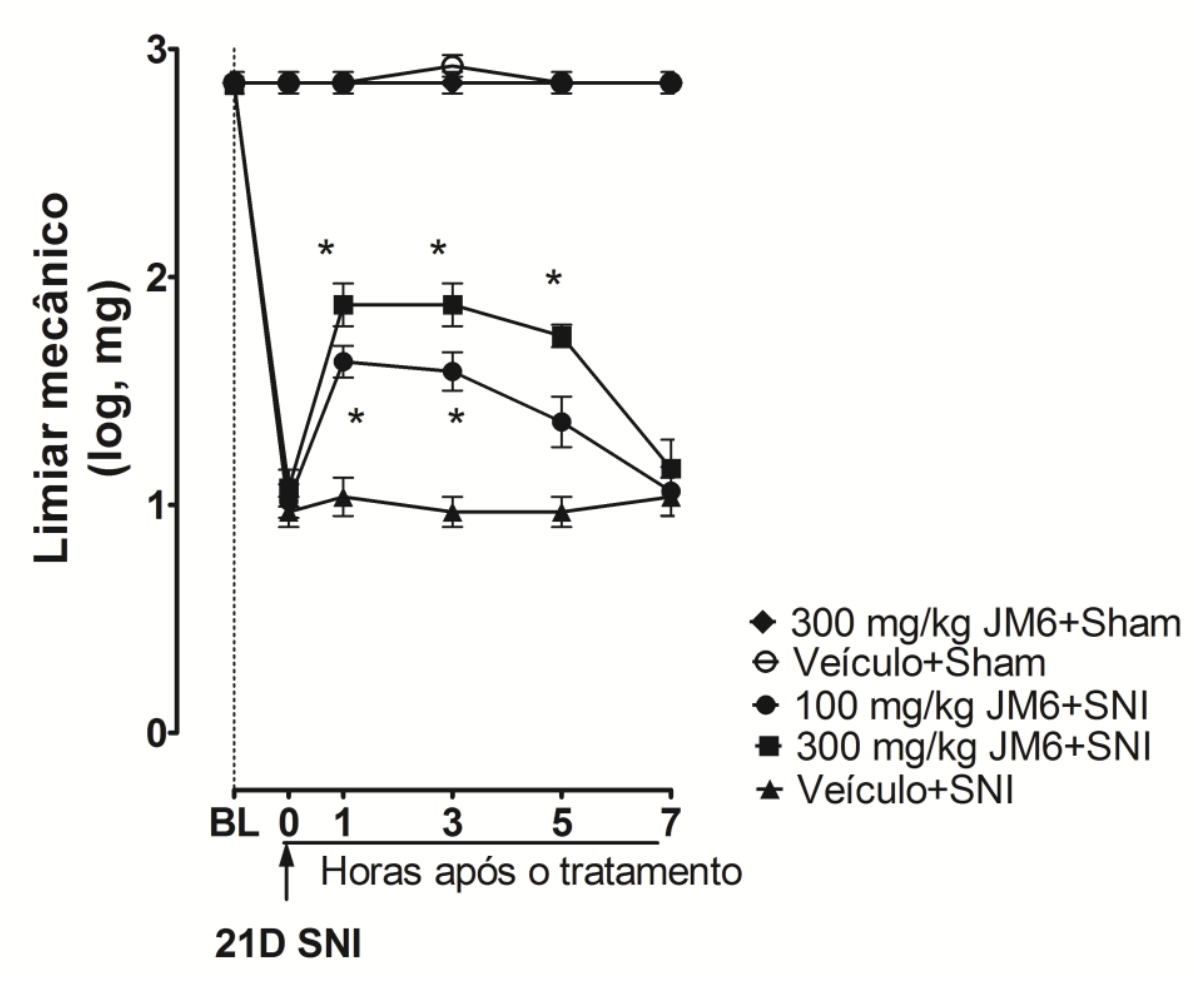

Figura 17. O tratamento por via oral com o JM6 reduz a hipersensibilidade nociceptiva mecânica em animais com neuropatia $\left(21^{\circ}\right.$ dia $)$. A intensidade de hipersensibilidade nociceptiva mecânica foi avaliada antes de qualquer procedimento (BL) e após a cirurgia no $21^{\circ}$ dia (zero hora). O Painel mostra a intensidade de hipersensibilidade nociceptiva mecânica avaliada pelos filamentos de von Frey no $7^{\circ}$ dia após a lesão de nervos, respectivamente, ao longo da $1^{\mathrm{a}}, 3^{\mathrm{a}}, 5^{\mathrm{a}}$ e $7^{\mathrm{a}}$ hora após a administração de do JM6 por via oral aos camundongos(n=6). * $p<0.05$ comparado com o grupo SNI+veículo. Teste ANOVA de duas vias seguido pelo teste de Bonferroni para comparar os tratamentos. O nível de significância adotado foi de $p<0.05$. 


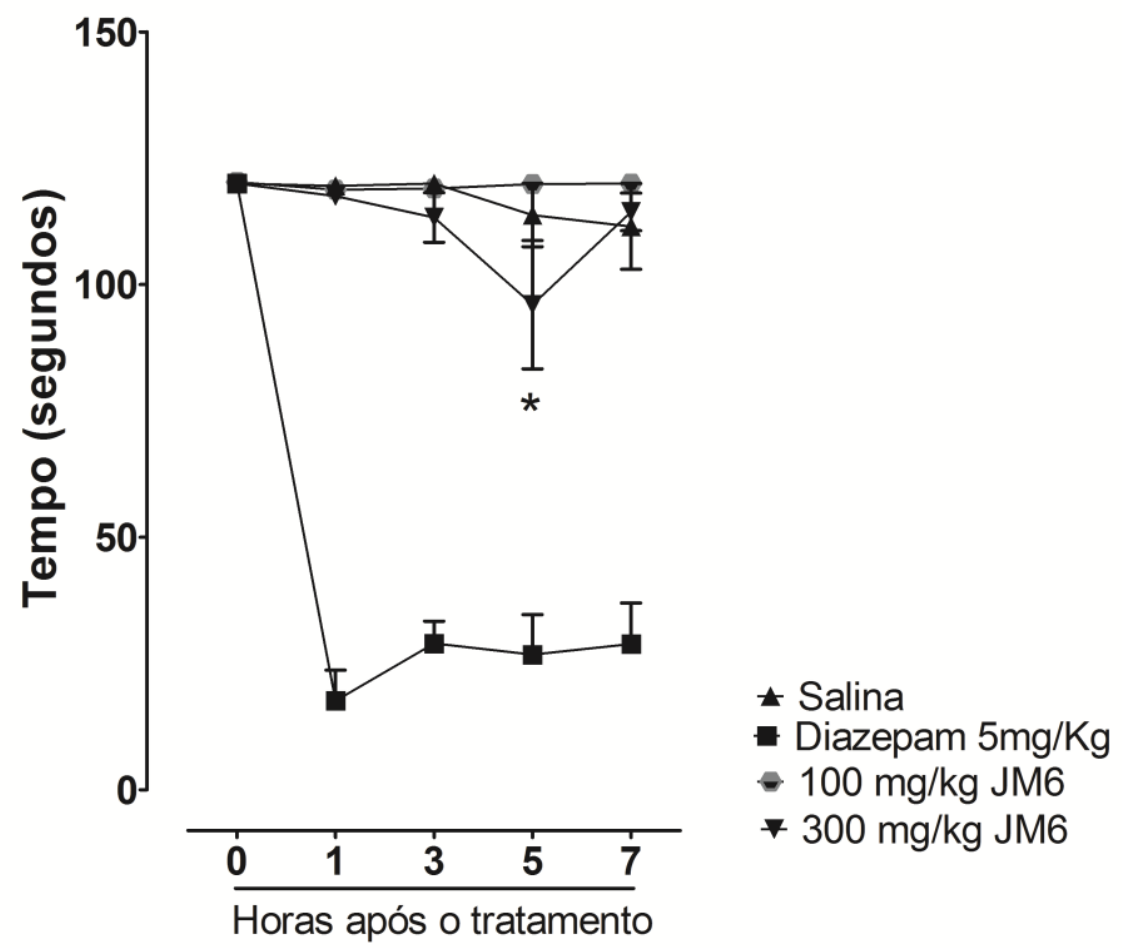

Figura 18. O JM6 interfere parcialmente com a capacidade locomotora dos animais avaliada pelo teste de Rota Rod. Os animais após receberem JM6 (100 ou 300 mg/animal/v.o.), veículo v.o. ou diazepam ( $5 \mathrm{mg} / \mathrm{Kg} /$ i.p.) foram submetidos a sessões para avaliação da capacidade motora. Os testes foram realizados em 1, 3, 5 e 7 horas após as injeções das drogas ( $\mathrm{n}=5 / 8$ por grupo). * indica diferença estatisticamente significante quando comparado com o grupo que recebeu apenas veículo/salina $(\mathrm{p}<0,05)$. 


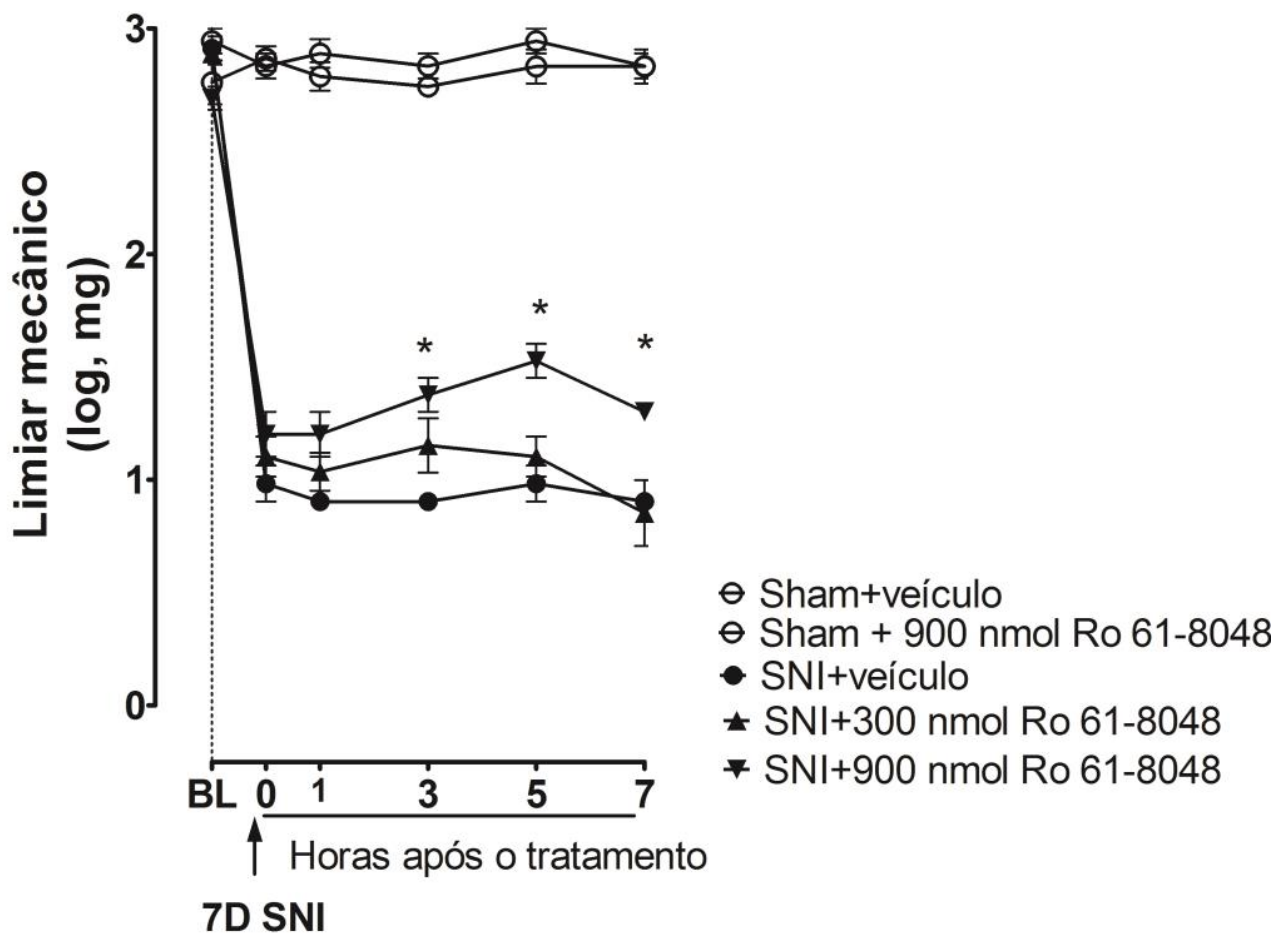

Figura 19. Efeito da microinjeção do Ro61-8048 no espaço intracerebroventricular de camundongos com neuropatia ( $7^{\circ}$ dia). A intensidade de hipersensibilidade nociceptiva mecânica foi avaliada antes de qualquer procedimento (BL) e após a cirurgia no $7^{\circ}$ (zero hora). O Painel mostra a intensidade de hipersensibilidade nociceptiva mecânica avaliada pelos filamentos de von Frey no $7^{\circ}$ dia após a lesão de nervos, respectivamente, ao longo da $1^{\mathrm{a}}, 3^{\mathrm{a}}$ e $5^{\mathrm{a}}$ hora após a administração de Ro 61-8048 no espaço intracerebroventricular dos camundongos $(\mathrm{n}=6)$. * $p<0.05$ comparado com o grupo SNI+veículo. Teste ANOVA de duas vias seguido pelo teste de Bonferroni para comparar os tratamentos. O nível de significância adotado foi de $p<0.05$. 


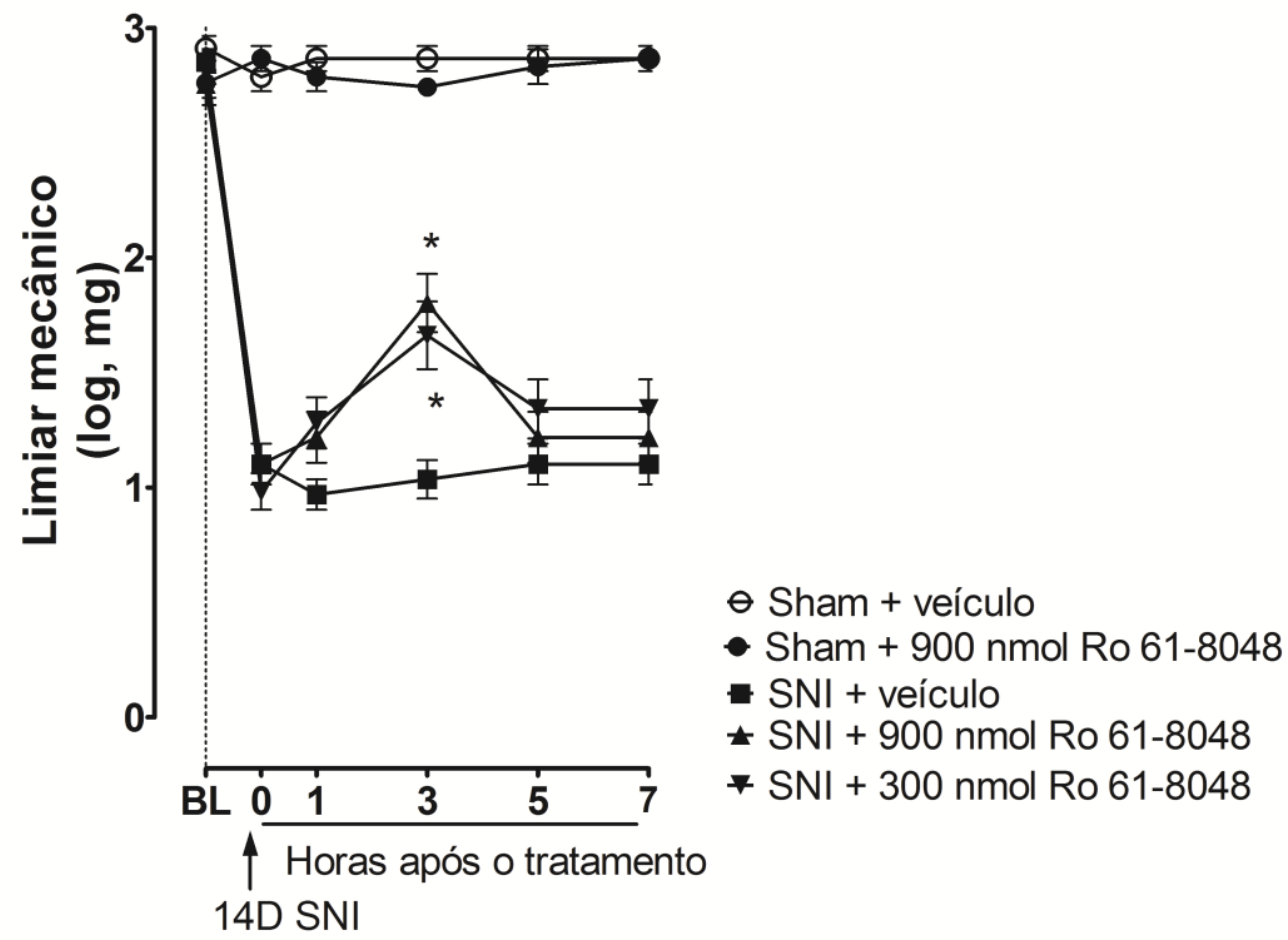

Figura 20. Efeito da microinjeção de Ro61-8048 no espaço intracerebroventricular de camundongos com neuropatia ( $1^{\circ}$ dia). A intensidade de hipersensibilidade nociceptiva mecânica foi avaliada antes de qualquer procedimento (BL) e após a cirurgia no $14^{\circ}$ (zero hora). O Painel mostra a intensidade de hipersensibilidade nociceptiva mecânica avaliada pelos filamentos de von Frey no $14^{\circ}$ dia após a lesão de nervos, respectivamente, ao longo da $1^{\mathrm{a}}, 3^{\mathrm{a}}$ e $5^{\mathrm{a}}$ hora após a administração de Ro 61-8048 no espaço intracerebroventricular dos camundongos $(\mathrm{n}=6)$. * $p<0.05$ comparado com o grupo SNI+veículo. Teste ANOVA de duas vias seguido pelo teste de Bonferroni para comparar os tratamentos. O nível de significância adotado foi de $p<0.05$. 


\subsection{Avaliação dos efeitos nociceptivos da microinjeção de quinurenina, ácido 3- hidroxiantranílico e ácido quinolínico no espaço intracerebroventricular de camundongos}

Para avaliar se os principais metabólitos da via das quinureninas, a quinurenina, ácido 3-hidroxiantranílico e o ácido quinolínico estariam relacionados com o desenvolvimento da hipersensibilidade mecânica induzida por SNI.

Primeiramente, foi implantando uma cânula guia no ventrículo lateral (i.c.v), para administração dos metabólitos acima mencionados. Após uma semana os animais tiveram o limar mecânico avaliado, seguido da microinjeção de quinurenina (Figura 21), 3-hidroxiantranílico (Figura 22) ou ácido quinolínico (Figuras 23a), na concentração de 0,8; 8 e 80 nmol, no espaço i.c.v. Inicialmente foi avaliado o limiar mecânico basal dos animais, hora zero e o efeito da microinjeção dos metabólitos foi avaliado na 1, 3, 5, 7 horas, 1 e 2 dias após a microinjeção. A microinjeção dos metabolitos induziu um quadro de hipersensibilidade nociceptiva mecânica de modo dose dependente quando comparado com o grupo que recebeu apenas a microinjeção de veículo (Figuras 21, 22 e 23a).

Para avaliar se hipersensibilidade nociceptiva mecânica induzida pela microinjeção de ácido quinolínico era dependente da ativação de receptores NMDA os animais receberam o pré tratamento com MK-801, antagonista seletivo e não competitivo dos receptores NMDA. O pré-tratamento com 10 nmol de MK-801 seguido da microinjeção de $80 \mathrm{nmol}$ de QUIN (30 min) reduziu a hipersensibilidade nociceptiva mecânica induzida por QUIN quando comparado com o grupo que recebeu a microinjeção de veículo (figura 23b). 
Na figura 24 é possível observar o efeito da microinjeção de $80 \mathrm{nmol}$ de KYN, 3-HAA e QUIN no mesma mesma figura, sendo possível observar que o ácido quinolínico causava a maior hipersensibilidade nociceptiva mecânica .

Por último, foi hipotetizado, haja vista que as principais enzimas da via das quinureninas, IDO1 e KMO, estão aumentadas durante a neuropatia em regiões supraespinais, elas poderiam produzir grandes quantidades de ácido quinolínico e a administração de MK-801 em animais neuropáticos poderia reduzir a hipersensibilidade nociceptiva mecânica dos animais.

Após avaliar o limiar mecânico basal dos animais, os mesmos foram submetido a indução de neuropatia, passados 7 dias foi implantado uma cânula guia para microinjeção de drogas, passados mais 7 dias, estando os animais no $14^{\circ}$ após a cirurgia de SNI, diversos grupos de animais receberam microinjeções de MK-801 ou veículo e o limiar mecânico dos mesmos foi avaliado utilizando-se de Von Frey na $1^{\mathrm{a}}, 3^{\mathrm{a}}, 5^{\mathrm{a}}$ e $7^{\mathrm{a}}$ hora. Dessa forma, a microinjeção de $10 \mathrm{nmol}$ de $\mathrm{MK}-801$ reduziu significativamente a hipersensibilidade nociceptiva mecânica induzida por SNI, $1^{\mathrm{a}}, 3^{\mathrm{a}}$ e $5^{\mathrm{a}}$ hora após a microinjeção, quando comparado com o grupo SNI que recebeu veículo (figura 25). 


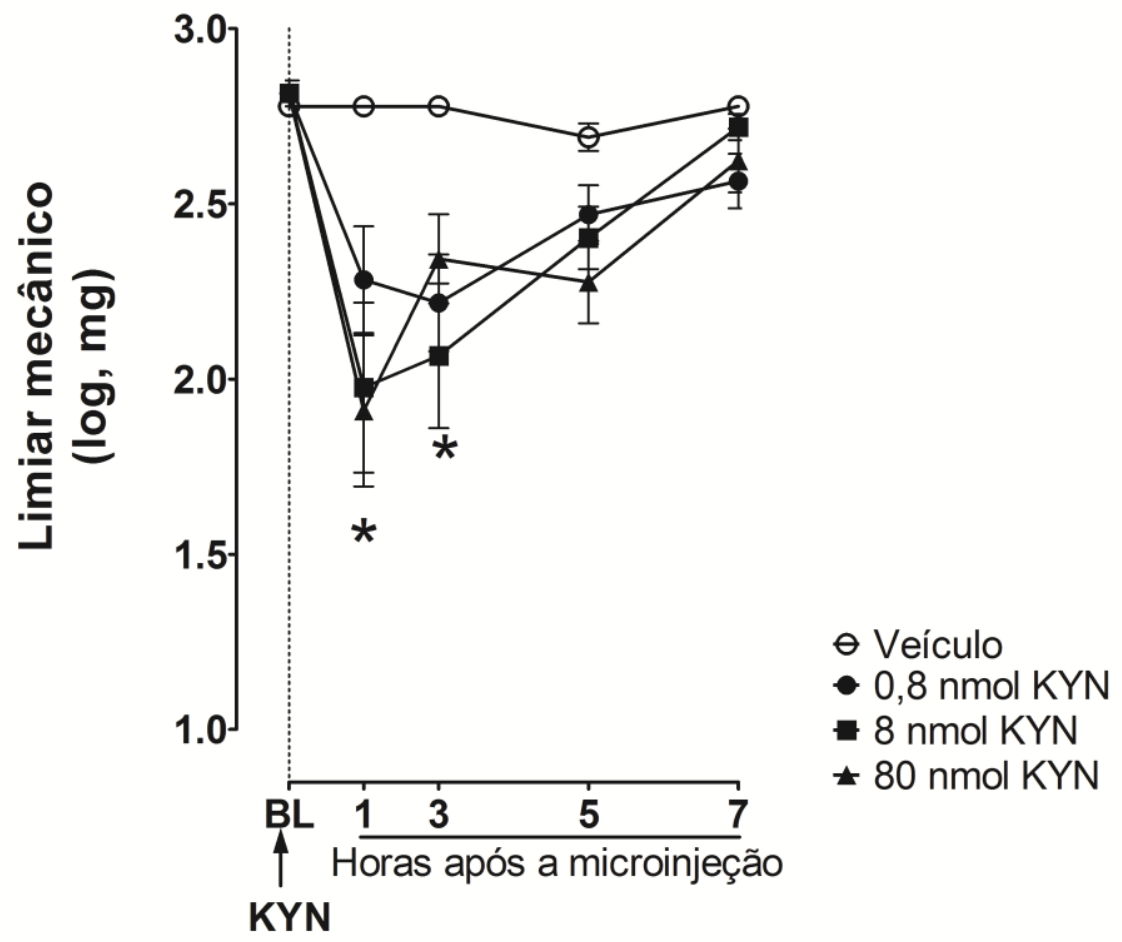

Figura 21. Efeito da microinjeção de quinurenina no espaço intracerebroventricular sob o limiar mecânico de camundongos naives. Curva dose-resposta para avaliar a hipersensibilidade nociceptiva mecânica mecânica em camundongos, após receberem doses crescentes de quinurenina 0,8; 8 e $80 \mathrm{nmol}$ ou veículo no espaço i.c.v.. A avaliação do liminar nociceptivo mecânico foi realizada em $0,1,3,5$, e 7 horas após as injeções $(\mathrm{n}=6) . * p<0.05$ comparado com o grupo veículo. Teste ANOVA de duas vias seguido pelo teste de Bonferroni para comparar os tratamentos. O nível de significância adotado foi de $p<0.05$. 


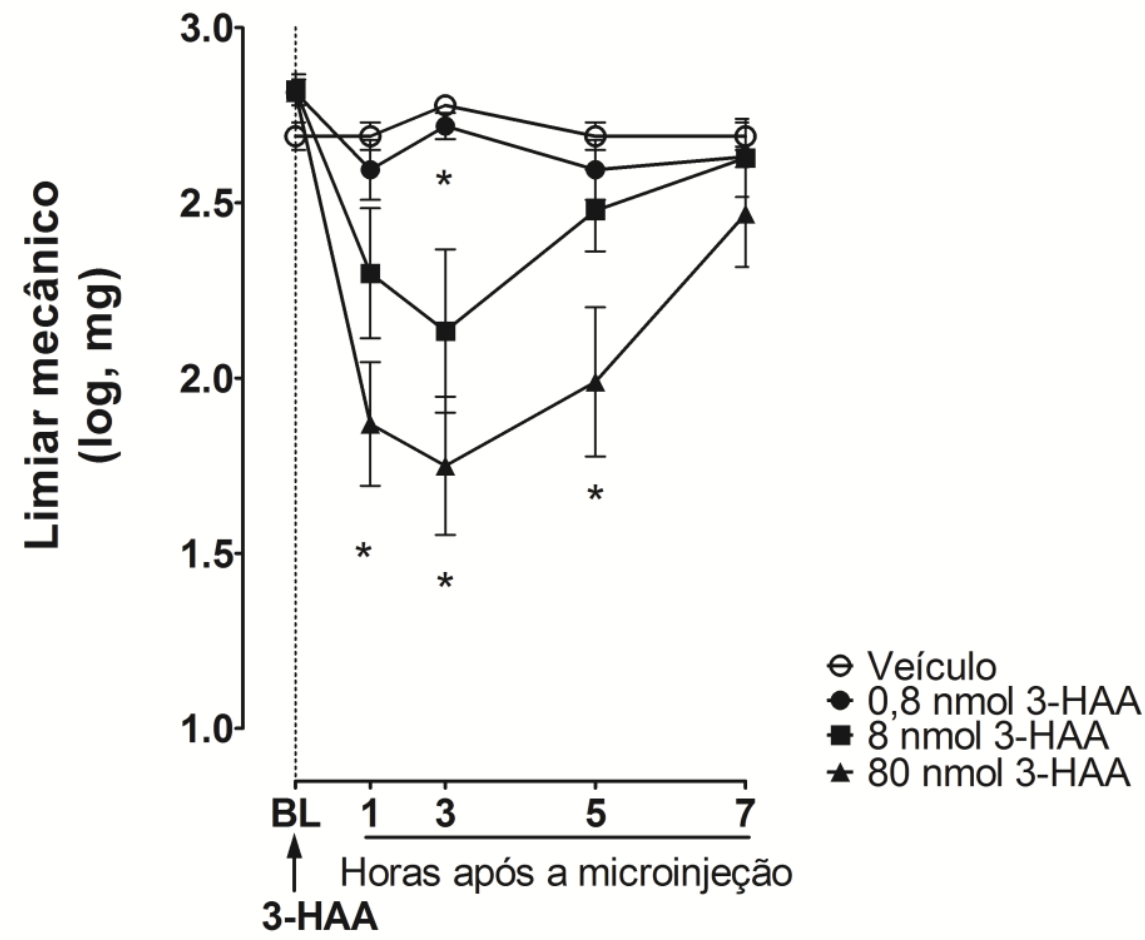

Figura 22. Efeito da microinjeção de ácido 3-hidroxiantranílico (3-HAA) no espaço intracerebroventricular sob o limiar mecânico de camundongos naives. Curva doseresposta para avaliar a hipersensibilidade nociceptiva mecânica em camundongos, após receberem doses crescentes de ácido 3-hidroxiantranílico 0,8; 8 e $80 \mathrm{nmol}$ ou veículo no espaço i.c.v.. A avaliação do liminar nociceptivo mecânico foi realizada em $0,1,3,5$, e 7 horas após as injeções $(\mathrm{n}=6) . * p<0.05$ comparado com o grupo veículo. Teste ANOVA de duas vias seguido pelo teste de Bonferroni para comparar os tratamentos. O nível de significância adotado foi de $p<0.05$. 

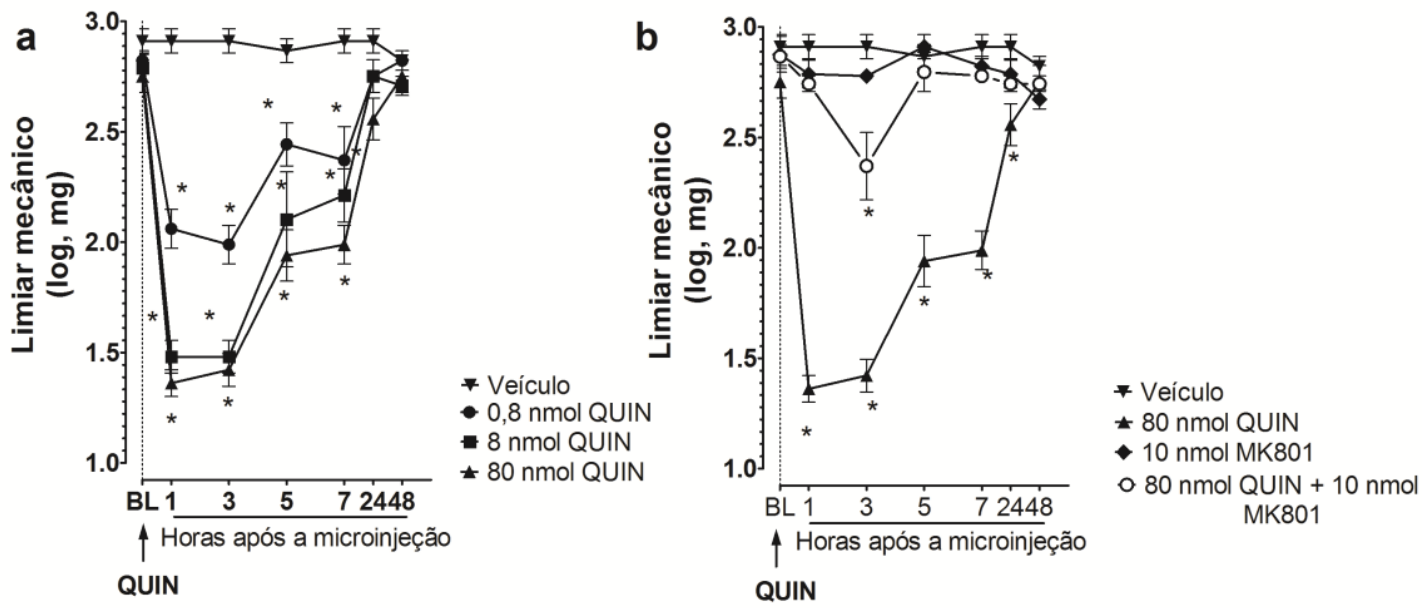

Figura 23. Efeito da microinjeção de ácido quinolínico (QUIN) no espaço intracerebroventricular sob o limiar mecânico de camundongos naives. Curva doseresposta para avaliar a hipersensibilidade nociceptiva mecânica em camundongos, após receberem doses crescentes de ácido quinolínico 0,8; 8 e 80 nmol (a); pré tratamento com $10 \mathrm{nmol}$ de MK801 seguido pela microinjeção de ácido quinolínico (80 nmol), $10 \mathrm{nmol}$ de MK801 ou veículo no espaço i.c.v. (b). A avaliação do liminar nociceptivo mecânico foi realizada em $0,1,3,5$, e 7 horas após as injeções $(\mathrm{n}=6)$. * $p<0.05$ comparado com o grupo veículo. Teste ANOVA de duas vias seguido pelo teste de Bonferroni para comparar os tratamentos. O nível de significância adotado foi de $p<0.05$. 


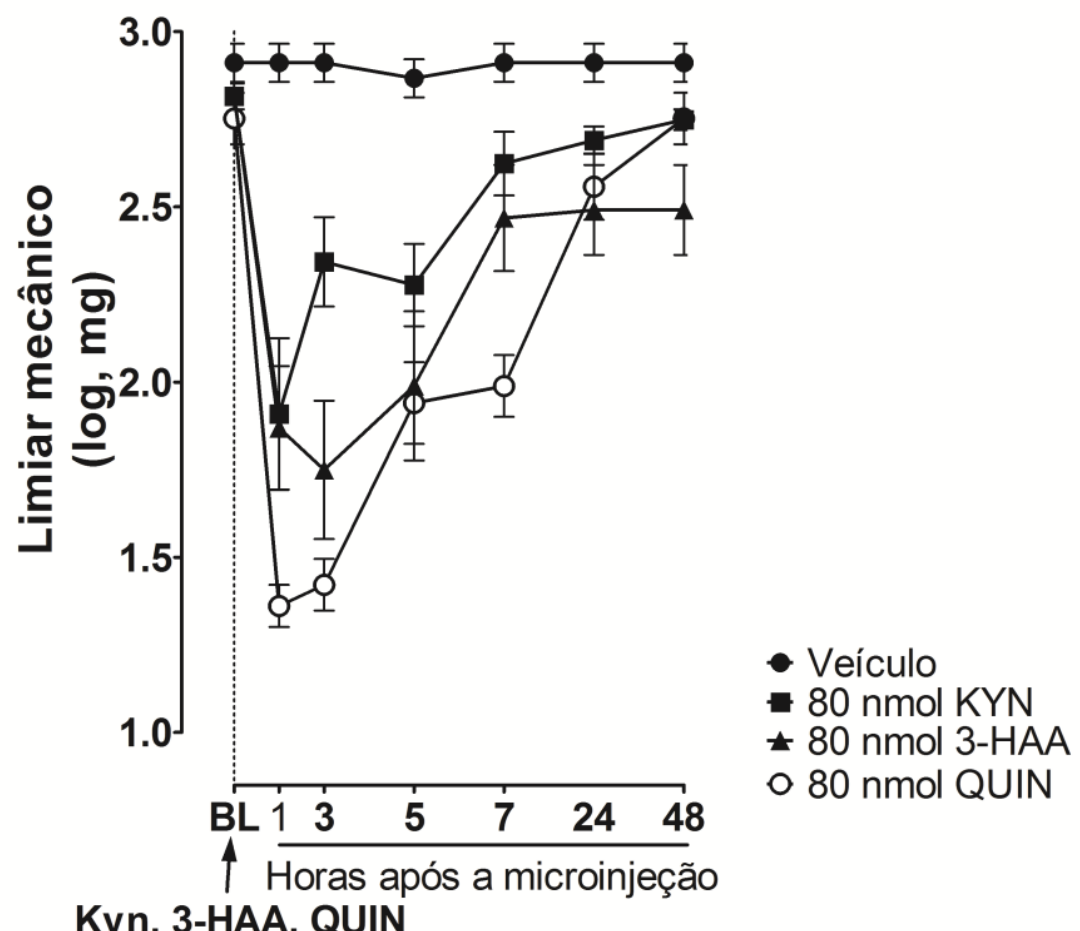

Figura 24. Comparação do efeito da microinjeção de doses equimolares (80 nmol) de quinurenina, ácido 3-hidroxiantranílico ou ácido quinolínico no espaço intracerebroventricular sob o limiar mecânico de camundongos naives. A administração de doses equimolares $(80 \mathrm{nmol})$ de quinurenina, ácido 3-hidroxiantranílico ou ácido quinolínico no espaço intracerebroventricular em camundongos causa hipersensibilidade nociceptiva mecânica em diferentes graus, sendo o ácido quinolínico o mais potente. A avaliação do liminar nociceptivo mecânico foi realizada em $0,1,3,5$, 7, 24 e 48 horas após as injeções (n=6). 


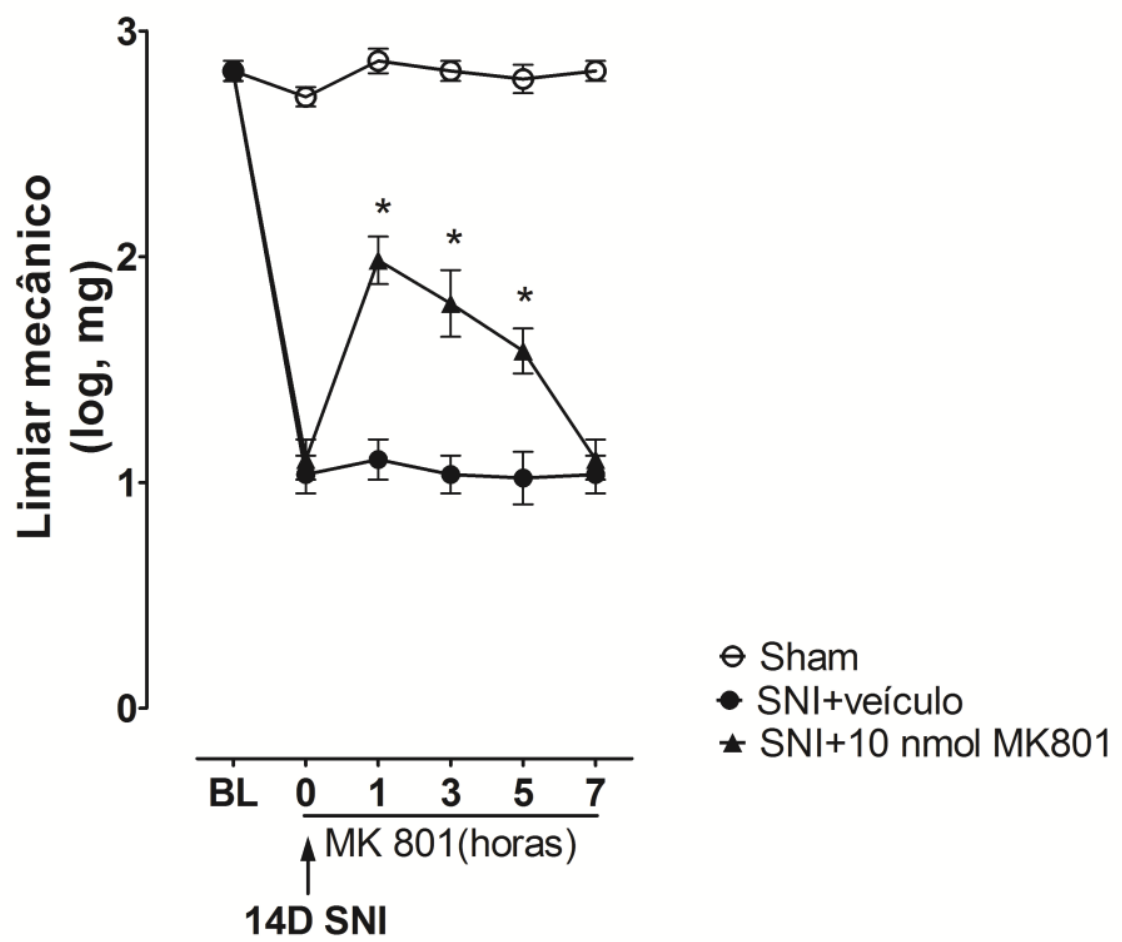

Figura 25. Efeito da microinjeção de MK-801 no espaço intracerebroventricular de camundongos com neuropatia (14 ${ }^{\circ}$ dia SNI). A intensidade de hipersensibilidade nociceptiva mecânica foi avaliada antes de qualquer procedimento (BL) e após a cirurgia no $14^{\circ}$ dia (zero hora). O Painel mostra a intensidade de hipersensibilidade nociceptiva mecânica avaliada pelos filamentos de von Frey no $14^{\circ}$ dia após a lesão de nervos, respectivamente, ao longo da $1^{\mathrm{a}}, 3^{\mathrm{a}}, 5^{\mathrm{a}}$ e $7^{\mathrm{a}}$ hora após a administração de MK-801 no espaço intracerebroventricular dos camundongos $(\mathrm{n}=5-6)$. * $p<0,05$ comparado com grupo SNI+veículo. Teste ANOVA de duas vias seguido pelo teste de Bonferroni para comparar os tratamentos. O nível de significância adotado foi de $p<0.05$. 


\subsection{A hipersensibilidade mecânica induzida por QUIN depende da ativação da via descendente facilitatória da dor e de ativação glial}

Hipotetizamos que o produto final da via das quinureninas, o QUIN, ativaria receptores glutamatérgicos do tipo NMDA na PAG e no RVM, sendo esses neurônios ativados o que compõem a via descendente facilitatória da dor, ao ser ativados liberariam 5-HT que ativaria receptores 5-HT3a no corno dorsal, facilitando a transmissão nociceptiva.

Para testar essa hipótese realizamos dois experimentos:

No primeiro foi realizado o pré-tratamento espinal com um antagonista dos receptores 5-HT3a, o LY 278,584 ou veículo, seguido pela microinjeção de $80 \mathrm{nmol}$ de QUIN ou veículo no espaço i.c.v. O QUIN causou hipersensibilidade nociceptiva mecânica quando comparado com o grupo que recebeu apenas veículo; o grupo que recebeu o pré-tratamento espinal com 20 nmol de LY-278,584 bloqueou parcialmente a hipersensibilidade induzida por QUIN (figura 26), sugerindo que o efeito nociceptivo do QUIN é parcialmente devido a ativação da via descente facilitatória da dor. 


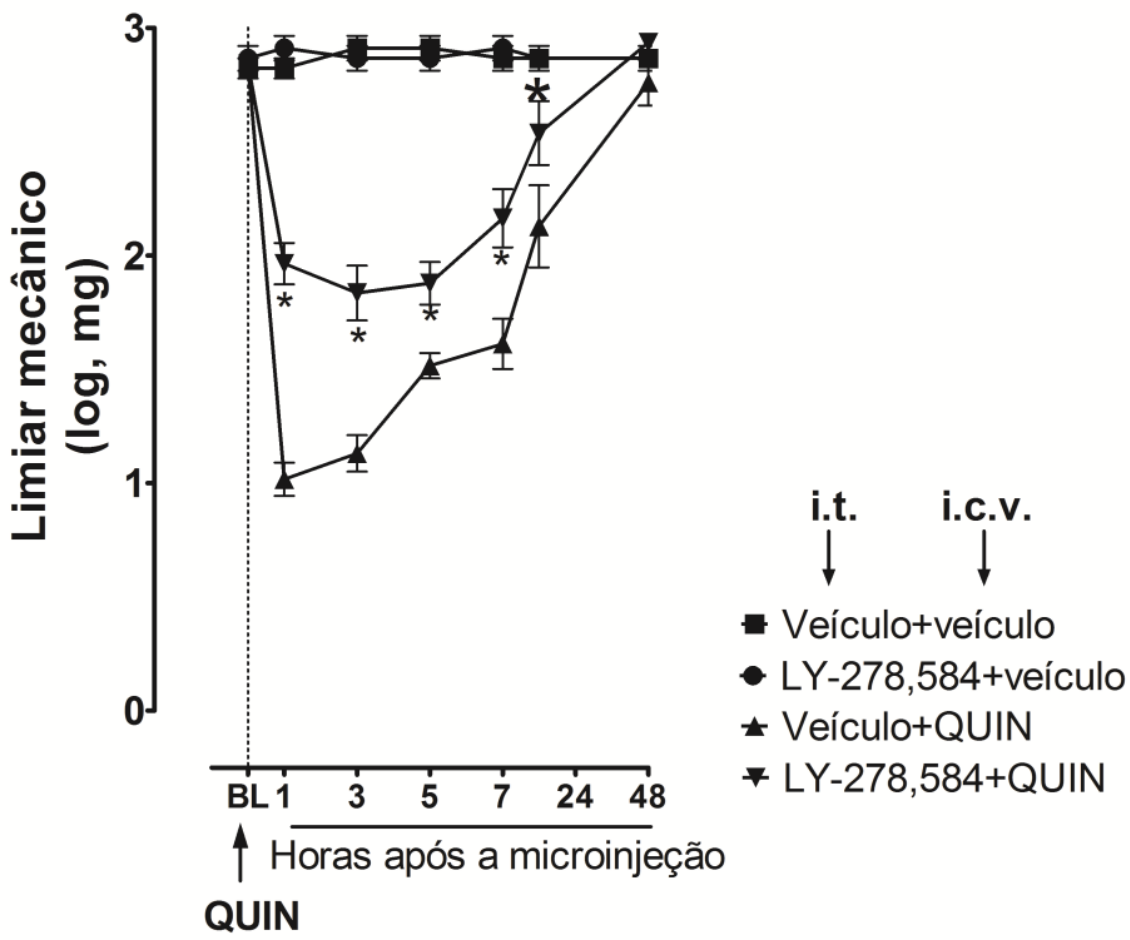

Figura 26. Efeito nociceptivo da microinjeção de ácido quinolínico (QUIN) no espaço intracerebroventricular depende parcialmente da ativação da via facilitatória descente da dor. Os animais receberam o pré-tratamento espinal com $20 \mathrm{nmol}$ de LY278,584, seguido ou não de uma microinjeção de 80 nmol de QUIN no espaço i.c.v.. A avaliação do liminar nociceptivo mecânico foi realizada em $0,1,3,5,7,24$ e 48 horas após as microinjeções $(\mathrm{n}=6)$. * $p<0.05$ comparado com o grupo veículo+QUIN. Teste ANOVA de duas vias seguido pelo teste de Bonferroni para comparar os tratamentos. $\mathrm{O}$ nível de significância adotado foi de $p<0.05$.

O segundo experimento foi realizado 21 dias após a lesão de nervos, modelo SNI, os animais receberam o pré-tratamento sistêmico com 1-Mt, Fluoxetina ou 1Mt+fluoxetina ou veículo. A fluoxetina ou 1-Mt reduziram de modo similar a hipersensibilidade nociceptiva mecânica induzida por SNI e o tratamento combinado 1Mt+fluoxetina potencializou o efeito analgésico dessas drogas (figura 27). 


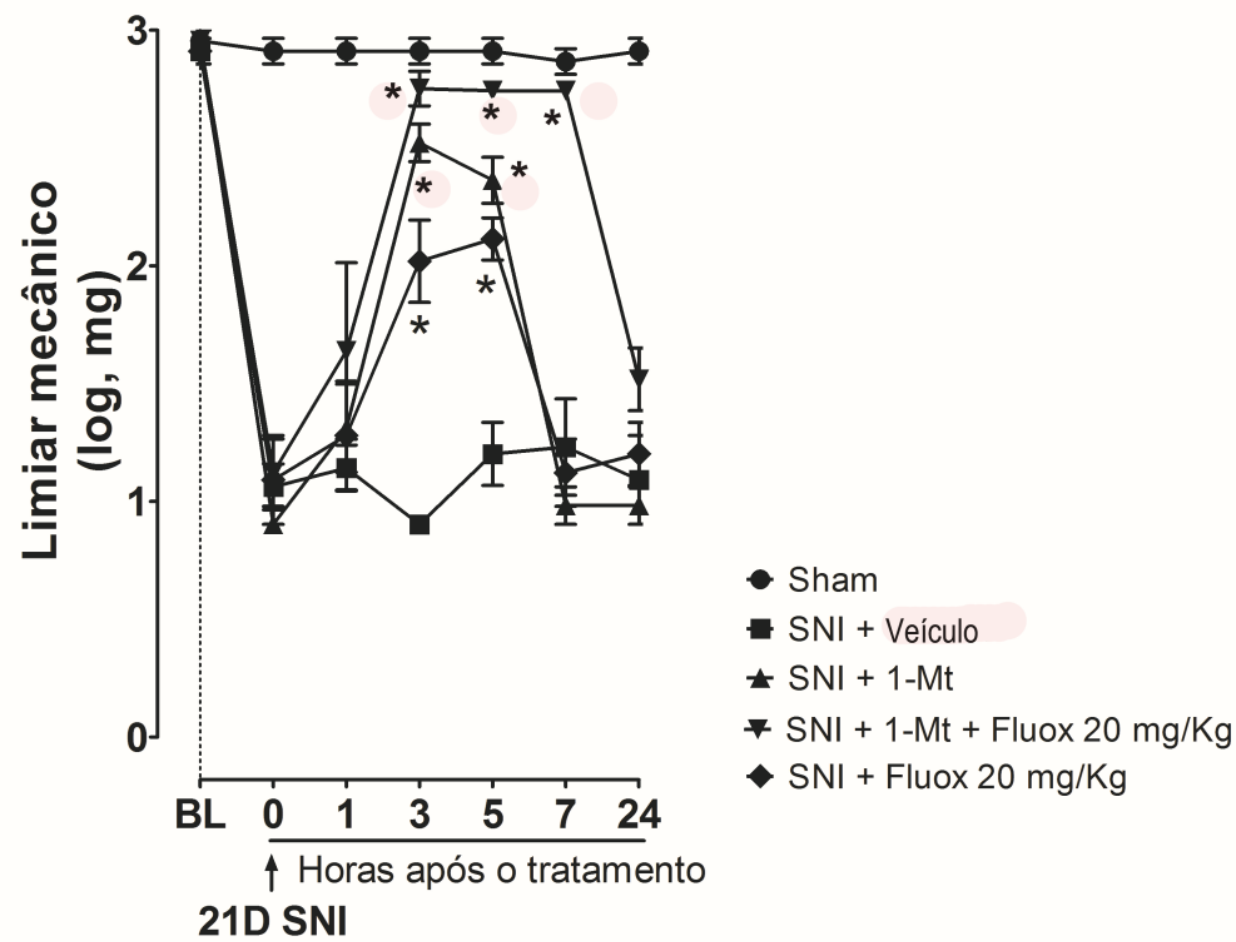

Figura 27. A fluoxetina potencializa o efeito antinociceptivo do 1-metil-triptofano após a lesão de nervos periféricos $\left(21^{\circ}\right.$ dias $\left.\mathrm{SNI}\right)$. Os animais receberam o prétratamento sistêmico com 1-metil-triptofano $(3 \mathrm{mg})$, fluoxetina $(20 \mathrm{mg} / \mathrm{kg})$ ou ambos, e foi avaliado o liminar nociceptivo mecânico na $0,1,3,5,7$ e 24 horas após os tratamentos $(\mathrm{n}=6) . * p<0.05$ comparado com o grupo SNI+veículo. Teste ANOVA de duas vias seguido pelo teste de Bonferroni para comparar os tratamentos. O nível de significância adotado foi de $p<0.05$.

4.7. Avaliação dos níveis de 5-HT no RVM de camundosngos submetidos a lesão de nervos periféricos

É sabido que a enzima IDO1 converte triptofano que é aminoácido essencial e precursor do neurotransmissor 5-HT. Além disso, sabe-se que o RVM é a principal fonte de projeções serotonérgicas que inervam o corno dorsal da medula espinal (Potrebic et 
al., 1994). Dessa forma, avaliamos pela técnica de imunofluorescência os níveis de 5-HT no RVM 7 dias após SNI em animais WT e IDO1 KO, bem como sham WT. Foi observado que os animais sham WT apresentavam níveis normais de 5-HT, entretanto os animais WT submetidos a SNI apresentavam os níveis de 5-HT severamente comprometidos (figura 28). Por outro lado, os animais IDO1 KO apresentam os níveis normais de 5-HT no RVM, sugerindo que em um primeiro momento o aumento da expressão da enzima IDO1 no RVM consumiria o triptofano, consequentemente reduziria os níveis de 5-HT diminuindo a eficiência da via descendente inibitória da dor.

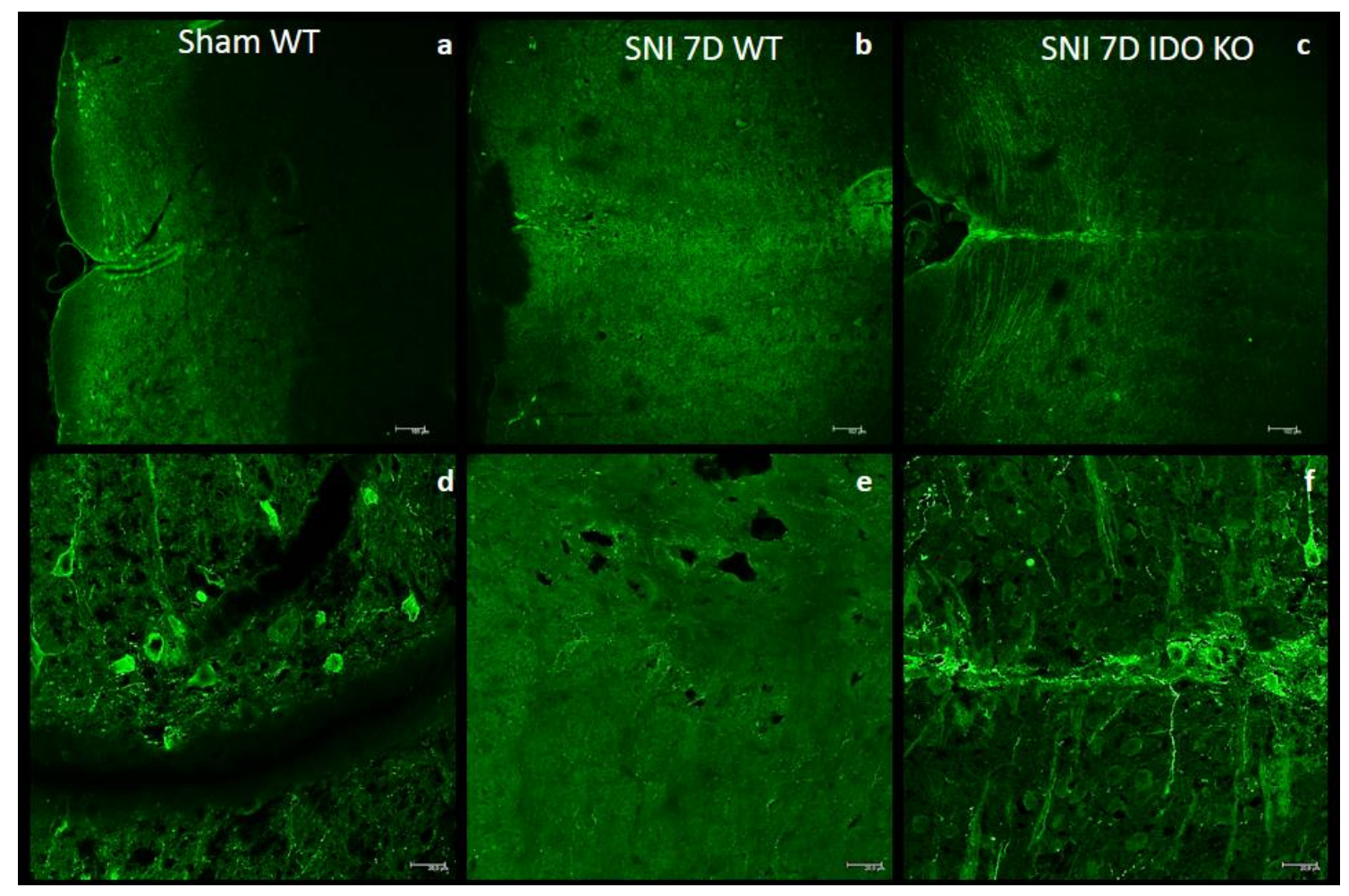

Figura 28. Avaliação dos níveis de 5-HT no RVM de animais submetidos a lesão de nervos periféricos. 7 dias após SNI os cérebros de animais sham e SNI WT, bem como SNI IDO KO foram coletados e os níveis de 5-HT foi avaliado pela técnica de imunofluorescência. A: Marcação de 5-HT no RVM de animais sham WT, 10x; D: Foco na imagem A, marcação de 5-HT, 63x; B: Marcação de 5-HT no RVM de animais SNI WT, 10x; E: Foco na imagem B, marcação de 5-HT, 63x; C: Marcação de 5-HT no RVM de animais SNI IDO KO, 10x; F: Foco na imagem C, marcação de 5-HT, 63x; 


\subsection{Participação de células T CD4+ e da citocina IFN- $\gamma$ na gênese da dor neuropática}

Sabe-se que neurônios, células da glia, neutrófilos, linfócitos e macrófagos estão envolvidos na gênese da dor neuropática. Nesse sentido, primeiramente avaliamos qual tipo de linfócitos estavam associados com o desenvolvimento da hipersensibilidade nociceptiva mecânica no modelo de SNI, bem como a participação dessas células da indução da enzima IDO1.

Inicialmente, induzimos a neuropatia em animais $\mathrm{CD} 4+^{-/-}, \mathrm{CD} 8+^{-/-}, \mathrm{B}^{-/-}$ (BKO), WT e avaliamos o limiar mecânico desses animais por 14 dias pelo método de von Frey. Foi observado que os animais WT, CD8 $+^{-{ }^{-}}, \mathrm{B}^{-{ }^{-}}(\mathrm{BKO})$ apresentam um intenso quadro e hiperalgesia mecânica após a lesão de nervos, enquanto os animais CD4+ ${ }^{-/-}$não desenvolvem hipersensibilidade nociceptiva mecânica (figura 29). Além disso, foi observado pela técnica de western blotting que tanto a PAG quanto o RVM de animais CD4+-/- não apresentam a enzima IDO1 induzida após a lesão de nervos periféricos em relação aos animais WT (dados não mostrados). 


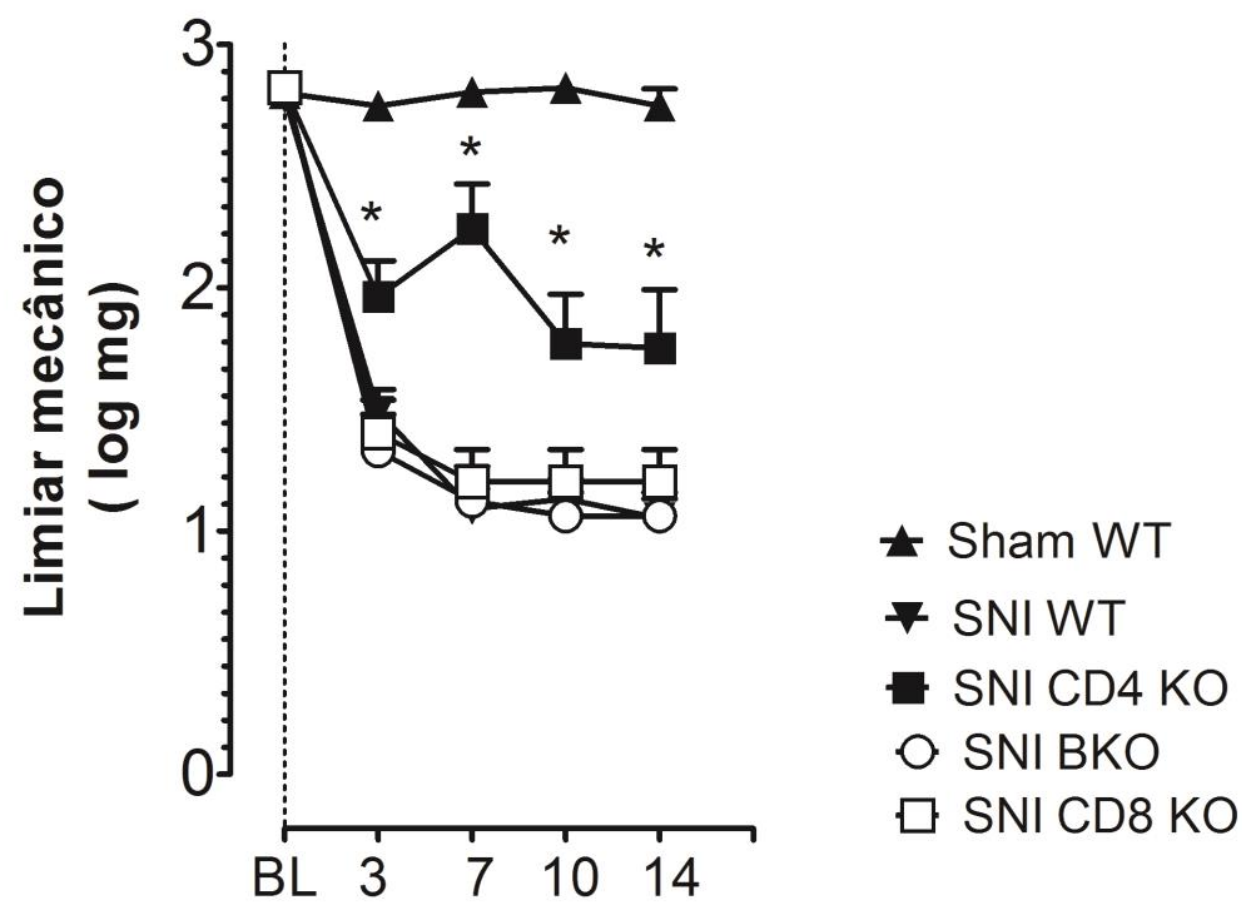

Figura 29. Avaliação da hipersensibilidade nociceptiva mecânica induzida pelo modelo de SNI em animais CD4+ ${ }^{--}$, CD8+ $+^{--}, \mathrm{B}^{-/-}(\mathrm{BKO})$ e WT. Camundongos C57BL/6, CD4 KO, CD8 KO e BKO foram submetidos à cirurgia para indução de neuropatia pelo método de SNI, assim como seu respectivo grupo controle sham. A hipersensibilidade nociceptiva mecânica foi avaliada em $0,3,7,10$ e 14 dias após a cirurgia. Os resultados foram expressos pela média \pm E.P.M. de 5 animais por grupo. * Indicam diferença estatisticamente significante quando comparado com o grupo de animais SNI WT $(\mathrm{p}<0,05)$.

A citocina pró-inflamatória IFN- $\gamma$ tem sido associada em muitos estados com a dor crônica (Austin \& Moalem-Taylor, 2010). Existem relatos que as células T CD4+ que infiltram o sistema nervoso após a lesão de nervos são IFN- $\gamma$ positivas. Além disso a citocina IFN- $\gamma$ é um potente indutor da enzima IDO1 e KMO.

Com o objeto de avaliar a participação dessa citocina no desenvolvimento da hipersensibilidade mecânica após a lesão de nervos, animais WT, bem como animais IFN- 
$\gamma \mathrm{KO}$ foram submetidos ao modelo SNI e o limiar mecânico nociceptivo avaliado pelo método de von Frey por 14 dias. Foi observado que os animais WT apresentam uma profunda hipersensibilidade nociceptiva mecânica, entretanto os animais IFN- $\gamma$ KO apresentam uma hipersensibilidade de menor magnitude, figura 30.

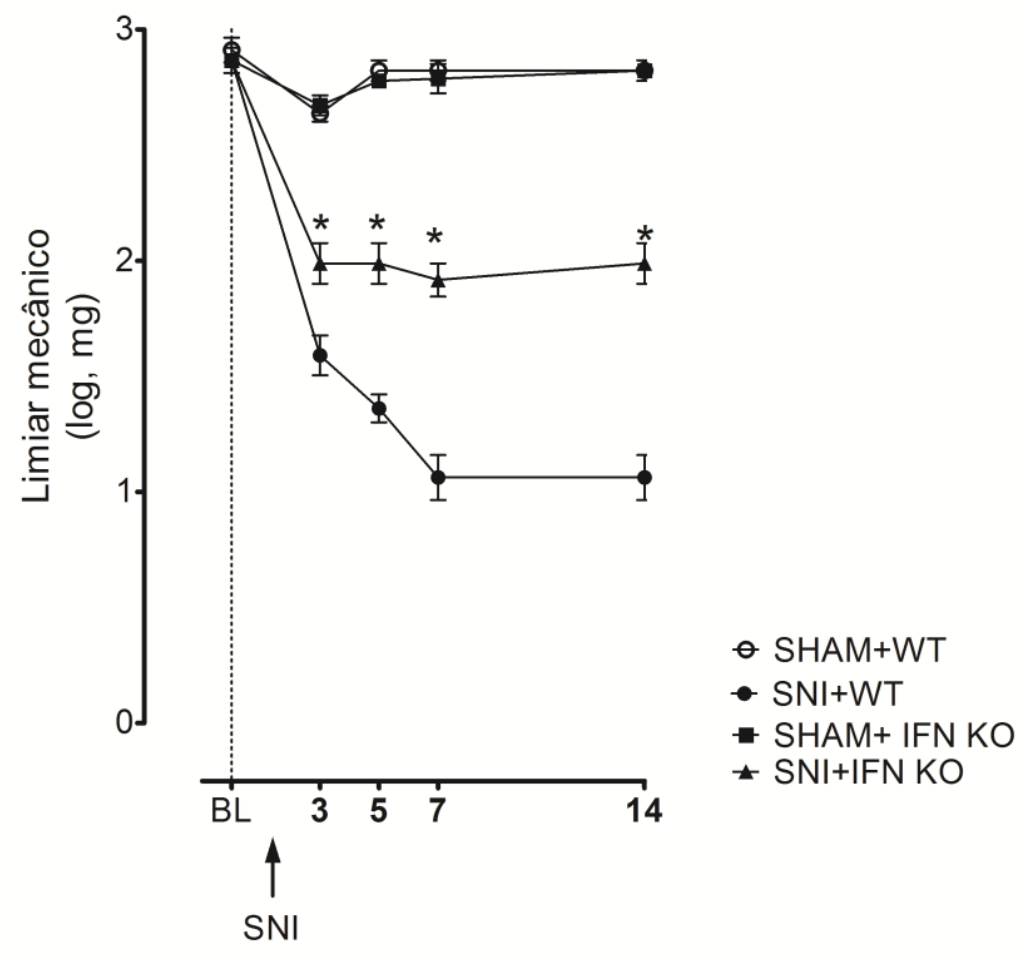

Figura 30. Avaliação da hipersensibilidade nociceptiva mecânica induzida pelo modelo de SNI em animais IFN- $\boldsymbol{\gamma}^{-/-}$e selvagens. Camundongos C57BL/6 ou IFN- $\gamma$ KO foram submetidos à cirurgia para indução de neuropatia pelo método de SNI, assim como seu respectivo grupo controle sham. A hipersensibilidade nociceptiva mecânica foi avaliada em $0,3,5,7$ e 14 dias após a cirurgia $(\mathrm{n}=5) ; * p<0.05$ comparado com o grupo SNI+WT. Teste ANOVA de duas vias seguido pelo teste de Bonferroni para comparar os tratamentos. O nível de significância adotado foi de $p<0.05$. 


\subsection{A expressão das enzimas IDO1 e KMO no RVM e na PAG após a lesão de nervos periféricos, modelo de SNI, depende da citocina IFN- $\gamma$}

Após induzir a neuropatia em animais WT bem como em animais IFN- $\gamma \mathrm{KO}$, passados 7 dias um grupo dos animais foram eutanasiados para remoção cirúrgica do RVM e em 14 dias para a PAG. Feito isso, os níveis da enzima IDO1 e KMO foram quantificados pela técnica de western blotting.

Dessa forma, foi observado que os animais WT apresentam níveis elevados da enzima IDO1 no 7 dia após a lesão e nervos, entretanto nos animais IFN- $\gamma$ KO esse aumento da expressão da IDO1 não ocorreu, figura 31. Na PAG, 14 dias após a indução da neuropatia pelo modelo SNI, foi observado uma redução significativa nos níveis da enzima IDO1 nos animais IFN- $\gamma$ KO, figura 32. Enquanto nos animais WT os níveis da enzima IDO1 está aumentada 14 dias após a lesão e nervos, porém nos animais IFN- $\gamma$ KO isso não foi observado.

Após avaliar a expressão da enzima IDO1 no RVM e na PAG de animais WT e IFN- $\gamma$ KO, foi avaliado a expressão da enzima KMO. No RVM, 7 dias após a indução da neuropatia pelo modelo SNI, não foi observado o aumento da expressão da enzima KMO como foi avaliado previamente no time course, figura 33. Enquanto no animais WT os níveis da enzima KMO está aumentada no RVM 7 dias após SNI nos animais IFN- $\gamma$ KO não. Na PAG, 7 dias após a indução da neuropatia pelo modelo SNI não foi observado diferenças significativas entre os níveis da enzima KMO dos animais WT e IFN- $\gamma$ KO, ambos aumentaram no $7^{\circ}$ dia após SNI, figura 34. Dessa forma, esses resultados indicam que a citocina IFN- $\gamma$ é crucial para o desenvolvimento da hipersensibilidade nociceptiva mecânica induzida por SNI, bem como para a indução da enzima IDO1 no RVM na PAG 
associada ao quadro de hipersensibilidade neuropática. Entretanto, a citocina IFN- $\gamma$ parece ter maior relevância na modulação da expressão da enzima KMO no RVM, visto que apenas nessa estrutura a sua expressão foi prejudicada após a deleção genética dessa citocina.

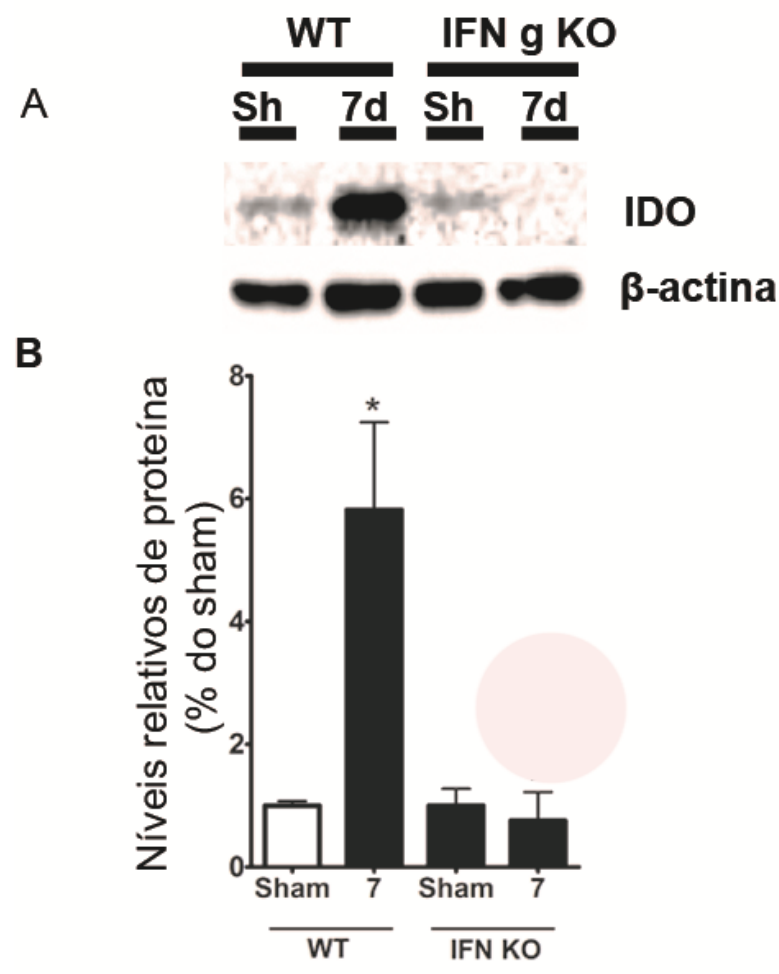

Figura 31. A expressão da enzima IDO1 no RVM após a lesão de nervos periféricos ( $7^{\circ}$ dia SNI) é dependente da citocina IFN- $\gamma$. Após cirurgia de lesão de nervos periféricos em camundongos WT e IFN $\gamma$ KO os RVM (n=3-4) foram removidos cirurgicamente no $7^{\circ}$ dia após a lesão e processados para a análise dos níveis proteicos da enzima IDO1 pela técnica de western blotting. A: Representação das bandas da IDO1 e $\beta$-actina na membrana de nitrocelulose. B: Os dados foram representados como densidade relativa, obtidos pelo cálculo da razão das densidades óticas e normalizados pelo grupo sham. * $p<0.05$ comparado com grupo sham WT. Teste ANOVA de uma via seguido pelo teste de Bonferroni para comparar os tratamentos. O nível de significância adotado foi de $p<0.05$. 


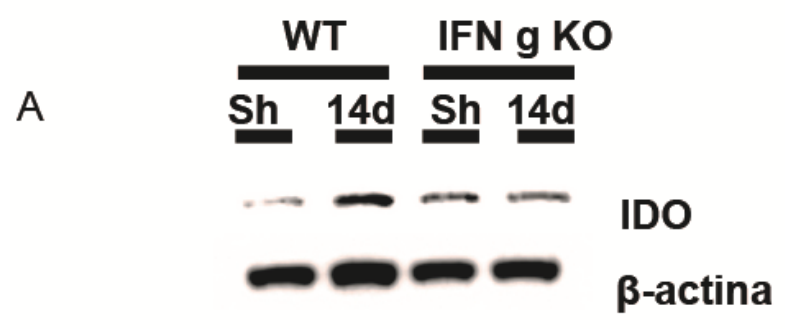

B

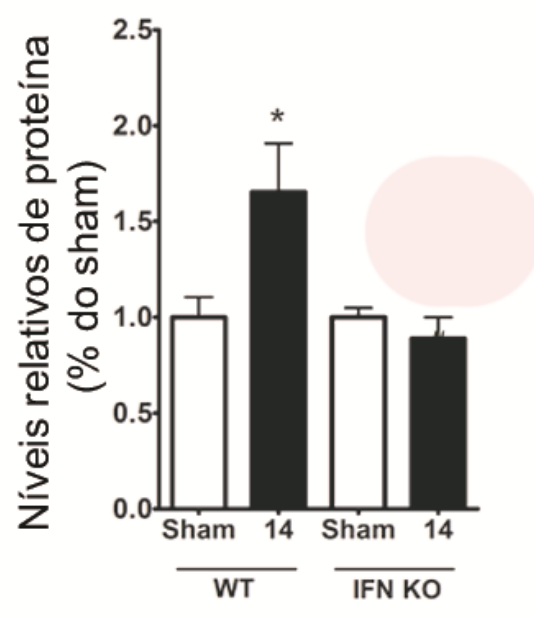

Figura 32. A expressão da enzima IDO1 na PAG após a lesão de nervos periféricos (14 ${ }^{\circ}$ dia SNI) é dependente da citocina IFN- $\gamma$. Após cirurgia de lesão de nervos periféricos em camundongos WT e IFN $\gamma \mathrm{KO}$ as PAG $(\mathrm{n}=4)$ foram removidas cirurgicamente no $14^{\circ}$ dia após a lesão e processados para a análise dos níveis proteicos da enzima IDO1 pela técnica de western blotting. A: Representação das bandas da IDO1 e $\beta$-actina na membrana de nitrocelulose. B: Os dados foram representados como densidade relativa, obtidos pelo cálculo da razão das densidades óticas e normalizados pelo grupo sham. $* p<0.05$ comparado com grupo sham WT. Teste ANOVA de uma via seguido pelo teste de Bonferroni para comparar os tratamentos. O nível de significância adotado foi de $p<0.05$ 

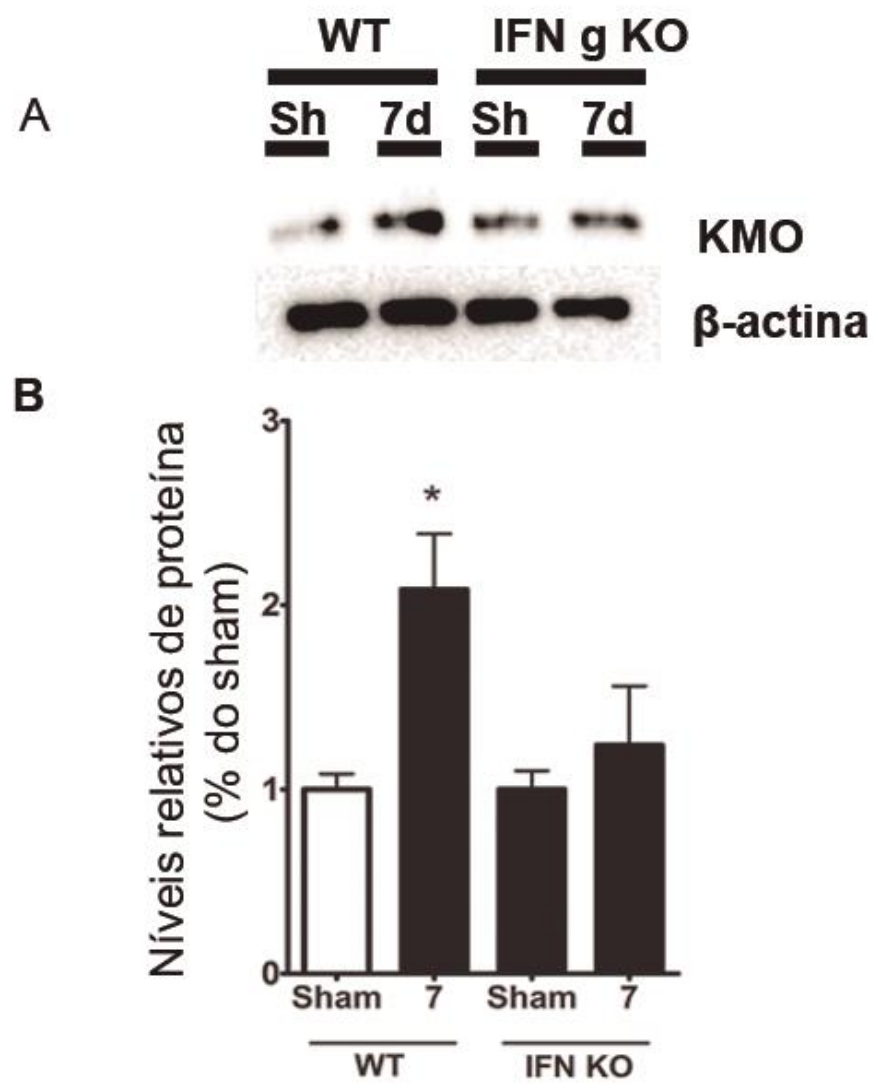

Figura 33. A expressão da enzima KMO no RVM após a lesão de nervos periféricos ( $7^{\circ}$ dia SNI) é dependente da citocina IFN- $\gamma$. Após cirurgia de lesão de nervos periféricos em camundongos WT e IFN $\gamma$ KO as PAG $(n=4)$ foram removidas cirurgicamente no $7^{\circ}$ dia após a lesão e processados para a análise dos níveis proteicos da enzima KMO pela técnica de western blotting. A: Representação das bandas da KMO e $\beta$-actina na membrana de nitrocelulose. B: Os dados foram representados como densidade relativa, obtidos pelo cálculo da razão das densidades óticas e normalizados pelo grupo sham. $* p<0.05$ comparado com grupo sham WT. Teste ANOVA de uma via seguido pelo teste de Bonferroni para comparar os tratamentos. O nível de significância adotado foi de $p<0.05$ 


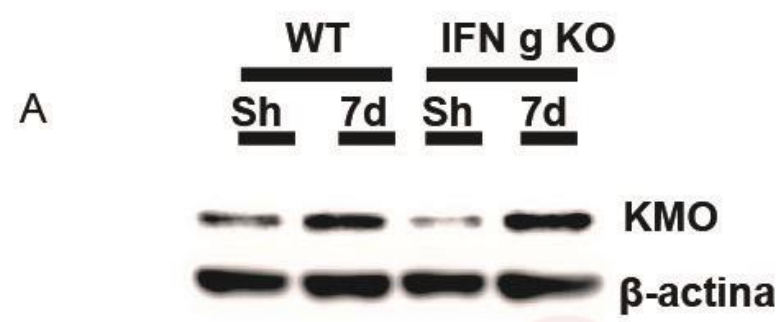

B

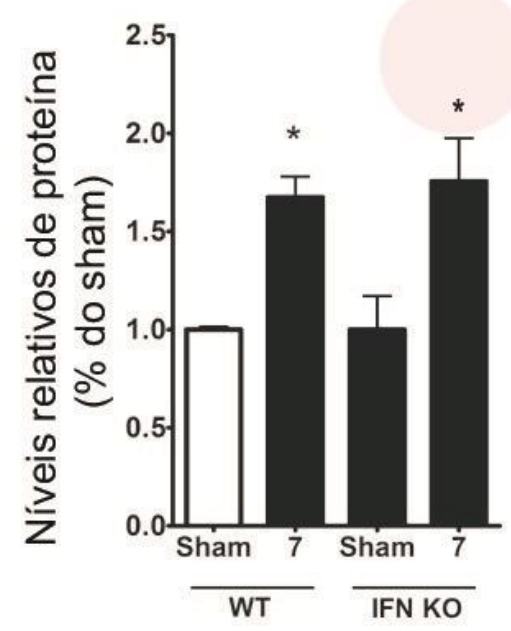

Figura 34. A expressão da enzima KMO na PAG após a lesão de nervos periféricos ( $7^{\circ}$ dia SNI) independe da citocina IFN- $\gamma$. Após cirurgia de lesão de nervos periféricos em camundongos WT e IFN $\gamma \mathrm{KO}$ as $\mathrm{PAG}(\mathrm{n}=4)$ foram removidas cirurgicamente no $7^{\circ}$ dia após a lesão e processados para a análise dos níveis proteicos da enzima KMO pela técnica de western blotting. A: Representação das bandas da KMO e $\beta$-actina na membrana de nitrocelulose. B: Os dados foram representados como densidade relativa, obtidos pelo cálculo da razão das densidades óticas e normalizados pelo grupo sham. * $p<0.05$ comparado com grupo sham WT. Teste ANOVA de uma via seguido pelo teste de Bonferroni para comparar os tratamentos. O nível de significância adotado foi de $p<0.05$ 


\subsection{Avaliação do efeito da microinjeção de IFN- $\gamma$ no espaço intracerebroventricular sob o limiar mecânico de camundongos naives}

Estudos prévios, sugerem que a administração de IFN- $\gamma$ na medula espinal induz hipersensibilidade nociceptiva mecânica por um longo período que se a assemelha a alodinia neuropática (Tsuda et al., 2009). Outros estudos realizados pelo nosso grupo, Fonseca et al 2015 (resultados não publicados) mostraram que animais deficientes para a citocina ou para o receptor do IFN- $\gamma$ são resistentes ao desenvolvimento da dor neuropática quando comparado com animais WT. Nesse mesmo estudo, foi demonstrado que a injeção intratecal de IFN- $\gamma$ induz hiperalgesia e está relacionada com o aumento da expressão da enzima IDO1.

Assim, a microinjeção de IFN- $\gamma$ no espaço i.c.v. na dose de $100 \mathrm{U}$ induziu hipersensibilidade nociceptiva mecânica 5, 7 horas e 1 dia após a microinjeção, figura 33 . A dose de $1000 \mathrm{U}$ induziu uma maior hipersensibilidade nociceptiva mecânica quando comparado com a dose menor, a hipersensibilidade nociceptiva mecânica estendeu-se da 3 hora até o 7 dia após a microinjeção da citocina, figura 35. Dessa forma, somado aos resultados que indicam que animais IFN- $\gamma \mathrm{KO}$ possuem menor hipersensibilidade nociceptiva mecânica após a lesão de nervos periféricos, bem como menor expressão de IDO no RVM e na PAG, a microinjeção de IFN- $\gamma$ no espaço i.c.v. induziu hipersensibilidade nociceptiva mecânica, sugerindo o papel dessa citocina nessa doença. 


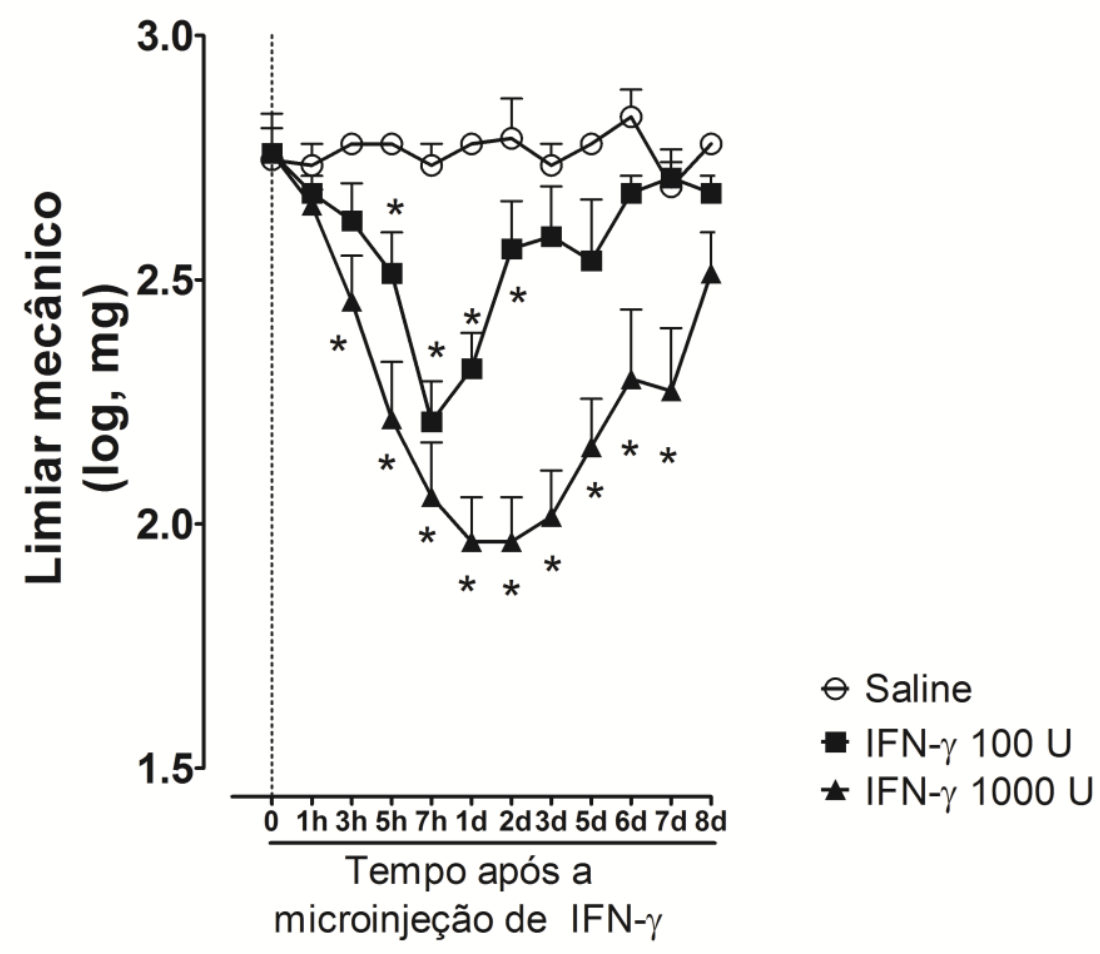

Figura 35. A microinjeção de IFN- $\gamma$ no espaço intracerebroventricular causa hipersensibilidade nociceptiva mecânica de camundongos naives. Curva doseresposta para avaliar a hipersensibilidade nociceptiva mecânica em camundongos, após receberem doses crescentes de IFN- $\gamma$ (100 e 1000 U/uL no espaço i.c.v.) ou salina. A avaliação do liminar nociceptivo mecânico foi realizada em $0,1,3,5$, e 7 horas, 1, 2, 3, $5,6,7$ e 8 dias após as injeções $(\mathrm{n}=5)$. * $p<0.05$ comparado com o grupo salina. Teste ANOVA de duas vias seguido pelo teste de Bonferroni para comparar os tratamentos. $\mathrm{O}$ nível de significância adotado foi de $p<0.05$. 


\subsection{O desenvolvimento da hipersensibilidade nociceptiva mecânica após a lesão de nervos periféricos está associada a um comportamento depressivo}

Sabe-se que após a lesão de nervos periféricos camundongos desenvolvem um comportamento do tipo depressivo o qual pode ser avaliado pelo teste do nado forçado, ainda, a depressão aumenta significativamente o risco da dor se cronificar, sendo assim uma comorbidade. Além disso, indivíduos depressivos e que sofrem de dores crônicas possuem níveis elevados da enzima IDO1 no plasma, bem como do seu metabolito, a quinurenina (Kim et al., 2012). Dessa forma, avaliamos se animais WT e geneticamente deficientes para a citocina IFN- $\gamma$ e CD4+ apresentam o comportamento do tipo depressivo no teste do nado forçado e se as enzimas IDO1 e KMO estão envolvidas no desenvolvimento dessa comorbidade.

Em 7(F 6, $35=48,95$, p <0,05, ANOVA de uma via seguido do pós-teste de Bonferroni ,figura 36), 14 (F 6, 35 = 124,7, p<0,05, ANOVA de uma via seguido do pósteste de Bonferroni, figura 37) e 21 (F 6, $35=112,6$, p<0,05, ANOVA de uma via seguido do pós-teste de Bonferroni, figura 38) dias, animais WT, IFN- $\gamma$ KO e CD4 KO foram submetidos a lesão de nervos periféricos e um grupo controle que recebeu o antidepressivo Imipramina (10 mg/kg i.p.) foram submetidos ao teste do nado forçado, 5 min, no qual foi avaliado o tempo de imobilidade. Foi observado que os animais WT após a lesão de nervos apresentam um comportamento do tipo depressivo em relação ao grupo Sham WT, representado pelo aumento do tempo de imobilidade; os animais CD4 KO Sham e SNI apresentavam um pequeno tempo de imobilidade, sendo o tempo dos CD4 KO SNI similar ao do Sham WT; os animais IFN- $\gamma$ KO Sham/SNI apresentam um curto tempo de imobilidade nesse teste, sendo os resultados similares aos observados com a 
administração de Imipramina. Esses resultados foram similares nos três momentos avaliados, 7, 14 e 21 dias após SNI.

Com o intuito de avaliar a participação das enzimas IDO1 e KMO no desenvolvimento da comorbidade depressão associada a lesão de nervos periféricos. Animais WT SNI receberam os seguintes tratamentos: veículo; 3 mg/animal de 1-metiltriptofano sistemicamente; $900 \mathrm{nmol}$ de Norharmane no espaço i.c.v.; animais IDO1 KO; 300mg/kg de JM6 sistemicamente; $300 \mathrm{nmol}$ de Ro61-8048 no espaço i.c.v; $10 \mathrm{mg} / \mathrm{kg}$ de imipramina sistemicamente. Os animais foram submetidos ao teste durante 3 horas aproximadamente da administração, isto é, no pico da reversão da hiperalgesia avaliado anteriormente. Foi observado que o tratamento com os inibidores das enzimas IDO1 e KMO sistemicamente e localmente (espaço i.c.v.) reduziu o tempo de imobilidade no teste do nado forçado, logo, tiveram um efeito antidepressivo, sendo efeito da microinjeção dos inibidores no espaço i.c.v. mais eficiente em relação ao sistêmico (F 7, $43=65,7 \mathrm{p}<0,05$, ANOVA de uma via seguido do pós-teste de Bonferroni, figura 39). 


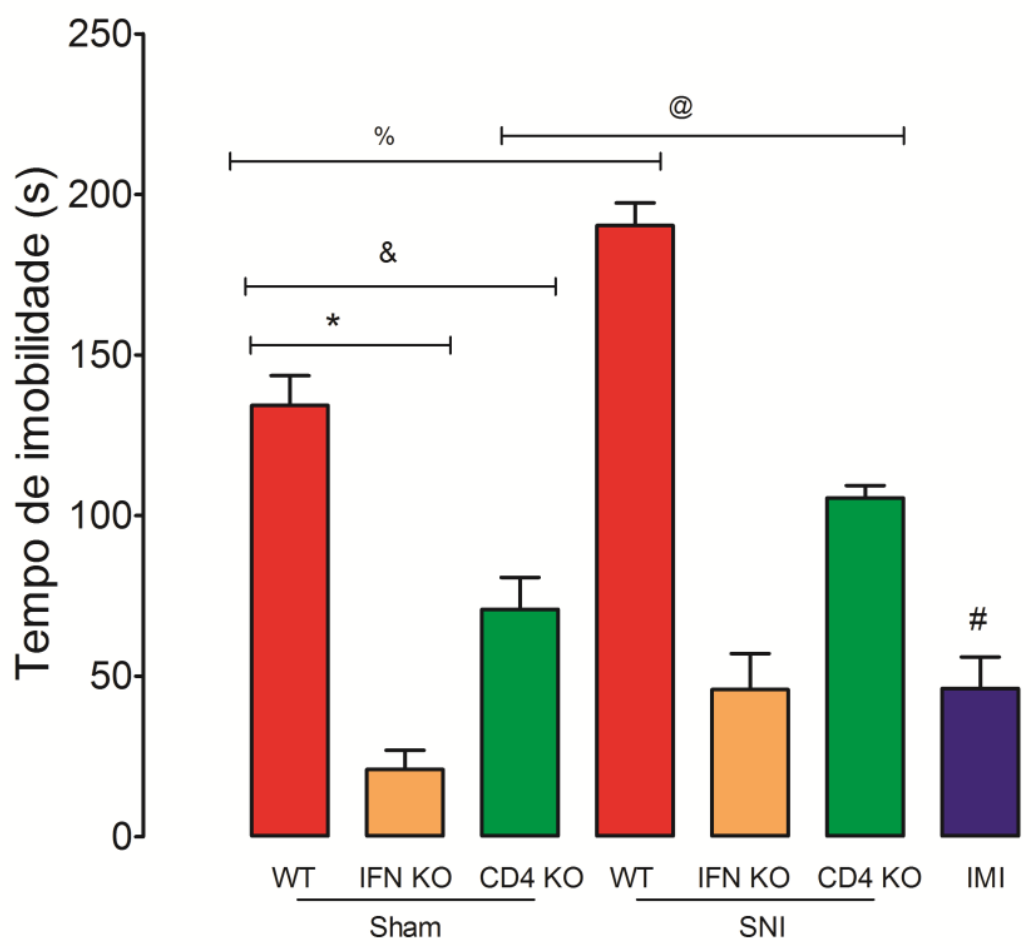

Figura 36. SNI ( 7 dias) induz um comportamento do tipo “depressivo" em camundongos WT, mas não em IFN- $\gamma$ KO e CD4 KO. 7 dias após a cirurgia de SNI ou falsa cirurgia(grupo sham), camundongos WT, IFN- $\gamma$ KO, CD4 KO, bem com o grupo que recebeu o antidepressivo Imipramina foram submetidos ao teste do nado forçado. Os dados foram representados como o tempo de imobilidade em segundos ao longo de 300 segundos do teste. ${ }^{*} p<0.05$ grupo WT sham comparado com grupo IFN KO Sham; $\$ p$ $<0.05$ grupo WT sham comparado com grupo CD4 KO Sham; \% $p<0.05$ grupo WT sham comparado com grupo WT SNI; @ $p<0.05$ grupo CD4 KO Sham comparado com grupo CD4 KO SNI; Teste ANOVA seguido pelo teste de Bonferroni para comparar os tratamentos. O nível de significância adotado foi de $p<0.05$. 


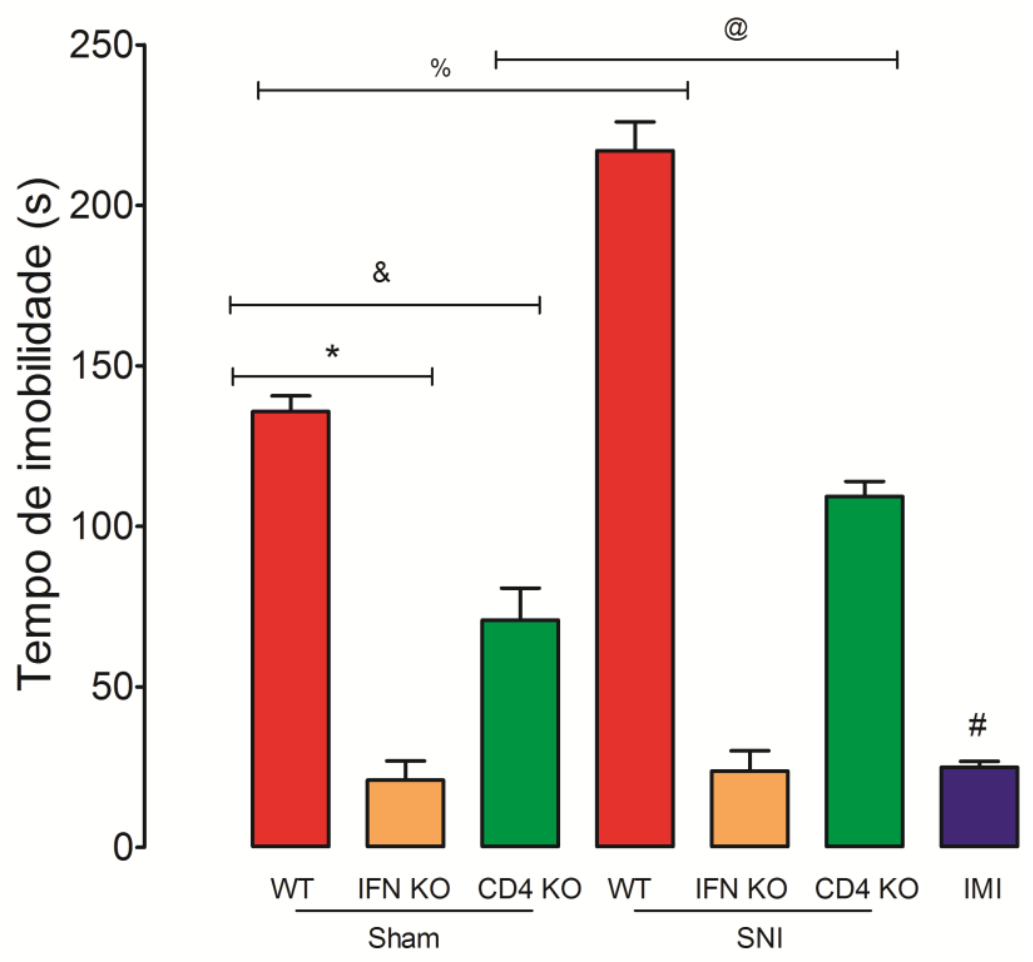

Figura 37. SNI ( 14 dias) induz um comportamento do tipo "depressivo" em camundongos WT, mas não em IFN- $\gamma$ KO e CD4 KO. 14 dias após a cirurgia de SNI ou falsa cirurgia, grupo sham, camundongos WT, IFN- $\gamma \mathrm{KO}, \mathrm{CD} 4 \mathrm{KO}$, bem com o grupo que recebeu o antidepressivo Imipramina foram submetidos ao teste do nado forçado. Os dados foram representados como o tempo de imobilidade em segundos ao longo de 300 segundos do teste. ${ }^{*} p<0.05$ grupo WT sham comparado com grupo IFN KO Sham; $\$ p$ $<0.05$ grupo WT sham comparado com grupo CD4 KO Sham; \% $p<0.05$ grupo WT sham comparado com grupo WT SNI; @ $p<0.05$ grupo CD4 KO Sham comparado com grupo CD4 KO SNI; Teste ANOVA seguido pelo teste de Bonferroni para comparar os tratamentos. O nível de significância adotado foi de $p<0.05$. 


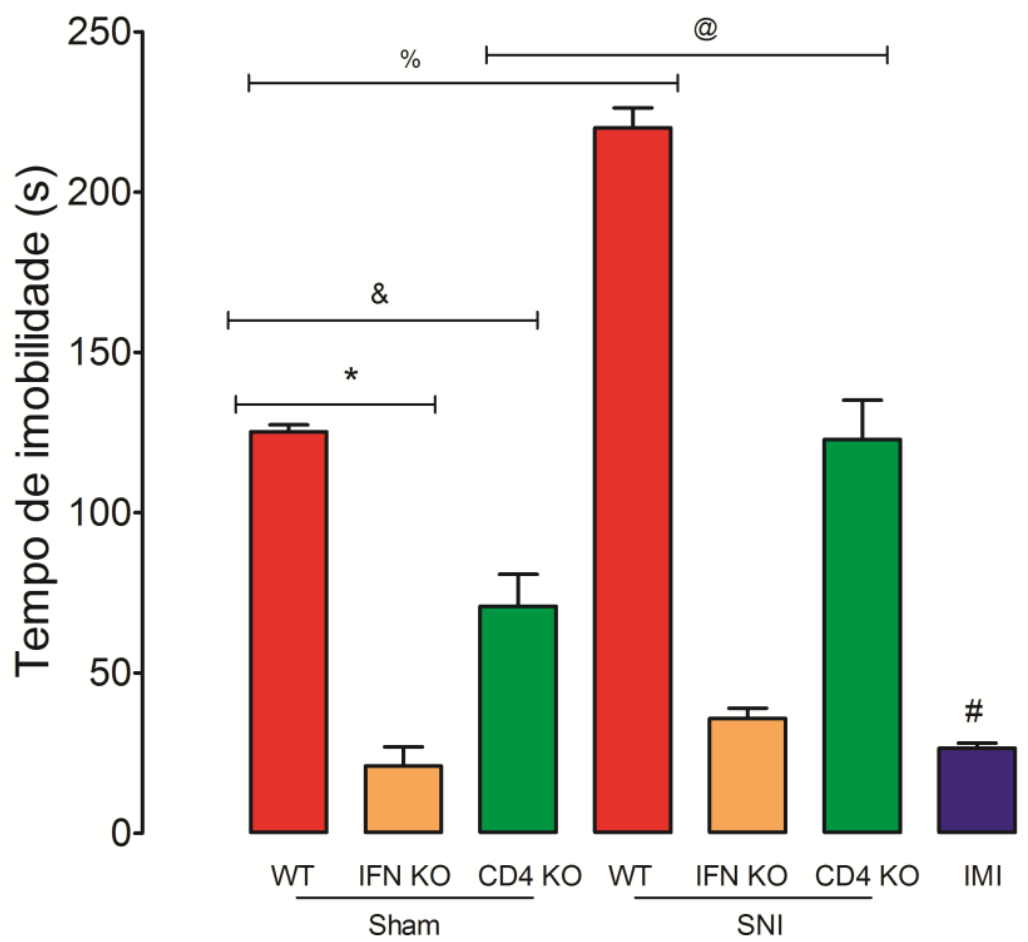

Figura 38. SNI (21 dias) induz um comportamento do tipo "depressivo" em camundongos WT, mas não em IFN- $\gamma$ KO e CD4 KO. 21 dias após a cirurgia de SNI ou falsa cirurgia, grupo sham, camundongos WT, IFN- $\gamma$ KO, CD4 KO, bem com o grupo que recebeu o antidepressivo Imipramina foram submetidos ao teste do nado forçado. Os dados foram representados como o tempo de imobilidade em segundos ao longo 300 segundos do teste. ${ }^{*} p<0.05$ grupo WT sham comparado com grupo IFN KO Sham; $\$ p$ $<0.05$ grupo WT sham comparado com grupo CD4 KO Sham; \% $p<0.05$ grupo WT sham comparado com grupo WT SNI; @ $p<0.05$ grupo CD4 KO Sham comparado com grupo CD4 KO SNI; Teste ANOVA seguido pelo teste de Bonferroni para comparar os tratamentos. O nível de significância adotado foi de $p<0.05$. 


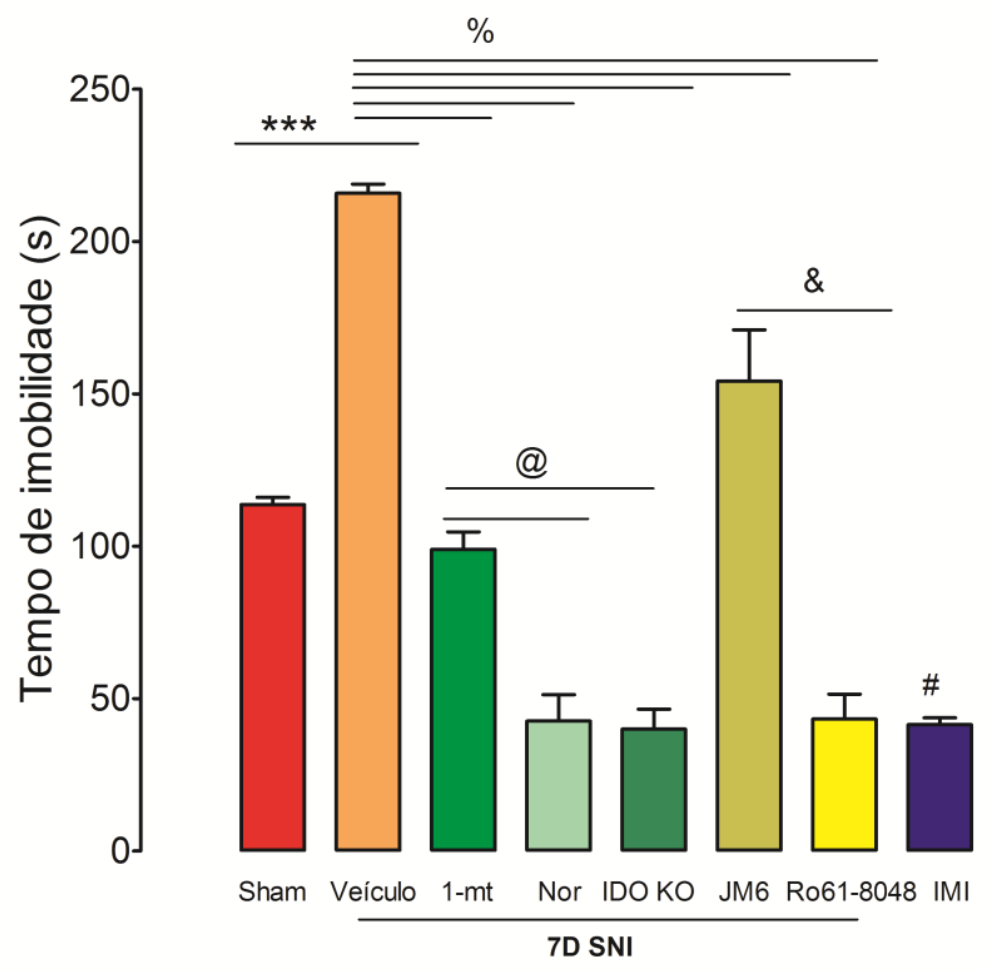

Figura 39. O comportamento depressivo induzido pela lesão de nervos periféricos depende das enzimas IDO1 e KMO. 7 dias após a cirurgia de SNI ou falsa cirurgia, grupo sham, camundongos WT SNI receberam o tratamento os inibidores da IDO1 (3mg/ animal 1-metil-triptofano, sistêmico; 900 nmol de Norharmane, espaço i.c.v) ou de inibidores da KMO (300 mg/kg JM6, sistêmico; 300 nmol de Ro61-8048, espaço i.c.v.), bem com o grupo que recebeu o antidepressivo Imipramina e animais geneticamente deficientes para a enzima IDO1 foram submetidos ao teste do nado forçado. Os dados foram representados como o tempo de imobilidade em segundos ao longo dos últimos 240 segundos de 360 segundos do teste. $* \$ \% p<0.05$ comparado com grupo SHAM.\# $p<0.05$ comparado com grupo WT SNI 21 dias. Teste ANOVA seguido pelo teste de Bonferroni para comparar os tratamentos. O nível de significância adotado foi de $p<0.05$. 


\section{DISCUSSÃO}




\section{DISCUSSÃO}

A dor é essencial para a sobrevivência, pois tem o objetivo de minimizar o dano tecidual frente a algum estímulo nocivo e por conseguinte, prolongar a sobrevivência. O início da dor resulta na adoção de comportamentos que pode tanto remover o organismo de um "ambiente perigoso" e permitir a reparação tecidual; por exemplo, descansando um membro quebrado para que osso possa reparar-se, quanto proteger os animais do meio ambiente, ensinando-nos que situações e comportamentos são susceptíveis de causar ferimentos. Dessa forma, a dor é um mecanismo homeostático altamente benéfico para a sobrevivência, sendo isso comprovado ao analisar os indivíduos que apresentaram mutações em genes relacionados com o controle/processamento da dor (Nav 1.7, por exemplo) e dessa forma eles eram insensíveis a dor. Essa insensibilidade era muito danosa uma vez que impedia a autopreservação dos mesmos frente a estímulos nocivos e reduzindo drasticamente a qualidade de vida (Cox et al., 2006).

Em algumas situações a dor perde a sua função homeostática, tornando-se uma condição crônica, uma condição debilitante com duração superior a 3 meses na ausência de um estímulo doloroso (Clark et al., 2014). Dentre as dores crônicas, destacase a dor neuropática.

O início da dor neuropática correlaciona-se com o aumento no número de disparos ectópicos espontâneos de potenciais de ação. Alguns trabalhos mostram que a excitabilidade exacerbada e a geração aumentada de potenciais ectópicos decorrem da liberação de fatores de crescimento que aumentam a expressão, distribuição e cinética de canais de $\mathrm{Ca}^{2+}$ e $\mathrm{Na}^{+}$no sítio da lesão e nas fibras lesadas (Vabnick et al., 1996; Hinson 
et al., 1997). Também ocorre alteração na expressão/liberação de neurotransmissores, citocinas pró-inflamatórias que, em conjunto, contribuem para a sensibilização e ativação das fibras sensoriais de pequeno e grosso calibre (Li et al., 2000). Um detalhe importante é que a dor neuropática normalmente não é revertida com os tratamentos convencionais para o alivio da dor, como anti-inflamatórios, por exemplo (Woolf et al., 1999; Woolf, 2004).

Dentre vários componentes que podem participar do desenvolvimento da dor neuropática, destaca-se o desequilíbrio na via descendente inibitória da dor. Essa via é composta pela substância cinzenta periaquedutal (PAG), o núcleo magno da rafe e as estruturas adjacentes do bulbo formando a bulbo ventromedial rostral (RVM) com suas projeções para o corno dorsal da medula espinal, constituem parte do sistema de controle descendente da dor (Vanegas et al., 2004). Sob circunstâncias normais, a via descendente fornece um controle negativo de sinais nociceptivos a nível medular, atenuando os sinais subsequentes e impedindo a dor excessiva (Fields et al., 1978). Os principais neurotransmissores dessa via são a serotonina e a noradrenalina (Fields et al., 1991; Millan, 2002)

A molécula 5-HT é sintetizada a partir do aminoácido triptofano, e desempenha diversas funções, tanto no SNC quanto em outros sistemas do organismo. No SNC, mais especificamente no sistema límbico, controla reações de ansiedade, medo, depressão, sono e percepção à dor. Assim, numerosos estudos têm sido realizados no intuito de identificar o papel específico da 5-HT na modulação ou tratamento da dor (Wei et al., 2012).

Um importante fator que poderia modular negativamente o controle descendente da dor após a lesão de nervos periféricos seria a degradação do aminoácido 
essencial para a formação de serotonina, o triptofano, pela ativação da via das quinureninas.

Nesse trabalho foi observado após a lesão de nervos periféricos o aumento da expressão da enzima IDO1 no RVM e na PAG, assim como uma hipersensibilidade mecânica após a lesão de nervos periféricos em relação ao grupo controle, sham. Dessa forma, a inibição farmacológica da IDO1 localizada nessas regiões supraespinais com Norhamane, reduziu significativamente a hipersensibilidade mecânica dos animais neuropáticos no $7^{\circ}, 14^{\circ}$ e $21^{\circ}$ dia após a indução da neuropática. Corroborando com esses achados, animais geneticamente deficientes para enzima IDO1 não desenvolvem hipersensibilidade mecânica após a lesão de nervos periféricos.

Nesse sentido, Kim e colaboradores (2012) que demonstraram em uma condição distinta de dor crônica, a dor crônica inflamatória (injeção de CFA na pata) ocorre o aumento da expressão da enzima IDO1 no hipocampo ao longo do processo doloroso e animais IDO1 KO não desenvolviam dor crônica inflamatória frente a injeção de CFA, sugerindo a participação dessa enzima no desenvolvimento da dor inflamatória crônica (Kim et al., 2012). Diferentemente de Kim, observamos que após a lesão de nervos periféricos ocorre o aumento da expressão da enzima IDO1 no RVM e na PAG, mas não hipocampo. Sugerindo que no caso da neuropatia, apesar de os animais terem um comportamento depressivo ocorre o aumento da enzima IDO1 apenas em regiões envolvidas com o controle descendente da dor (Norman et al., 2010). Recentemente, foi demonstrado que pacientes com síndrome dolorosa complexa regional apresentavam baixos níveis plasmáticos de L-triptofano em relação ao grupo controle, nesse mesmo trabalho foi demonstrado que esses pacientes apresentavam a relação Ltriptofano/quinurenina aumentada, sugerindo uma intensa ativação da via das 
quinureninas com consumo de triptofano, formação de quinurenina e possivelmente QUIN (Alexander et al., 2013). Portanto, esses resultados sugerem que a enzima IDO1 localizada em regiões supraespinais participa do processo neuropático após a lesão de nervos periféricos.

Além disso, sabe-se que outros mecanismos possam estar envolvidos na manutenção da neuropatia nesse momento como o BDNF, receptores $\mathrm{P} 2 \mathrm{X} 4 \mathrm{e}$ hiperatividade glial (Tsuda et al., 2003; Ulmann et al., 2008; Ikeda et al., 2012; Masuda et al., 2014) e outras regiões como a medula espinal (resultados não publicados, Souza et al, 2015).

Possivelmente o efeito antinociceptivo do Norharmane seja devido o aumento da disponibilidade de triptofano, levando ao aumento nos níveis de 5-HT de regiões suprasepinais, aumentanto dessa forma a eficência da via inibitória descendente da dor e pelo fato de inibir a produção de quinurenina, conseguentemente a de ácido quinolinico, dessa forma ao reduzir a disponibilidade de ácido quinolínico reduziria a ativação de receptores NMDA que ativaria a via descendente facilitatoria da dor contribuindo para o quadro neuropático.

Ao avaliar se a expressão da enzima KMO correlaciona-se com o desenvolvimento da dor neuropática, foi observado o aumento da expressão da enzima KMO no RVM e na PAG após a lesão de nervos periféricos, assim como aumento da hipersensibilidade mecânica dos animais neuropáticos em relação ao grupo controle, sham.

Para verificar a participação dessa enzima no processo neuropático foi administrado num primeiro momento o JM6 pela via oral e em um segundo momento o Ro61-8048 no espaço i.c.v. sendo que ambos os tratamentos reduziram 
significativamente a hipersensibilidade mecânica induzida por SNI. Dessa forma, o efeito antinociceptivo do JM6 e do Ro61-8048 possivelmente a redução dos níveis de ácido quinolinico em regiões suprasepinais que ativaria a via descendente facilitatória ou pelo acúmulo de quinurenina que seria convertida a ácido quinurênico, que inibiria a ativação da via desdente facilitatória da dor (Pineda-Farias et al., 2013b).

Após bloquear a enzima KMO e reduzir a hipersensibilidade mecânica desencadeada pela lesão de nervos seria um indicativo da participação do QUIN no desenvolvimento da neuropatia pois sabe-se que o metabolismo da quinurenina é preferencialmente direcionada para a formação de QUIN (Hughes et al., 2012). Nesse sentido, foi demonstrado níveis plasmáticos elevados glutamato em pacientes com síndrome dolorosa complexa regional sugerindo a relevância do aumento da neurotransmissão glutamatérgica no desenvolvimento da neuropatia (Alexander et al., 2013), entretanto não há até o momento na literatura evidência alguma que o QUIN participe no desenvolvimento da dor neuropática.

Sabe-se que ao inibir a enzima KMO reduz-se os níveis de QUIN, entretanto também ocorre o aumento dos níveis de quinurenina e posteriormente de ácido quinurênico (KYNA)(Chiarugi et al., 2001). O KYNA é um agente neuroprotetor endógeno presente no SNC age principalmente como um antagonista no sítio modulatório da glicina no receptor NMDA (Moroni et al., 1991; Stone, 1993). Alguns estudos demonstraram que antagonistas dos receptores NMDA possuem efeitos antinociceptivo em modelos da dor neuropática, causando em alguns casos problemas motores (Mao et al., 1992; Hao et al., 1996; Chaplan et al., 1997).

Corroborando com esses achados foi demonstrado que a administração de KYNA reduz a dor inflamatória (Mecs et al., 2009), diminui a nocicepção no teste da 
placa quente, tail-flick e contorções abdominais induzidas por ácido acético (Heyliger et al., 1998; Cosi et al., 2011), por último foi demonstrado que a administração combinada de L-quinurenina e probenicida reduz a hipersensibilidade induzila pela lesão de nervos periféricos pelo acúmulo de KYNA no SNC (Pineda-Farias et al., 2013a).

Com o intuito de confirmar a hipótese que o QUIN era o principal metabólito da via das quinureninas que participa da hipernocicepção induzida pela lesão de nervos periféricos. Animais naives receberam a microinjeção de doses crescentes dos principais metabólitos da via das quinureninas: quinurenina, ácido 3-hidroxiantranlínico e QUIN no espaço i.c.v. Foi observado a seguinte ordem em induzir hipersensibilidade mecânica: QUIN>>>ácido 3-hidroxiantranlinico>quinureninas.

Além disso, demonstramos que a hipersensibilidade induzida por QUIN é dependente da ativação de receptores NMDA, pois o pré-tratamento supraespinal com MK-801 atenuou parcialmente o efeito nociceptivo desse metabólito. Outros trabalhos demonstraram anteriormente que o QUIN aumenta os níveis de glutamato através do "overrelease" de glutamato no estriado e no córtex, possivelmente por mecanismos présinápticos, por exemplo (Fedele et al., 1993; Chen et al., 1999).

Sabe-se que a ligação parcial do nervo isquiático induz o aumento da fosforilação da subunidade NR1 e NR2b no corno dorsal da medula espinal (Ultenius et al., 2006; Liu et al., 2008). A fosforilação da subunidade NR1 está relacionada com o aumento da eficiência sináptica e desenvolvimento da sensibilização central em 7 dias após a lesão de nervos (Gao et al., 2005). Além disso, atualmente está claro a participação das vias glutamatérgicas no desenvolvimento de diferentes tipos de dores crônicas. (Smith et al., 2002; Baron et al., 2010). Foram relatados níveis elevados de glutamato na medula 
espinal de ratos durante a inflamação (Pitcher et al., 2007) e após a lesão de nervos periféricos (Hudson et al., 2002).

Sabendo que o QUIN era o principal metabólito da via das quinureninas responsável pela hipernocicepção induzida pela lesão de nervos periféricos, modelo SNI, investigamos os mecanismos pelos quais o QUIN causava hipernocicepção. Partindo-se do pressuposto que haveria um desbalanço entre a via descente facilitatória e inibitória da dor na dor neuropática. Nesse contexto, o QUIN ativaria a via descendente facilitatória de dor e a degradação de triptofano pela enzima IDO1, consequentemente redução dos níveis de 5-HT, diminuindo a eficiência da via descendente inibitória da dor.

Comprovamos que o QUIN ativa a via descendente facilitatória realizando o seguinte experimento: em um primeiro momento realizamos a injeção i.t. de $20 \mathrm{nmol}$ de LY-278,584 (antagonista seletivos dos receptores 5-HT3a) seguido pela microinjeção de $80 \mathrm{nmol}$ de QUIN no espaço i.c.v. Observamos que o pré-tratamento com LY-278,584 atenuou parcialmente a hipersensibilidade induzida por QUIN. Sugerindo que o QUIN ativa a via descendente facilitatória, liberando 5-HT no corno dorsal, ativando receptores 5-HT3a e facilitando a transmissão nociceptiva.

A manutenção da dor neuropática é atribuída a ativação da via descendente facilitatória resultante de alterações plásticas em estruturas supraespinais, RVM (Vanderah et al., 2001). Estímulos nocivos ativam a circuitaria serotonérgica presente no RVM, causando o aumento no turnover espinal de 5-HT e contribuindo para a facilitação descendente (Zhuo et al., 1997; Mason, 1999).

A influência da via descendente serotonérgica sobre a transmissão nociceptiva depende do tipo de receptor ativado (Millan, 2002). Alguns estudos sugerem que a ativação de receptores 5-HT3a é relevante para a manutenção da dor crônica (Green 
et al., 2000; Zeitz et al., 2002). Além disso, receptores 5-HT3a presentes na medula espinal compõem a via descendente facilitatória e está relacionado com o aumento da duração das condições de dor crônica(Suzuki et al., 2002). Por ultimo, a depleção de 5HT por 5,7-DHT elimina do efeito antinociceptivo do ondasentron (antagonista 5-HT3a), sugerindo que o efeito antinociceptivo do ondasentrona recessita da 5-HT possivelmente ao inibir o 5-HT3a na via descendente facilitatória e aumentando a eficiência da via descendente inibitória

A redução da eficiência da via descendente inibitória foi avaliada realizando o seguinte experimento: animais submetidos a cirurgia de SNI foram tratados sistemicamente com 1-MT, Fluoxetina ou 1-MT+Fluoxetina. Foi observado que o 1-MT e a fluoxetina reduziram a hipersensibilidade neuropática de modo similar, entretanto a administração de ambos potencializou o efeito antinociceptivo, mostrando um efeito sinérgico, pois a inibição da IDO1 aumentaria os níveis de triptofano, reduziria os de QUIN, a fluoxetina aumentaria os níveis de 5-HT nas fendas sinápticas e o tratamento combinado causou tanto o aumento dos níveis de triptofano, consequentemente de 5-HT. Dessa forma, ao restaurar os níveis de 5-HT, restaurou-se a eficiência da via descendente inibitória da dor. 5-HT apresenta efeitos inibitórios quando ativa receptores 5-HT1 e 5HT2, caracterizado pelo efeito antinociceptivo e ativação da via descendente inibitória da dor (Oatway et al., 2004).

A primeira evidência que as quinureninas teriam alguma função no cérebro foi descrita por Lapin (1978) que observou convulsões provocadas pela administração intracerebroventricular de QUIN (Lapin, 1978). Posteriormente, em 1981, Stone e Perkins demonstraram que o QUIN era um agonista NMDA (Stone et al., 1981), Schwarcz e colaboradores foram os primeiros a demonstrar que o QUIN causa lesões em 
células neuronais (Schwarcz et al., 1983). A administração intra-arterial micromolar ou milimolar de QUIN resulta em um acúmulo insignificante desse metabólito no cérebro, sugerindo que a barreira hematoencefálica protege o cérebro do QUIN periférico (Foster et al., 1984).

Dessa forma, o QUIN é capaz de aumentar os níveis de glutamato ao inibir a captação por astrócitos e aumentar a liberação, aumentado consequentemente a concentração de QUIN no microambiente, causando excitotoxidade (Tavares et al., 2000; Tavares et al., 2002) . Em 2012, Takaki e colaboradores demonstraram que micróglias liberam glutamato que diminui os níveis de transportadores de glutamato em astrócitos durante a neuroinflamação, isto é, facilita o aumento dos níveis extracelulares de glutamato durante a neuroinflamação (Takaki et al., 2012).

Nesse sentido, o aumento dos níveis de QUIN decorrente da ativação das via das quinureninas poderia ser relevante para o desenvolvimento da hipersensibilidade associada a lesão de nervos, pois ativaria receptores NMDA, facilitando o desenvolvimento da sensibilização central (fosforilação de subunidades do receptor NMDA, por exemplo), aumentando os níveis de glutamato (aumento da liberação/diminuição da captação) e consequentemente propiciando o desenvolvimento da dor neuropática.

Dessa forma o QUIN agiria em neurônios ativando a circuitaria glutamatérgica, de modo sinérgico aumentaria os níveis de glutamato ao facilitar a liberação e inibir a receptação por astrócitos. Portanto, o efeito nociceptivo dos QUIN é via ativação da via descendente facilitatória via liberação de 5-HT/5-HT3a e da modulação da atividade glial. 
Embora os mecanismos responsáveis pela manutenção da dor neuropática sejam pouco entendidos até o momento, uma série de evidências que esse tipo de dor esteja associado a um infiltrado de células $\mathrm{T} \mathrm{CD} 4^{+}$:

- Primeiro, essas células atravessam a barreira hematoencefálica e infiltrariam em regiões envolvidas com a modulação da dor, principalmente a medula espinal (Costigan et al., 2009a).

- Segundo, animais que não possuem células $\mathrm{T}$ funcionais apresentam menor hipersensibilidade mecânica.

- Terceiro, essa hipersensibilidade reduzida pode ser revertida pela transferência de células T CD4+ provenientes de animais neuropáticos (Cao et al., 2008; Zhang et al., 2014).

- Por último, animais geneticamente deficientes para o receptor do IFN- $\gamma$ apresentam menor hipersensibilidade mecânica após a lesão de nervos periféricos (Tsuda et al., 2009).

Em um primeiro momento os animais foram submetidos a lesão de nervos periféricos, modelo SNI, em animais geneticamente deficientes para células T CD4 ${ }^{+}, \mathrm{T}$ $\mathrm{CD}^{+}$, B e WT, foi observado que apenas os animais $\mathrm{T} \mathrm{CD} 4^{+} \mathrm{KO}$ apresentavam menor hipersensibilidade mecânica em relação aos demais grupos.

Baseando-se nesse achado a PAG e o RVM desses animais $\mathrm{T} \mathrm{CD} 4^{+} \mathrm{KO}$ bem como de animais WT foram retiradas e foi realizado um western blotting para enzima IDO1, constatando que os animais $\mathrm{T} \mathrm{CD}^{+} \mathrm{KO}$ não apresentam os níveis da enzima IDO1 aumenta após a indução da neuropatia nessas regiões em relação aos animais WT. Além disso, possivelmente apresentam menor dor por apresentarem menores níveis da enzima 
IDO1 e da citocina IFN- $\gamma$, pois essa citocina além de ser produzida por células T CD4 ${ }^{+}$é uma potente indutora das enzimas da via das quinureninas(Takikawa et al., 1988).

Com o intuito de avaliar a participação da citocina IFN- $\gamma$ no contexto de desenvolvimento de hiperalgesia mecânica e indução das enzimas IDO1 e KMO após SNI. Animais geneticamente deficientes para a citocina IFN- $\gamma$ e WT foram submetidos a SNI, sendo observado que os animais IFN- $\gamma$ KO apresentavam menor hipersensibilidade mecânica em relação ao grupo controle. Além disso, também foi induzido a neuropatia para animais geneticamente deficientes para os IFN- $\alpha$ e $\beta$, entretanto esses animais desenvolveram a mesma hipersensibilidade mecânica em relação aos WT (resultados não mostrados).

Sabe-se as praticamente todas as enzimas da via da quinureninas, incluindo as enzimas IDO1 e KMO, são induzidas por citocinas pró-inflamatórias destacando-se o IFN- $\gamma$ (Mandi et al., 2012). Nesse sentido, os níveis da enzima IDO após a lesão de nervos no RVM e na PAG estavam reduzidos em relação ao grupo controle, entretanto os níveis da enzima KMO estavam diminuídos apenas no RVM e não na PAG.

Tem sido proposto que após lesão de nervos periféricos a citocina IFN- $\gamma$ possa ser liberada por diversas células, tais como astrócitos ativados, neurônios danificados e também por células Th1 infiltradas na medula (Racz et al., 2008; Costigan et al., 2009b). Foi demonstrado que o aumento nos níveis de IFN- $\gamma$ na medula espinal, após lesão do nervo ciático até o vigésimo primeiro dia, sugerindo que essa citocina seja produzida por células Th1 que migraram para o tecido, possivelmente ocorra a mesma coisa no RVM e na PAG (Costigan et al., 2009b).

Explorando ainda mais os efeitos do IFN- $\gamma$, constatamos que uma única microinjeção dessa citocina no espaço i.c.v. de animais naives provocou um quadro de 
hipersensibilidade mecânica moderada e intensa, na menor e maior dose, respectivamente. Resultados similares foram descritos por Tsuda et al. (2009) e Xu et al. (1994) os quais propuzeram que a hipersensibilidade nociceptiva mecânica desenvolvida pela administração intratecal de IFN- $\gamma$ ocorreria pelo aumento da excitabilidade no corno dorsal, devido a redução do controle inibitório da via descendente da dor (Xu et al., 1994; Tsuda et al., 2009). Além disso, parece que o IFN- $\gamma$ pode desequilibrar o papel inibitório de neurônios gabaérgicos e alterar a expressão de receptores do tipo NMDA (Vikman et al., 2005; Vikman et al., 2007). Assim, o IFN- $\gamma$ parece induzir a sensibilização central através de vários mecanismos, além da modulação em neuronais, já que está fortemente implicado na ativação de micróglia, provocando “up regulation” de várias proteínas (Racz et al., 2008; Tsuda et al., 2009).

Indicando que além do fato do animal IFN- $\gamma \mathrm{KO}$ apresentar menor hipersensibilidade, expressão das enzimas IDO1 e KMO reduzidas, a citocina IFN- $\gamma$ é capaz de causar hipersensibilidade mecânica de até uma semana. Corroborando com essas achados, Saito e colaboradores (1991) demonstraram a administração de IFN- $\gamma$ a cada 3 dias durante 39 dias levou a uma ativação da enzima IDO1 no cérebro, bem como de quinureninas e ácido quinolínico, fortalecendo os nossos achados em relação a deleção genética da citocina IFN- $\gamma$ e expressão da enzima IDO1. (Saito et al., 1991)

As células da glia, assim como neurônios, possuem em sua superfície celular o IFN- $\gamma$ R (Robertson et al., 1997; Tsuda et al., 2009). Uma vez ativadas ou estimuladas através destes receptores, a transcrição gênica para IDO poderia ser aumentada.

O envolvimento de estruturas supraespinais na dor neuropática fornece o substrato entre estados emocionais e dor/percepção da dor (Rhudy et al., 2005).. O possível elo entre dor e depressão é a neuroinflamação, algumas citocinas são potentes 
moduladoras do comportamento, como a IL-1 $\beta$ e o IFN- $\gamma$ (Maes et al., 1994; Watkins et al., 2005).

A dor neuropática induz diversas alterações em estruturas supraespinais, facilitando a transmissão nociceptiva ao ativar a via descendente facilitatória da dor, composta pelo RVM e pela PAG, principalmente. $\mathrm{O}$ fato de diversas estruturas supraespinais estarem envolvidas no controle tanto na dor crônica quanto da depressão pode explicar a comorbidade dor crônica e depressão (Delgado, 2004; Norman et al., 2010).

Dessa forma, hipotetizamos que a ativação da via das quinureninas, IDO1 e KMO, causaria redução dos níveis de triptofano, consequentemente de 5-HT e produção de um agonista NMDA, o QUIN, que estaria associada com o desenvolvimento da hipersensibilidade neuropática e com a comorbidade depressão. Corroborando com essa hipótese foi observado que pacientes com dor neuropática apresentam altos níveis de glutamato, menor efetividade de analgésicos opióides, alterações no humor e as vezes depressão (Osikowicz et al., 2013), somado a isso foi descrito que durante a depressão ocorre o aumento da produção de QUIN no cérebro(Steiner et al., 2011). Além disso, a ativação dessa via seria responsável pela redução dos níveis de 5-HT e triptofano, desencadeando a depressão (Maes et al., 2011). Portanto, o que foi dito acima representa a nova hipótese da 5-HT e ativação da via das quinureninas no desenvolvimento da depressão.

Baseado no que foi dito acima, submetemos animais WT que sabidamente possuem uma ativação na via das quinureninas associada a lesão de nervos, bem como animais $\mathrm{CD} 4+\mathrm{KO}$ e IFN- $\gamma \mathrm{KO}$ que sabidamente apresentam menor ativação da via das quinureninas ao teste do nado forçado em 7, 14 e 21 dias após a indução da neuropatia. 
Os animais WT+SNI em 7, 14 e 21 dias após a lesão de nervos apresentam um comportamento do tipo depressivo no teste do nado forçado; os animais IFN- $\gamma \mathrm{KO}+\mathrm{SNI}$ em 7, 14 e 21 dia após a lesão de nervos apresentaram um pequeno tempo de imobilidade, similar ao grupo que recebeu o tratamento com o antidepressivo imipramina, caracterizando um comportamento do tipo "antidepressivo" no teste do nado forçado; os animais CD4+ KO+SNI em 7, 14 e 21 dias após a lesão de nervos apresentaram um tempo de imobilidade menor que os animais WT+SNI. Assim, os animais WT submetidos a lesão de nervos apresentaram a comorbidade depressão nos três momentos avaliados, 7,14 e 21 dias; animais CD4+KO que possuem um déficit no aumento da expressão da enzima IDO1 após a lesão de nervos apresentaram um menor tempo de imobilidade, menor até que os animais sham+WT; por último os animais IFN- $\gamma$ KO apresentavam um comportamento antidepressivo no teste do nado forçado após a lesão de nervos periféricos, sugerindo que a citocina IFN- $\gamma$, consequentemente a ativação da via das quinureninas sabidamente prejudicas nesses animais teriam um efeito depressivo.

Com o intuito de comprovar a participação da ativação da via das quinureninas no desenvolvimento da comorbidade depressão associada a lesão de nervos periféricos animais WT foram submetidos à SNI e as enzimas IDO1/KMO foram inibidas e submetidos ao teste do nado forçado 7 dias após a indução da neuropatia. Dessa forma, três horas após a administração de 1-mt 3mg/animal (sistêmico, i.p.) ou Norharmane 900 nmol ( espaço i.c.v.), bem como os animais IDO1 KO foram submetidos ao teste do nado forçado. Foi observado uma redução significativa no tempo de imobilidade no teste, sendo a inibição supraespinal mais eficiente que a sistêmica. A inibição sistêmica da KMO com 300 mg/kg de JM6 (sistêmico v.o.) e 300 nmol de Ro61-8048 (espaço i.c.v.) também reduziu o tempo de imobilidade em relação, sendo a inibição supraespinal mais eficiente. Assim, demonstramos que em 7 dias após a indução da neuropatia a inibição 
das principais enzimas da via das quinureninas, IDO1 e KMO, possui um efeito antidepressivo, corroborando com esses achados os animais geneticamente deficientes para a enzima IDO1 possuem um comportamento antidepressivo no teste. Além disso, a inibição supraespinal das enzimas IDO1 e KMO foi mais eficiente que o sistêmico, sugerindo que a ativação da via das quinureninas localizadas nessas regiões sejam importantes para o desenvolvimento da comorbidade depressão associada a lesão de nervos periféricos.

Os achados descritos acima mostraram de forma clara a relação da ativação da via das quinureninas associada a lesão de nervos periféricos com o desenvolvimento da comorbidade depressão. Além disso, sugerem que a inibição das enzimas IDO1 e KMO atuariam tanto na redução da hipersensibilidade quando no comportamento depressivo associado a neuropatia.

Por último, foi avaliado pela técnica de imunofluorescência os níveis de 5HT no RVM de animais sham WT, 7 d SNI WT e 7d SNI IDO1 KO. Os animais sham WT tinham uma marcação considerável de 5-HT, sendo níveis maiores que os dos animais SNI WT que estavam drasticamente reduzidos. Felizmente os níveis de 5-HT nos animais SNI IDO1 KO era muito maiores que os dos animais sham/SNI WT, sugerindo que a enzima IDO1 tenha um papel relevante na depuração de triptofano, afetando diretamente os níveis de 5-HT. Assim, de fato os mecanismos relacionados ao desenvolvimento da hiperalgesia mecânica, bem como a depressão associada ao modelo SNI é devido a redução dos níveis de 5-HT no cérebro. Esses achados estão de acordo com Liu e colaboradores (2010) que demonstraram a perda ou a redução da via descendente inibitória serotonérgica após a lesão do nervo espinal está associada a sensibilização central/desenvolvimento da dor neuropática (Liu et al., 2010). 
Com este conjunto de resultados, sugerimos que a IDO1 e KMO representam dois possíveis alvos para o tratamento da dor neuropática e da comorbidade depressão. 
CONCLUSÃO 


\section{CONCLUSÃO}

O conjunto de resultados exposto e discutido acima nos permite inferir as seguintes conclusões:

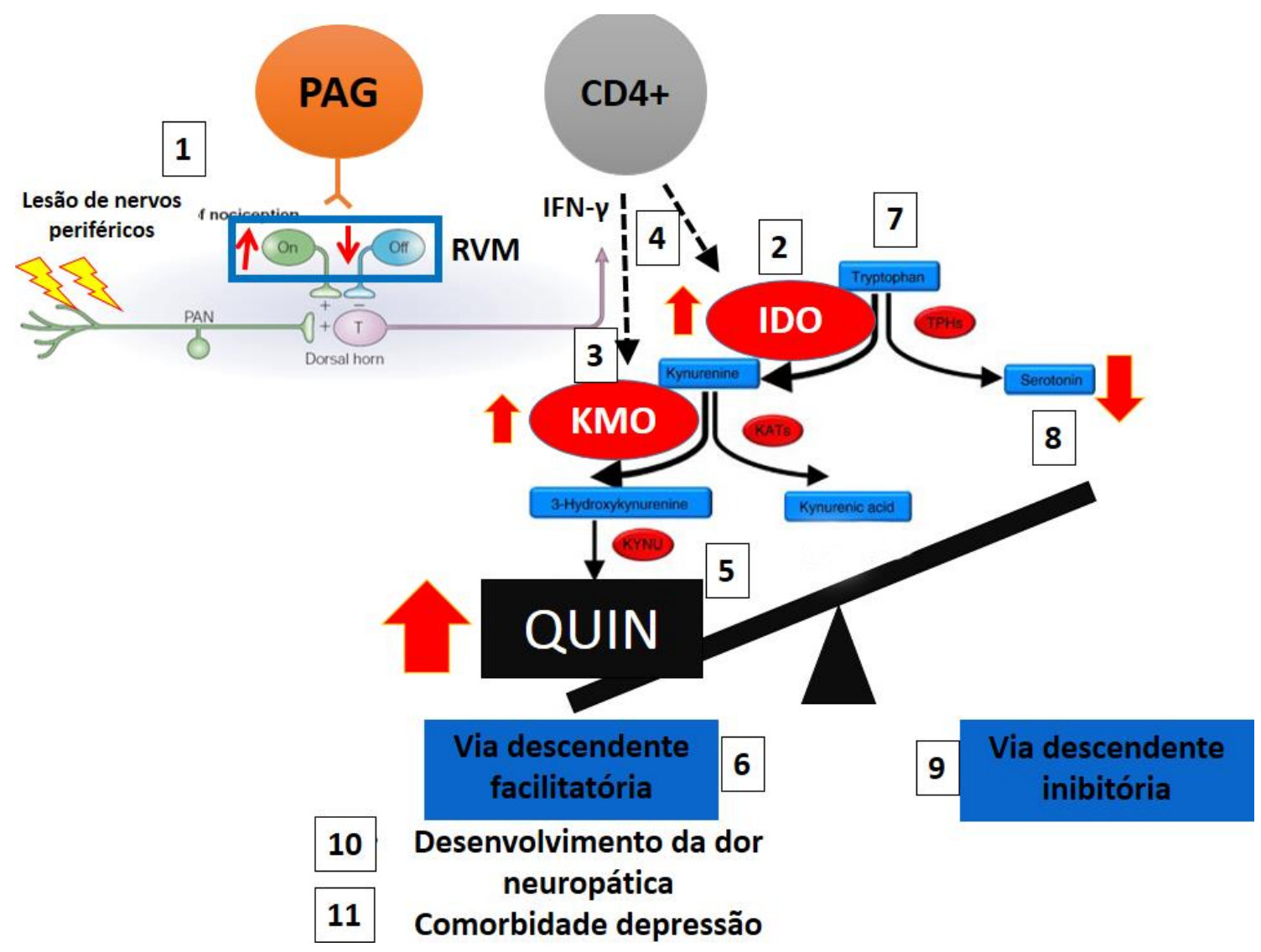

1. Após a lesão de nervos periféricos ocorre uma série de alterações celulares e moleculares no RVM e na PAG que contribuem para a ineficiência da via descendente inibitória e ativação da via descendente facilitatória da dor;

2. Aumento da expressão da enzima IDO1 após a lesão de nervos periféricos;

3. Aumento da expressão da enzima KMO após a lesão de nervos periféricos;

4. Tanto a enzima IDO1 quando a KMO tem a expressão dependente da citocina IFN- $\gamma$ e de células CD4+, possivelmente as células produtoras dessa citocina;

5. A ativação da via das quinureninas (IDO1 e KMO) aumenta os níveis de QUIN nesse microambiente; 
6. O QUIN ativa preferencialmente receptores glutamatérgicos do tipo NMDA. Esse metabólito ativa a via descendente facilitatória da dor, pois o pré-tratamento espinal com um antagonista 5-HT3a reduz parcialmente a hipersensibilidade induzida por QUIN;

7. A ativação da via das quinureninas, principalmente da enzima IDO1, reduz os níveis de triptofano, um aminoácido precursor da 5-HT;

8. Ao reduzir os níveis de triptofano, ocorre a diminuição dos níveis de 5-HT, principalmente no RVM,

9. A diminuição dos níveis de 5-HT causa a diminuição da eficiência da via descendente inibitória da dor

10. Tanto a ativação da via descendente facilitatória pelo QUIN quanto a diminuição da eficiência da via descendente inibitória da dor pela diminuição dos níveis de 5-HT contribuem para o desenvolvimento e manutenção da hipersensibilidade mecânica associada a lesão de nervos periféricos;

11. O aumento dos níveis de QUIN, consequente ativação da circuitaria glutamatérgica, assim como a diminuição da biodisponibilidade de 5-HT contribuem para o desenvolvimento da comorbidade depressão associado a lesão de nervos periféricos.

Dessa forma, o trabalho mostra a relevância da ativação das enzimas da via das quinureninas no sentido de produção de QUIN em detrimento dos níveis de triptofano/5-HT contribui para o desenvolvimento da hipersensibilidade mecânica e da depressão associada a lesão de nervos periféricos. 


\section{REFERÊNCIASBIBLIOGRÁFICAS}




\section{7-REFERÊNICAS BIBLIOGRÁFICAS}

Aimone LD, Gebhart GF (1986). Stimulation-produced spinal inhibition from the midbrain in the rat is mediated by an excitatory amino acid neurotransmitter in the medial medulla. The Journal of neuroscience : the official journal of the Society for Neuroscience 6(6): 1803-1813.

Aimone LD, Jones SL, Gebhart GF (1987). Stimulation-produced descending inhibition from the periaqueductal gray and nucleus raphe magnus in the rat: mediation by spinal monoamines but not opioids. Pain 31(1): 123-136.

Alberati-Giani D, Ricciardi-Castagnoli P, Kohler C, Cesura AM (1996). Regulation of the kynurenine metabolic pathway by interferon-gamma in murine cloned macrophages and microglial cells. Journal of neurochemistry 66(3): 996-1004.

Alexander GM, Reichenberger E, Peterlin BL, Perreault MJ, Grothusen JR, Schwartzman RJ (2013). Plasma amino acids changes in complex regional pain syndrome. Pain research and treatment 2013: 742407.

Altamura CA, Mauri MC, Ferrara A, Moro AR, D'Andrea G, Zamberlan F (1993). Plasma and platelet excitatory amino acids in psychiatric disorders. The American journal of psychiatry 150(11): 1731-1733.

Amir R, Michaelis M, Devor M (2002). Burst discharge in primary sensory neurons: triggered by subthreshold oscillations, maintained by depolarizing afterpotentials. The Journal of neuroscience : the official journal of the Society for Neuroscience 22(3): 1187-1198.

Apkarian AV, Lavarello S, Randolf A, Berra HH, Chialvo DR, Besedovsky HO, et al. (2006). Expression of IL-1beta in supraspinal brain regions in rats with neuropathic pain. Neuroscience letters 407(2): 176-181.

Argoff C (2011). Mechanisms of pain transmission and pharmacologic management. Current medical research and opinion 27(10): 2019-2031.

Baker MD, Wood JN (2001). Involvement of $\mathrm{Na}+$ channels in pain pathways. Trends in pharmacological sciences 22(1): 27-31.

Ball HJ, Sanchez-Perez A, Weiser S, Austin CJ, Astelbauer F, Miu J, et al. (2007).

Characterization of an indoleamine 2,3-dioxygenase-like protein found in humans and mice.

Gene 396(1): 203-213. 
Ball HJ, Yuasa HJ, Austin CJ, Weiser S, Hunt NH (2009). Indoleamine 2,3-dioxygenase-2; a new enzyme in the kynurenine pathway. The international journal of biochemistry \& cell biology 41(3): 467-471.

Baron R, Mahn F (2010). [Types of topical treatment for peripheral neuropathic pain : Mechanism of action and indications]. Schmerz 24(4): 317-325.

Berthold-Losleben M, Himmerich H (2008). The TNF-alpha system: functional aspects in depression, narcolepsy and psychopharmacology. Current neuropharmacology 6(3): 193-202.

Bonica JJ (1990). Evolution and current status of pain programs. Journal of pain and symptom management 5(6): 368-374.

Bourquin AF, Suveges M, Pertin M, Gilliard N, Sardy S, Davison AC, et al. (2006). Assessment and analysis of mechanical allodynia-like behavior induced by spared nerve injury (SNI) in the mouse. Pain 122(1-2): 14 e11-14.

Brooks J, Tracey I (2005). From nociception to pain perception: imaging the spinal and supraspinal pathways. Journal of anatomy 207(1): 19-33.

Calejesan AA, Kim SJ, Zhuo M (2000). Descending facilitatory modulation of a behavioral nociceptive response by stimulation in the adult rat anterior cingulate cortex. Eur J Pain 4(1): 83-96.

Cao L, DeLeo JA (2008). CNS-infiltrating CD4+ T lymphocytes contribute to murine spinal nerve transection-induced neuropathic pain. European journal of immunology 38(2): 448-458.

Carter GT, Galer BS (2001). Advances in the management of neuropathic pain. Physical medicine and rehabilitation clinics of North America 12(2): 447-459.

Cerne R, Jiang M, Randic M (1992). Cyclic adenosine 3'5'-monophosphate potentiates excitatory amino acid and synaptic responses of rat spinal dorsal horn neurons. Brain research 596(1-2): 111-123.

Chaplan SR, Malmberg AB, Yaksh TL (1997). Efficacy of spinal NMDA receptor antagonism in formalin hyperalgesia and nerve injury evoked allodynia in the rat. The Journal of pharmacology and experimental therapeutics 280(2): 829-838.

Chen Q, Surmeier DJ, Reiner A (1999). NMDA and non-NMDA receptor-mediated excitotoxicity are potentiated in cultured striatal neurons by prior chronic depolarization. Experimental neurology 159(1): 283-296. 
Chiarugi A, Cozzi A, Ballerini C, Massacesi L, Moroni F (2001). Kynurenine 3-mono-oxygenase activity and neurotoxic kynurenine metabolites increase in the spinal cord of rats with experimental allergic encephalomyelitis. Neuroscience 102(3): 687-695.

Chong MS, Bajwa ZH (2003). Diagnosis and treatment of neuropathic pain. Journal of pain and symptom management 25(5 Suppl): S4-S11.

Clark AK, Malcangio M (2014). Fractalkine/CX3CR1 signaling during neuropathic pain. Frontiers in cellular neuroscience 8: 121.

Cosi C, Mannaioni G, Cozzi A, Carla V, Sili M, Cavone L, et al. (2011). G-protein coupled receptor 35 (GPR35) activation and inflammatory pain: Studies on the antinociceptive effects of kynurenic acid and zaprinast. Neuropharmacology 60(7-8): 1227-1231.

Costigan M, Moss A, Latremoliere A, Johnston C, Verma-Gandhu M, Herbert TA, et al. (2009a). T-cell infiltration and signaling in the adult dorsal spinal cord is a major contributor to neuropathic pain-like hypersensitivity. The Journal of neuroscience : the official journal of the Society for Neuroscience 29(46): 14415-14422.

Costigan M, Moss A, Latremoliere A, Johnston C, Verma-Gandhu M, Herbert TA, et al. (2009b). T-Cell Infiltration and Signaling in the Adult Dorsal Spinal Cord Is a Major Contributor to Neuropathic Pain-Like Hypersensitivity. The Journal of neuroscience : the official journal of the Society for Neuroscience 29(46): 14415.

Cox JJ, Reimann F, Nicholas AK, Thornton G, Roberts E, Springell K, et al. (2006). An SCN9A channelopathy causes congenital inability to experience pain. Nature 444(7121): 894-898.

Cryan JF, Markou A, Lucki I (2002). Assessing antidepressant activity in rodents: recent developments and future needs. Trends in pharmacological sciences 23(5): 238-245.

Cui M, Feng Y, McAdoo DJ, Willis WD (1999). Periaqueductal gray stimulation-induced inhibition of nociceptive dorsal horn neurons in rats is associated with the release of norepinephrine, serotonin, and amino acids. The Journal of pharmacology and experimental therapeutics 289(2): 868-876.

Dahlstrom A, Fuxe K (1964). Localization of monoamines in the lower brain stem. Experientia 20(7): 398-399.

Dantzer R, O'Connor JC, Freund GG, Johnson RW, Kelley KW (2008). From inflammation to sickness and depression: when the immune system subjugates the brain. Nature reviews. Neuroscience 9(1): 46-56. 
Davis JL, Lewis SB, Gerich JE, Kaplan RA, Schultz TA, Wallin JD (1977). Peripheral diabetic neuropathy treated with amitriptyline and fluphenazine. JAMA : the journal of the American Medical Association 238(21): 2291-2292.

Delgado PL (2004). Common pathways of depression and pain. The Journal of clinical psychiatry 65 Suppl 12: 16-19.

Delgado PL (2006). Monoamine depletion studies: implications for antidepressant discontinuation syndrome. The Journal of clinical psychiatry 67 Suppl 4: 22-26.

DiNatale BC, Murray IA, Schroeder JC, Flaveny CA, Lahoti TS, Laurenzana EM, et al. (2010). Kynurenic acid is a potent endogenous aryl hydrocarbon receptor ligand that synergistically induces interleukin- 6 in the presence of inflammatory signaling. Toxicological sciences : an official journal of the Society of Toxicology 115(1): 89-97.

Dunham NW, Miya TS (1957). A note on a simple apparatus for detecting neurological deficit in rats and mice. Journal of the American Pharmaceutical Association. American Pharmaceutical Association 46(3): 208-209.

Dworkin RH, Backonja M, Rowbotham MC, Allen RR, Argoff CR, Bennett GJ, et al. (2003). Advances in neuropathic pain: diagnosis, mechanisms, and treatment recommendations. Archives of neurology 60(11): 1524-1534.

Dworkin RH, Gitlin MJ (1991). Clinical aspects of depression in chronic pain patients. Clin J Pain 7(2): 79-94.

Eastman CL, Guilarte TR (1989). Cytotoxicity of 3-hydroxykynurenine in a neuronal hybrid cell line. Brain research 495(2): 225-231.

Farghaly HS, Abdel-Zaher AO, Mostafa MG, Kotb HI (2012a). Comparative evaluation of the effect of tricyclic antidepressants on inducible nitric oxide synthase expression in neuropathic pain model. Nitric oxide : biology and chemistry / official journal of the Nitric Oxide Society 27(2): 88-94.

Farghaly HSM, Abdel-Zaher AO, Mostafa MG, Kotb HI (2012b). Comparative evaluation of the effect of tricyclic antidepressants on inducible nitric oxide synthase expression in neuropathic pain model. Nitric oxide : biology and chemistry / official journal of the Nitric Oxide Society 27(2): 88-94.

Fedele E, Foster AC (1993). An evaluation of the role of extracellular amino acids in the delayed neurodegeneration induced by quinolinic acid in the rat striatum. Neuroscience 52(4): 911-917.

Fields HL, Basbaum Al (1978). Brainstem control of spinal pain-transmission neurons. Annual review of physiology 40: 217-248. 
Fields HL, Heinricher MM, Mason P (1991). Neurotransmitters in nociceptive modulatory circuits. Annual review of neuroscience 14: 219-245.

Foster AC, Miller LP, Oldendorf WH, Schwarcz R (1984). Studies on the disposition of quinolinic acid after intracerebral or systemic administration in the rat. Experimental neurology 84(2): 428-440.

FRANKLIN KB, Paxinos G (2007). The mouse brain in stereotaxic coordinates with CD-ROM: Academic Press, New York, NY, USA.

Ganong AH, Cotman CW (1986). Kynurenic acid and quinolinic acid act at N-methyl-D-aspartate receptors in the rat hippocampus. The Journal of pharmacology and experimental therapeutics 236(1): 293-299.

Gao X, Kim HK, Chung JM, Chung K (2005). Enhancement of NMDA receptor phosphorylation of the spinal dorsal horn and nucleus gracilis neurons in neuropathic rats. Pain 116(1-2): 62-72.

Gebhart GF (1982). Opiate and opioid peptide effects on brain stem neurons: relevance to nociception and antinociceptive mechanisms. Pain 12(2): 93-140.

Gebhart GF (2004). Descending modulation of pain. Neuroscience and biobehavioral reviews 27(8): 729-737.

Giorgini F, Moller T, Kwan W, Zwilling D, Wacker JL, Hong S, et al. (2008). Histone deacetylase inhibition modulates kynurenine pathway activation in yeast, microglia, and mice expressing a mutant huntingtin fragment. The Journal of biological chemistry 283(12): 7390-7400.

Goettl VM, Huang Y, Hackshaw KV, Stephens RL, Jr. (2002). Reduced basal release of serotonin from the ventrobasal thalamus of the rat in a model of neuropathic pain. Pain 99(1-2): 359366.

Green GM, Scarth J, Dickenson A (2000). An excitatory role for 5-HT in spinal inflammatory nociceptive transmission; state-dependent actions via dorsal horn 5-HT(3) receptors in the anaesthetized rat. Pain 89(1): 81-88.

Guillemin GJ, Smythe G, Takikawa O, Brew BJ (2005). Expression of indoleamine 2,3dioxygenase and production of quinolinic acid by human microglia, astrocytes, and neurons. Glia 49(1): 15-23.

Hansen AM, Ball HJ, Mitchell AJ, Miu J, Takikawa O, Hunt NH (2004). Increased expression of indoleamine 2,3-dioxygenase in murine malaria infection is predominantly localised to the vascular endothelium. International journal for parasitology 34(12): 1309-1319. 
Hao JX, Xu XJ (1996). Treatment of a chronic allodynia-like response in spinally injured rats: effects of systemically administered nitric oxide synthase inhibitors. Pain 66(2-3): 313-319.

Heyes MP, Saito K, Crowley JS, Davis LE, Demitrack MA, Der M, et al. (1992). Quinolinic acid and kynurenine pathway metabolism in inflammatory and non-inflammatory neurological disease. Brain : a journal of neurology 115 ( Pt 5): 1249-1273.

Heyes MP, Saito K, Major EO, Milstien S, Markey SP, Vickers JH (1993). A mechanism of quinolinic acid formation by brain in inflammatory neurological disease. Attenuation of synthesis from L-tryptophan by 6-chlorotryptophan and 4-chloro-3-hydroxyanthranilate. Brain : a journal of neurology 116 ( Pt 6): 1425-1450.

Heyliger SO, Goodman CB, Ngong JM, Soliman KF (1998). The analgesic effects of tryptophan and its metabolites in the rat. Pharmacological research : the official journal of the Italian Pharmacological Society 38(4): 243-250.

Hinson AW, Gu XQ, Dib-Hajj S, Black JA, Waxman SG (1997). Schwann cells modulate sodium channel expression in spinal sensory neurons in vitro. Glia 21(4): 339-349.

Hu J, Wang Z, Guo YY, Zhang XN, Xu ZH, Liu SB, et al. (2009). A role of periaqueductal grey NR2B-containing NMDA receptor in mediating persistent inflammatory pain. Molecular pain 5: 71.

Hudson LJ, Bevan S, McNair K, Gentry C, Fox A, Kuhn R, et al. (2002). Metabotropic glutamate receptor 5 upregulation in A-fibers after spinal nerve injury: 2-methyl-6-(phenylethynyl)pyridine (MPEP) reverses the induced thermal hyperalgesia. The Journal of neuroscience : the official journal of the Society for Neuroscience 22(7): 2660-2668.

Hughes MM, Carballedo A, McLoughlin DM, Amico F, Harkin A, Frodl T, et al. (2012). Tryptophan depletion in depressed patients occurs independent of kynurenine pathway activation. Brain, behavior, and immunity 26(6): 979-987.

Ignatowski TA, Covey WC, Knight PR, Severin CM, Nickola TJ, Spengler RN (1999). Brain-derived TNFalpha mediates neuropathic pain. Brain research 841(1-2): 70-77.

Ikeda H, Kiritoshi T, Murase K (2012). Contribution of microglia and astrocytes to the central sensitization, inflammatory and neuropathic pain in the juvenile rat. Molecular pain 8: 43.

Jaggi AS, Singh N (2011). Role of different brain areas in peripheral nerve injury-induced neuropathic pain. Brain research 1381: 187-201.

Jensen TS, Gottrup H, Sindrup SH, Bach FW (2001). The clinical picture of neuropathic pain. European journal of pharmacology 429(1-3): 1-11. 
Ji RR, Woolf CJ (2001). Neuronal plasticity and signal transduction in nociceptive neurons: implications for the initiation and maintenance of pathological pain. Neurobiology of disease 8(1): 1-10.

Kim H, Chen L, Lim G, Sung B, Wang S, McCabe MF, et al. (2012). Brain indoleamine 2,3dioxygenase contributes to the comorbidity of pain and depression. The Journal of clinical investigation 122(8): 2940-2954.

Kim HK, Park SK, Zhou JL, Taglialatela G, Chung K, Coggeshall RE, et al. (2004). Reactive oxygen species (ROS) play an important role in a rat model of neuropathic pain. Pain 111(1-2): 116124.

Kim JS, Schmid-Burgk W, Claus D, Kornhuber HH (1982). Increased serum glutamate in depressed patients. Archiv fur Psychiatrie und Nervenkrankheiten 232(4): 299-304.

Koo JW, Duman RS (2008). IL-1beta is an essential mediator of the antineurogenic and anhedonic effects of stress. Proceedings of the National Academy of Sciences of the United States of America 105(2): 751-756.

Kuner R (2010). Central mechanisms of pathological pain. Nature medicine 16(11): 1258-1266.

Kwon M, Altin M, Duenas H, Alev L (2013). The Role of Descending Inhibitory Pathways on Chronic Pain Modulation and Clinical Implications. Pain practice : the official journal of World Institute of Pain.

Lapin IP (1978). Stimulant and convulsive effects of kynurenines injected into brain ventricles in mice. Journal of neural transmission 42(1): 37-43.

Lee BH, Park SH, Won R, Park YG, Sohn JH (2000). Antiallodynic effects produced by stimulation of the periaqueductal gray matter in a rat model of neuropathic pain. Neuroscience letters 291(1): 29-32.

Leklem JE (1971). Quantitative aspects of tryptophan metabolism in humans and other species: a review. The American journal of clinical nutrition 24(6): 659-672.

Leyton M, Young SN, Benkelfat C (1997). Relapse of depression after rapid depletion of tryptophan. Lancet 349(9068): 1840-1841.

Li Y, Dorsi MJ, Meyer RA, Belzberg AJ (2000). Mechanical hyperalgesia after an L5 spinal nerve lesion in the rat is not dependent on input from injured nerve fibers. Pain 85(3): 493-502. 
Lima D, Almeida A (2002). The medullary dorsal reticular nucleus as a pronociceptive centre of the pain control system. Progress in neurobiology 66(2): 81-108.

Liu FY, Qu XX, Ding X, Cai J, Jiang H, Wan Y, et al. (2010). Decrease in the descending inhibitory 5-HT system in rats with spinal nerve ligation. Brain research 1330: 45-60.

Liu XJ, Gingrich JR, Vargas-Caballero M, Dong YN, Sengar A, Beggs S, et al. (2008). Treatment of inflammatory and neuropathic pain by uncoupling Src from the NMDA receptor complex. Nature medicine 14(12): 1325-1332.

Lopez-Munoz F, Alamo C (2009). Monoaminergic neurotransmission: the history of the discovery of antidepressants from 1950s until today. Current pharmaceutical design 15(14): 1563-1586.

Lovick TA (2008). Pro-nociceptive action of cholecystokinin in the periaqueductal grey: a role in neuropathic and anxiety-induced hyperalgesic states. Neuroscience and biobehavioral reviews 32(4): 852-862.

Maes M, Leonard BE, Myint AM, Kubera M, Verkerk R (2011). The new '5-HT' hypothesis of depression: Cell-mediated immune activation induces indoleamine 2,3-dioxygenase, which leads to lower plasma tryptophan and an increased synthesis of detrimental tryptophan catabolites (TRYCATs), both of which contribute to the onset of depression. Progress in NeuroPsychopharmacology and Biological Psychiatry 35(3): 702-721.

Maes M, Scharpe S, Meltzer HY, Okayli G, Bosmans E, Dhondt P, et al. (1994). Increased Neopterin and Interferon-Gamma Secretion and Lower Availability of L-Tryptophan in Major Depression - Further Evidence for an Immune-Response. Psychiat Res 54(2): 143-160.

Maj J, Rogoz Z, Skuza G, Sowinska H (1992). Effects of MK-801 and antidepressant drugs in the forced swimming test in rats. European neuropsychopharmacology : the journal of the European College of Neuropsychopharmacology 2(1): 37-41.

Mandi Y, Vecsei L (2012). The kynurenine system and immunoregulation. Journal of neural transmission 119(2): 197-209.

Mao J, Price DD, Hayes RL, Lu J, Mayer DJ (1992). Differential roles of NMDA and non-NMDA receptor activation in induction and maintenance of thermal hyperalgesia in rats with painful peripheral mononeuropathy. Brain research 598(1-2): 271-278.

Mason P (1999). Central mechanisms of pain modulation. Current opinion in neurobiology 9(4): 436-441. 
Masu M, Nakajima Y, Moriyoshi K, Ishii T, Akazawa C, Nakanashi S (1993). Molecular characterization of NMDA and metabotropic glutamate receptors. Annals of the New York Academy of Sciences 707: 153-164.

Masuda T, Iwamoto S, Yoshinaga R, Tozaki-Saitoh H, Nishiyama A, Mak TW, et al. (2014). Transcription factor IRF5 drives P2X4R+-reactive microglia gating neuropathic pain. Nature communications 5: 3771.

Mayer DJ, Price DD (1976). Central nervous system mechanisms of analgesia. Pain 2(4): 379404.

Mecs L, Tuboly G, Nagy E, Benedek G, Horvath G (2009). The peripheral antinociceptive effects of endomorphin-1 and kynurenic acid in the rat inflamed joint model. Anesthesia and analgesia 109(4): 1297-1304.

Messing RB, Lytle LD (1977). Serotonin-containing neurons: their possible role in pain and analgesia. Pain 4(0): 1-21.

Metz R, Duhadaway JB, Kamasani U, Laury-Kleintop L, Muller AJ, Prendergast GC (2007). Novel tryptophan catabolic enzyme IDO2 is the preferred biochemical target of the antitumor indoleamine 2,3-dioxygenase inhibitory compound D-1-methyl-tryptophan. Cancer research 67(15): 7082-7087.

Michaelis M, Liu X, Janig W (2000). Axotomized and intact muscle afferents but no skin afferents develop ongoing discharges of dorsal root ganglion origin after peripheral nerve lesion. The Journal of neuroscience : the official journal of the Society for Neuroscience 20(7): 2742-2748.

Michelsen KA, Prickaerts J, Steinbusch HW (2008). The dorsal raphe nucleus and serotonin: implications for neuroplasticity linked to major depression and Alzheimer's disease. Progress in brain research 172: 233-264.

Millan MJ (2002). Descending control of pain. Progress in neurobiology 66(6): 355-474.

Miller AH, Maletic V, Raison CL (2009). Inflammation and its discontents: the role of cytokines in the pathophysiology of major depression. Biological psychiatry 65(9): 732-741.

Miller DB, O'Callaghan JP (2005). Depression, cytokines, and glial function. Metabolism: clinical and experimental 54(5 Suppl 1): 33-38.

Mitani H, Shirayama Y, Yamada T, Maeda K, Ashby Jr CR, Kawahara R (2006). Correlation between plasma levels of glutamate, alanine and serine with severity of depression. Progress in Neuro-Psychopharmacology and Biological Psychiatry 30(6): 1155-1158. 
Moalem G, Tracey DJ (2006). Immune and inflammatory mechanisms in neuropathic pain. Brain research reviews 51(2): 240-264.

Mor D, Bembrick AL, Austin PJ, Wyllie PM, Creber NJ, Denyer GS, et al. (2010). Anatomically specific patterns of glial activation in the periaqueductal gray of the sub-population of rats showing pain and disability following chronic constriction injury of the sciatic nerve.

Neuroscience 166(4): 1167-1184.

Morgan MM, Gold MS, Liebeskind JC, Stein C (1991). Periaqueductal gray stimulation produces a spinally mediated, opioid antinociception for the inflamed hindpaw of the rat. Brain research 545(1-2): 17-23.

Moroni F, Russi P, Carla V, De Luca G, Politi V (1991). The regulation of brain kynurenic acid content: focus on indole-3-pyruvic acid. Advances in experimental medicine and biology 294: 299-308.

Munn DH, Mellor AL (2013). Indoleamine 2,3 dioxygenase and metabolic control of immune responses. Trends in immunology 34(3): 137-143.

Nicol GD, Lopshire JC, Pafford CM (1997). Tumor necrosis factor enhances the capsaicin sensitivity of rat sensory neurons. The Journal of neuroscience : the official journal of the Society for Neuroscience 17(3): 975-982.

Norman GJ, Karelina K, Zhang N, Walton JC, Morris JS, Devries AC (2010). Stress and IL-1beta contribute to the development of depressive-like behavior following peripheral nerve injury. Molecular psychiatry 15(4): 404-414.

Oatway MA, Chen Y, Weaver LC (2004). The 5-HT3 receptor facilitates at-level mechanical allodynia following spinal cord injury. Pain 110(1-2): 259-268.

Obata K, Yamanaka H, Fukuoka T, Yi D, Tokunaga A, Hashimoto N, et al. (2003). Contribution of injured and uninjured dorsal root ganglion neurons to pain behavior and the changes in gene expression following chronic constriction injury of the sciatic nerve in rats. Pain 101(1-2): 6577.

Okuda S, Nishiyama N, Saito H, Katsuki H (1996). Hydrogen peroxide-mediated neuronal cell death induced by an endogenous neurotoxin, 3-hydroxykynurenine. Proceedings of the National Academy of Sciences of the United States of America 93(22): 12553-12558.

Oliveras JL, Besson JM, Guilbaud G, Liebeskind JC (1974). Behavioral and electrophysiological evidence of pain inhibition from midbrain stimulation in the cat. Experimental brain research 20(1): 32-44. 
Osikowicz M, Mika J, Przewlocka B (2013). The glutamatergic system as a target for neuropathic pain relief. Experimental physiology 98(2): 372-384.

Ossipov MH, Dussor GO, Porreca F (2010). Central modulation of pain. The Journal of clinical investigation 120(11): 3779-3787.

Papir-Kricheli D, Frey J, Laufer R, Gilon C, Chorev M, Selinger Z, et al. (1987). Behavioural effects of receptor-specific substance P agonists. Pain 31(2): 263-276.

Pertovaara A, Wei H, Hamalainen MM (1996). Lidocaine in the rostroventromedial medulla and the periaqueductal gray attenuates allodynia in neuropathic rats. Neuroscience letters 218(2): 127-130.

Pineda-Farias JB, Perez-Severiano F, Gonzalez-Esquivel DF, Barragan-Iglesias P, BravoHernandez M, Cervantes-Duran C, et al. (2013a). The L-kynurenine-probenecid combination reduces neuropathic pain in rats. European journal of pain 17(9): 1365-1373.

Pineda-Farias JB, Perez-Severiano F, Gonzalez-Esquivel DF, Barragan-Iglesias P, BravoHernandez M, Cervantes-Duran C, et al. (2013b). The L-kynurenine-probenecid combination reduces neuropathic pain in rats. Eur J Pain 17(9): 1365-1373.

Pitcher MH, Ribeiro-da-Silva A, Coderre TJ (2007). Effects of inflammation on the ultrastructural localization of spinal cord dorsal horn group I metabotropic glutamate receptors. The Journal of comparative neurology 505(4): 412-423.

Platten M, Wick W, Van den Eynde BJ (2012). Tryptophan catabolism in cancer: beyond IDO and tryptophan depletion. Cancer research 72(21): 5435-5440.

Porreca F, Ossipov MH, Gebhart GF (2002). Chronic pain and medullary descending facilitation. Trends in neurosciences 25(6): 319-325.

Porsolt RD, Le Pichon M, Jalfre M (1977). Depression: a new animal model sensitive to antidepressant treatments. Nature 266(5604): 730-732.

Potrebic SB, Fields HL, Mason P (1994). Serotonin immunoreactivity is contained in one physiological cell class in the rat rostral ventromedial medulla. The Journal of neuroscience : the official journal of the Society for Neuroscience 14(3 Pt 2): 1655-1665.

Racz I, Nadal X, Alferink J, Baños JE, Rehnelt J, Martín M, et al. (2008). Interferon- $\gamma$ Is a Critical Modulator of CB(2) Cannabinoid Receptor Signaling during Neuropathic Pain. The Journal of Neuroscience 28(46): 12136-12145. 
Raison CL, Miller AH (2013). Do cytokines really sing the blues? Cerebrum : the Dana forum on brain science 2013: 10.

Ren K, Dubner R (2002). Descending modulation in persistent pain: an update. Pain 100(1-2): 1-6.

Reynolds DV (1969). Surgery in the rat during electrical analgesia induced by focal brain stimulation. Science 164(3878): 444-445.

Rhudy JL, Williams AE, Mccabe KM, Thu MA, Nguyen V, Rambo P (2005). Affective modulation of nociception at spinal and supraspinal levels. Psychophysiology 42(5): 579-587.

Ro LS, Chen ST, Tang LM, Jacobs JM (1999). Effect of NGF and anti-NGF on neuropathic pain in rats following chronic constriction injury of the sciatic nerve. Pain 79(2-3): 265-274.

Robertson B, Xu XJ, Hao JX, Wiesenfeld-Hallin Z, Mhlanga J, Grant G, et al. (1997). Interferongamma receptors in nociceptive pathways: role in neuropathic pain-related behaviour. Neuroreport 8(5): 1311-1316.

Rover S, Cesura AM, Huguenin P, Kettler R, Szente A (1997). Synthesis and biochemical evaluation of $\mathrm{N}$-(4-phenylthiazol-2-yl)benzenesulfonamides as high-affinity inhibitors of kynurenine 3-hydroxylase. Journal of medicinal chemistry 40(26): 4378-4385.

Saito K, Markey SP, Heyes MP (1991). Chronic effects of gamma-interferon on quinolinic acid and indoleamine-2,3-dioxygenase in brain of C57BL6 mice. Brain research 546(1): 151-154.

Scholz J, Woolf CJ (2007). The neuropathic pain triad: neurons, immune cells and glia. Nature neuroscience 10(11): 1361-1368.

Schwarcz R, Bruno JP, Muchowski PJ, Wu HQ (2012). Kynurenines in the mammalian brain: when physiology meets pathology. Nature reviews. Neuroscience 13(7): 465-477.

Schwarcz R, Whetsell WO, Jr., Mangano RM (1983). Quinolinic acid: an endogenous metabolite that produces axon-sparing lesions in rat brain. Science 219(4582): 316-318.

Seifert F, Maihofner C (2009). Central mechanisms of experimental and chronic neuropathic pain: findings from functional imaging studies. Cellular and molecular life sciences : CMLS 66(3): 375-390.

Sikandar S, Dickenson AH (2011). Pregabalin modulation of spinal and brainstem visceral nociceptive processing. Pain 152(10): 2312-2322. 
Sindrup SH, Otto M, Finnerup NB, Jensen TS (2005). Antidepressants in the treatment of neuropathic pain. Basic \& clinical pharmacology \& toxicology 96(6): 399-409.

Smith EL, Whedon MB, Bookbinder M (2002). Quality improvement of painful peripheral neuropathy. Seminars in oncology nursing 18(1): 36-43.

Sommer C (2003). Painful neuropathies. Current opinion in neurology 16(5): 623-628.

Steiner J, Walter M, Gos T, Guillemin G, Bernstein H-G, Sarnyai Z, et al. (2011). Severe depression is associated with increased microglial quinolinic acid in subregions of the anterior cingulate gyrus: Evidence for an immune-modulated glutamatergic neurotransmission? Journal of neuroinflammation 8(1): 94.

Stone TW (1993). Neuropharmacology of quinolinic and kynurenic acids. Pharmacological reviews 45(3): 309-379.

Stone TW (2007). Kynurenic acid blocks nicotinic synaptic transmission to hippocampal interneurons in young rats. The European journal of neuroscience 25(9): 2656-2665.

Stone TW, Perkins MN (1981). Quinolinic acid: a potent endogenous excitant at amino acid receptors in CNS. European journal of pharmacology 72(4): 411-412.

Su X, Liang AH, Urban MO (2009). The effect of amitriptyline on ectopic discharge of primary afferent fibers in the $L 5$ dorsal root in a rat model of neuropathic pain. Anesthesia and analgesia 108(5): 1671-1679.

Sugimoto H, Oda S, Otsuki T, Hino T, Yoshida T, Shiro Y (2006). Crystal structure of human indoleamine 2,3-dioxygenase: catalytic mechanism of $\mathrm{O} 2$ incorporation by a heme-containing dioxygenase. Proceedings of the National Academy of Sciences of the United States of America 103(8): 2611-2616.

Suzuki R, Morcuende S, Webber M, Hunt SP, Dickenson AH (2002). Superficial NK1-expressing neurons control spinal excitability through activation of descending pathways. Nat Neurosci 5(12): 1319-1326.

Suzuki R, Rygh LJ, Dickenson AH (2004). Bad news from the brain: descending 5-HT pathways that control spinal pain processing. Trends in pharmacological sciences 25(12): 613-617.

Swartz KJ, During MJ, Freese A, Beal MF (1990). Cerebral synthesis and release of kynurenic acid: an endogenous antagonist of excitatory amino acid receptors. The Journal of neuroscience : the official journal of the Society for Neuroscience 10(9): 2965-2973. 
Taguchi K, Suzuki Y (1992). The response of the 5-hydroxyindole oxidation current to noxious stimuli in the spinal cord of anesthetized rats: modification by morphine. Brain research 583(12): 150-154.

Takaki J, Fujimori K, Miura M, Suzuki T, Sekino Y, Sato K (2012). L-glutamate released from activated microglia downregulates astrocytic L-glutamate transporter expression in neuroinflammation: the 'collusion' hypothesis for increased extracellular L-glutamate concentration in neuroinflammation. Journal of neuroinflammation 9: 275.

Takeda K, Muramatsu M, Chikuma T, Kato T (2009). Effect of memantine on the levels of neuropeptides and microglial cells in the brain regions of rats with neuropathic pain. Journal of molecular neuroscience : MN 39(3): 380-390.

Takikawa O, Kuroiwa T, Yamazaki F, Kido R (1988). Mechanism of interferon-gamma action. Characterization of indoleamine 2,3-dioxygenase in cultured human cells induced by interferon-gamma and evaluation of the enzyme-mediated tryptophan degradation in its anticellular activity. The Journal of biological chemistry 263(4): 2041-2048.

Tang Y, Chu GY, He HX, Yu CP, An JX, Guo XY (2009). Screening of differentially expressed genes in the hypothalamus of a rat neuropathic pain model following sciatic nerve injury. Chinese medical journal 122(23): 2893-2897.

Tavares RG, Tasca Cl, Santos CE, Alves LB, Porciuncula LO, Emanuelli T, et al. (2002). Quinolinic acid stimulates synaptosomal glutamate release and inhibits glutamate uptake into astrocytes. Neurochemistry international 40(7): 621-627.

Tavares RG, Tasca Cl, Santos CE, Wajner M, Souza DO, Dutra-Filho CS (2000). Quinolinic acid inhibits glutamate uptake into synaptic vesicles from rat brain. Neuroreport 11(2): 249-253.

Toth C, Lander J, Wiebe S (2009). The prevalence and impact of chronic pain with neuropathic pain symptoms in the general population. Pain medicine 10(5): 918-929.

Trullas R, Skolnick P (1990). Functional antagonists at the NMDA receptor complex exhibit antidepressant actions. European journal of pharmacology 185(1): 1-10.

Tsuda M, Masuda T, Kitano J, Shimoyama H, Tozaki-Saitoh H, Inoue K (2009). IFN-gamma receptor signaling mediates spinal microglia activation driving neuropathic pain. Proceedings of the National Academy of Sciences of the United States of America 106(19): 8032-8037.

Tsuda M, Shigemoto-Mogami Y, Koizumi S, Mizokoshi A, Kohsaka S, Salter MW, et al. (2003). $\mathrm{P} 2 \mathrm{X} 4$ receptors induced in spinal microglia gate tactile allodynia after nerve injury. Nature 424(6950): 778-783. 
Ulmann L, Hatcher JP, Hughes JP, Chaumont S, Green PJ, Conquet F, et al. (2008). Upregulation of $\mathrm{P} 2 \mathrm{X} 4$ receptors in spinal microglia after peripheral nerve injury mediates BDNF release and neuropathic pain. The Journal of neuroscience : the official journal of the Society for Neuroscience 28(44): 11263-11268.

Ultenius C, Linderoth B, Meyerson BA, Wallin J (2006). Spinal NMDA receptor phosphorylation correlates with the presence of neuropathic signs following peripheral nerve injury in the rat. Neuroscience letters 399(1-2): 85-90.

Urban MO, Gebhart GF (1999). Supraspinal contributions to hyperalgesia. Proceedings of the National Academy of Sciences of the United States of America 96(14): 7687-7692.

Vabnick I, Novakovic SD, Levinson SR, Schachner M, Shrager P (1996). The clustering of axonal sodium channels during development of the peripheral nervous system. The Journal of neuroscience : the official journal of the Society for Neuroscience 16(16): 4914-4922.

Vanderah TW, Suenaga NM, Ossipov MH, Malan TP, Jr., Lai J, Porreca F (2001). Tonic descending facilitation from the rostral ventromedial medulla mediates opioid-induced abnormal pain and antinociceptive tolerance. The Journal of neuroscience : the official journal of the Society for Neuroscience 21(1): 279-286.

Vanegas H, Barbaro NM, Fields HL (1984). Midbrain stimulation inhibits tail-flick only at currents sufficient to excite rostral medullary neurons. Brain research 321(1): 127-133.

Vanegas H, Schaible HG (2004). Descending control of persistent pain: inhibitory or facilitatory? Brain research. Brain research reviews 46(3): 295-309.

Viisanen H, Pertovaara A (2010). Roles of the rostroventromedial medulla and the spinal 5$\mathrm{HT}(1 \mathrm{~A})$ receptor in descending antinociception induced by motor cortex stimulation in the neuropathic rat. Neuroscience letters 476(3): 133-137.

Vikman KS, Duggan AW, Siddall PJ (2007). Interferon-gamma induced disruption of GABAergic inhibition in the spinal dorsal horn in vivo. Pain 133(1-3): 18-28.

Vikman KS, Siddall PJ, Duggan AW (2005). Increased responsiveness of rat dorsal horn neurons in vivo following prolonged intrathecal exposure to interferon-gamma. Neuroscience 135(3): 969-977.

Vivoli E, Di Cesare Mannelli L, Salvicchi A, Bartolini A, Koverech A, Nicolai R, et al. (2010). Acetyl-L-carnitine increases artemin level and prevents neurotrophic factor alterations during neuropathy. Neuroscience 167(4): 1168-1174. 
Wang JH, Simonavicius N, Wu XS, Swaminath G, Reagan J, Tian H, et al. (2006). Kynurenic acid as a ligand for orphan $\mathrm{G}$ protein-coupled receptor GPR35. Journal of Biological Chemistry 281(31): 22021-22028.

Wang QP, Nakai Y (1994). The dorsal raphe: an important nucleus in pain modulation. Brain research bulletin 34(6): 575-585.

Watkins LR, Maier SF (2005). Immune regulation of central nervous system functions: from sickness responses to pathological pain. J Intern Med 257(2): 139-155.

Wei F, Guo W, Zou S, Ren K, Dubner R (2008). Supraspinal glial-neuronal interactions contribute to descending pain facilitation. The Journal of neuroscience : the official journal of the Society for Neuroscience 28(42): 10482-10495.

Willis WD, Jr. (1985). Central nervous system mechanisms for pain modulation. Applied neurophysiology 48(1-6): 153-165.

Woolf CJ (2004). Pain: moving from symptom control toward mechanism-specific pharmacologic management. Annals of internal medicine 140(6): 441-451.

Woolf CJ (2007). Central sensitization: uncovering the relation between pain and plasticity. Anesthesiology 106(4): 864-867.

Woolf CJ, American College of P, American Physiological S (2004). Pain: moving from symptom control toward mechanism-specific pharmacologic management. Annals of internal medicine 140(6): 441-451.

Woolf CJ, Mannion RJ (1999). Neuropathic pain: aetiology, symptoms, mechanisms, and management. Lancet 353(9168): 1959-1964.

Xie W, Strong JA, Ye L, Mao J-X, Zhang J-M Knockdown of sodium channel NaV1.6 blocks mechanical pain and abnormal bursting activity of afferent neurons in inflamed sensory ganglia. Pain(0).

Xu XJ, Hao JX, Olsson T, Kristensson K, van der Meide PH, Wiesenfeld-Hallin Z (1994). Intrathecal interferon-gamma facilitates the spinal nociceptive flexor reflex in the rat. Neuroscience letters 182(2): 263-266.

Yilmaz A, Schulz D, Aksoy A, Canbeyli R (2002). Prolonged effect of an anesthetic dose of ketamine on behavioral despair. Pharmacology, biochemistry, and behavior 71(1-2): 341-344.

Zeitz KP, Guy N, Malmberg AB, Dirajlal S, Martin WJ, Sun L, et al. (2002). The 5-HT3 subtype of serotonin receptor contributes to nociceptive processing via a novel subset of myelinated and 
unmyelinated nociceptors. The Journal of neuroscience : the official journal of the Society for Neuroscience 22(3): 1010-1019.

Zhang X, Wu Z, Hayashi Y, Okada R, Nakanishi H (2014). Peripheral role of cathepsin S in Th1 cell-dependent transition of nerve injury-induced acute pain to a chronic pain state. The Journal of neuroscience : the official journal of the Society for Neuroscience 34(8): 3013-3022.

Zhuo M, Gebhart GF (1997). Biphasic modulation of spinal nociceptive transmission from the medullary raphe nuclei in the rat. Journal of neurophysiology 78(2): 746-758.

Zimmermann M (2001). Pathobiology of neuropathic pain. European journal of pharmacology 429(1-3): 23-37.

Zou X, Lin Q, Willis WD (2000). Enhanced phosphorylation of NMDA receptor 1 subunits in spinal cord dorsal horn and spinothalamic tract neurons after intradermal injection of capsaicin in rats. The Journal of neuroscience : the official journal of the Society for Neuroscience 20(18): 6989-6997.

Zwilling D, Huang SY, Sathyasaikumar KV, Notarangelo FM, Guidetti P, Wu HQ, et al. (2011). Kynurenine 3-monooxygenase inhibition in blood ameliorates neurodegeneration. Cell 145(6): 863-874. 
ANEXO 


\section{ANEXO A: CERTIFICADO DA COMISSÃO DE ÉTICA EM EXPERIMENTAÇÃO ANIMAL}

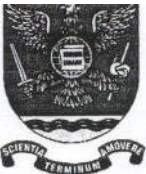

UNIVEKSIUAUE UE SAU RAULU FACULDADE DE MEDICINA DE RIBEIRÃO PRETO

Comissão de Ética em Experimentação Animal

$3602-3301$

\section{E R T I F I C A D O}

Certificamos que o Protocolo para Uso de Animais em Experimentação $\mathbf{n}^{\circ} \mathbf{0 4 5} / \mathbf{2 0 1 3}$, sobre o projeto intitulado "Investigação do papel da enzima indoleamina 2,3-dioxigenase em estruturas supraespinais na indução e manutenção da dor neuropática.", sob a responsabilidade do Professor Doutor Thiago Mattar Cunha está de acordo com os Princípios Éticos em Experimentação Animal adotado pelo Conselho Naciọnal de Controle de Experimentação Animal (CONCEA) e foi APROVADO em reunião de 24 de junho de 2013.

We certify that the protocol $\mathrm{n}^{\circ}$ 045/2013, entitled "The role of indoleamine 2,3-dioxygenase in supraspinal structures in the induction and maintenance of neuropathic pain", is in accordance with the Ethical Principles in Animal Research adopted by the National Council for the Control of Animal Experimentation (CONCEA) and was approved by the Local Animal Ethical Committee from the School of Medicine of Ribeirão Preto of the University of São Paulo in 06/24/2013.

Ribeirão Preto, 24 de junho de 2013.

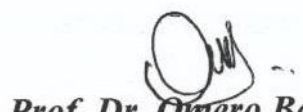

Prof. Dr. Omero Benedicto Poli-Neto

Presidente da Comissão de Ética em

Experimentação Animal FMRP-USP 